Argonne

ANL-16/03

MEDICAL ISOTOPE PRODUCTION ANALYSES IN KIPT NEUTRON SOURCE FACILITY

Nuclear Engineering Division 


\section{About Argonne National Laboratory}

Argonne is a U.S. Department of Energy laboratory managed by UChicago Argonne, LLC under contract DE-AC02-06CH11357. The Laboratory's main facility is outside Chicago, at 9700 South Cass Avenue, Argonne, Illinois 60439. For information about Argonne and its pioneering science and technology programs, see www.anl.gov.

\section{DOCUMENT AVAILABILITY}

Online Access: U.S. Department of Energy (DOE) reports produced after 1991 and a growing number of pre-1991 documents are available free via DOE's SciTech Connect (http://www.osti.gov/scitech/)

Reports not in digital format may be purchased by the public from the National Technical Information Service (NTIS):

U.S. Department of Commerce

National Technical Information Service

5301 Shawnee Rd

Alexandria, VA 22312

www.ntis.gov

Phone: (800) 553-NTIS (6847) or (703) 605-6000

Fax: (703) 605-6900

Email: orders@ntis.gov

Reports not in digital format are available to DOE and DOE contractors from the Office of Scientific and Technical Information (OSTI):

U.S. Department of Energy

Office of Scientific and Technical Information

P.O. Box 62

Oak Ridge, TN 37831-0062

www.osti.gov

Phone: (865) 576-8401

Fax: (865) 576-5728

Email: reports@osti.gov

\section{Disclaimer}

This report was prepared as an account of work sponsored by an agency of the United States Government. Neither the United States Government nor any agency thereof, nor UChicago Argonne, LLC, nor any of their employees or officers, makes any warranty, express or implied, or assumes any legal liability or responsibility for the accuracy, completeness, or usefulness of any information, apparatus, product, or process disclosed, or represents that its use would not infringe privately owned rights. Reference herein to any specific commercial product, process, or service by trade name, trademark, manufacturer, or otherwise, does not necessarily constitute or imply its endorsement, recommendation, or favoring by the United States Government or any agency thereof. The views and opinions of document authors expressed herein do not necessarily state or reflect those of the United States Government or any agency thereof, Argonne National Laboratory, or UChicago Argonne, LLC. 
ANL-16/03

\section{MEDICAL ISOTOPE PRODUCTION ANALYSES IN KIPT NEUTRON SOURCE FACILITY}

By

Alberto Talamo and Yousry Gohar

Nuclear Engineering Division, Argonne National Laboratory

January 2016 


\section{MEDICAL ISOTOPE PRODUCTION ANALYSES IN KIPT NEUTRON SOURCE FACILITY}

\section{$\underline{\text { Table of Contents }}$}

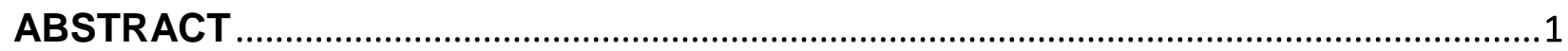

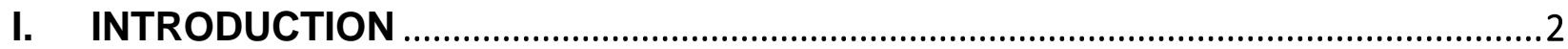

II. COMPUTATIONAL MODEL ................................................................................

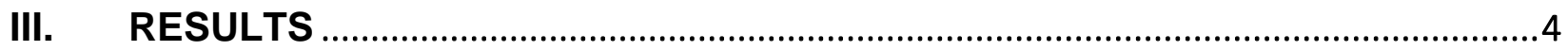

III.A. Effective Multiplication Factor ……............................................................................................ 4

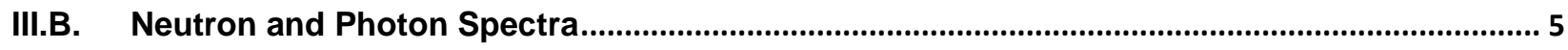

III.C. Specific Activities of Radioactive Isotopes without Considering Self-Shielding Effect ......... 5

III.D. Specific Activity of ${ }^{99}$ Mo with Self-Shielding effect.................................................................... 5

III.E. Specific Activity of Strong Neutron Absorbers with Self-Shielding ....................................... 6

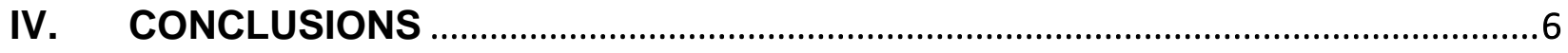

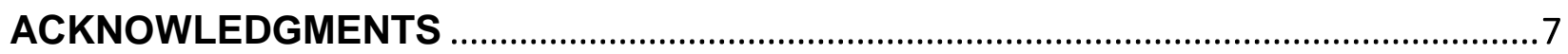

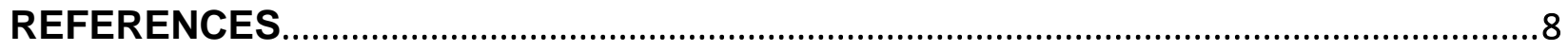




\section{MEDICAL ISOTOPE PRODUCTION ANALYSES IN KIPT NEUTRON SOURCE FACILITY}

\section{List of Figures}

Figure 1. Vertical (top plot) and horizontal (bottom plot) cross sections of the model with 37 fuel assemblies and irradiation sample at position $1 \ldots \ldots \ldots \ldots .12$

Figure 2. Zoom of the vertical cross section for the configuration with 37 fuel assemblies and irradiation sample at position 1

Figure 3. Zoom of the horizontal cross section for the configuration with 37 fuel assemblies and irradiation sample at position 1

Figure 4. Zoom of the horizontal cross section for the configuration with 37 fuel assemblies and irradiation sample at position 2

Figure 5. Zoom of the horizontal cross section for the configuration with 37 fuel assemblies and irradiation sample at position 3

Figure 6. Zoom of the horizontal cross section for the configuration with 38 fuel assemblies and irradiation sample at position 1

Figure 7. Zoom of the horizontal cross section for the configuration with 38 fuel

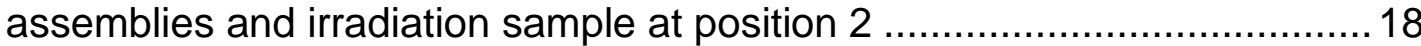

Figure 8. Zoom of the horizontal cross section for the configuration with 37 fuel

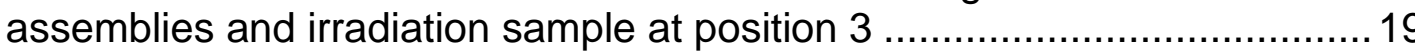

Figure 9. Horizontal cross section of the fuel assembly .................................20

Figure 10. Neutron spectrum in different irradiation positions .............................. 21

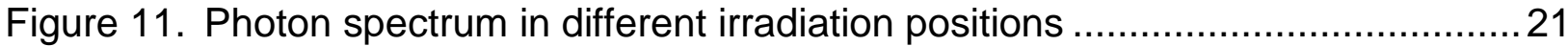

Figure $12 .{ }^{111} \mathrm{Ag}$ specific activity as a function of the irradiation time ......................22

Figure 13. ${ }^{82} \mathrm{Br}$ specific activity as a function of the irradiation time ....................... 22

Figure 14. ${ }^{58} \mathrm{Co}$ specific activity as a function of the irradiation time .......................23

Figure 15. ${ }^{58} \mathrm{Co}$ specific activity as a function of the irradiation time ........................23

Figure 16. ${ }^{60} \mathrm{Co}$ specific activity as a function of the irradiation time ......................... 24

Figure 17. ${ }^{51} \mathrm{Cr}$ specific activity as a function of the irradiation time ....................... 24

Figure 18. ${ }^{64} \mathrm{Cu}$ specific activity as a function of the irradiation time .......................25

Figure 19. ${ }^{165}$ Dy specific activity as a function of the irradiation time .......................25

Figure 20. ${ }^{59} \mathrm{Fe}$ specific activity as a function of the irradiation time ........................26

Figure $21 .{ }^{159} \mathrm{Gd}$ specific activity as a function of the irradiation time......................26 
Figure 22. ${ }^{166} \mathrm{Ho}$ specific activity as a function of the irradiation time ...........................2 27

Figure 23. ${ }^{192}$ Ir specific activity as a function of the irradiation time ............................ 27

Figure 24. ${ }^{194}$ Ir specific activity as a function of the irradiation time ............................. 28

Figure 25. ${ }^{42} \mathrm{~K}$ specific activity as a function of the irradiation time .............................. 28

Figure 26. ${ }^{99}$ Mo specific activity as a function of the irradiation time.............................29

Figure 27. ${ }^{24} \mathrm{Na}$ specific activity as a function of the irradiation time ...........................22

Figure 28. ${ }^{32} \mathrm{P}$ specific activity as a function of the irradiation time .............................. 30

Figure 29. ${ }^{32} \mathrm{P}$ specific activity as a function of the irradiation time .............................. 30

Figure $30 .{ }^{33} \mathrm{P}$ specific activity as a function of the irradiation time ............................. 31

Figure $31 .{ }^{103} \mathrm{Pd}$ specific activity as a function of the irradiation time .......................... 31

Figure 32. ${ }^{103} \mathrm{Pd}$ specific activity as a function of the irradiation time ............................ 32

Figure 33. ${ }^{186} \mathrm{Re}$ specific activity as a function of the irradiation time .......................... 32

Figure $34 .{ }^{188} \mathrm{Re}$ specific activity as a function of the irradiation time ............................. 33

Figure $35 .{ }^{35} \mathrm{~S}$ specific activity as a function of the irradiation time ............................... 33

Figure 36. ${ }^{47} \mathrm{Sc}$ specific activity as a function of the irradiation time ........................... 34

Figure $37 .{ }^{153} \mathrm{Sm}$ specific activity as a function of the irradiation time ...........................3 34

Figure 38. ${ }^{188} \mathrm{~W}$ specific activity as a function of the irradiation time ..............................35

Figure 39. ${ }^{90} \mathrm{Y}$ specific activity as a function of the irradiation time ................................ 35

Figure 40. ${ }^{99}$ Mo specific activity from $\mathrm{MoO}_{3}$ irradiation, with self-shielding effect, as a function of the irradiation time for $(\mathrm{n}, \gamma)$ reaction .................................... 36

Figure 41. ${ }^{99} \mathrm{Mo}$ specific activity from $\mathrm{MoO}_{3}$ irradiation, with self-shielding effect, as a function of the irradiation time for $(\gamma, n)$ reaction ...................................... 36

Figure 42. Zoom of the horizontal cross section for the configuration with 38 fuel assemblies and irradiation sample at position $1 \ldots \ldots \ldots \ldots \ldots \ldots \ldots \ldots \ldots \ldots \ldots \ldots \ldots . . .37$

Figure 43. Zoom of the horizontal cross section for the configuration with 38 fuel

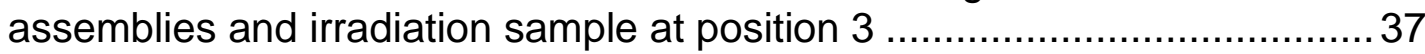

Figure 44. ${ }^{60}$ Co specific activity, with self-shielding effect, as a function of the

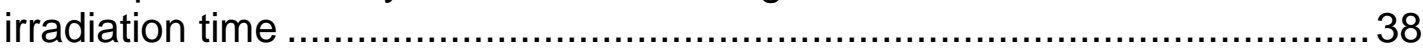

Figure 45. ${ }^{64} \mathrm{Cu}$ specific activity, with self-shielding effect, as a function of the irradiation time

Figure $46 .{ }^{159} \mathrm{Gd}$ specific activity, with self-shielding effect, as a function of the irradiation time

Figure 47. ${ }^{166} \mathrm{Ho}$ specific activity, with self-shielding effect, as a function of the irradiation time 
Figure 48. ${ }^{192}$ Ir specific activity, with self-shielding effect, as a function of the irradiation time

Figure 49. ${ }^{194}$ Ir specific activity, with self-shielding effect, as a function of the irradiation time

Figure 50. ${ }^{186} \mathrm{Re}$ specific activity, with self-shielding effect, as a function of the irradiation time

Figure $51 .{ }^{188} \mathrm{Re}$ specific activity, with self-shielding effect, as a function of the irradiation time

Figure 52. ${ }^{153} \mathrm{Sm}$ specific activity, with self-shielding effect, as a function of the irradiation time

Figure 53. ${ }^{188} \mathrm{~W}$ specific activity, with self-shielding effect, as a function of the irradiation time

Figure 54. ${ }^{82} \mathrm{Br}$ specific activity, with self-shielding effect, as a function of the irradiation time

Figure 55. ${ }^{165}$ Dy specific activity, with self-shielding effect, as a function of the irradiation time

Figure 56. ${ }^{24} \mathrm{Na}$ specific activity, with self-shielding effect, as a function of the irradiation time

Figure 57. ${ }^{90} \mathrm{Y}$ specific activity, with self-shielding effect, as a function of the irradiation time

Figure 58. Capture cross section of the parent nuclides with $\sigma_{\gamma}$ lower than $10 \mathrm{~b}$ at $0.02 \mathrm{eV}$

Figure 59. Capture cross section of the parent nuclides with $\sigma_{\gamma}$ higher than $10 \mathrm{~b}$ at $0.02 \mathrm{eV}$ 


\section{MEDICAL ISOTOPE PRODUCTION ANALYSES IN KIPT NEUTRON SOURCE FACILITY}

\section{List of Tables}

Table I. Effective multiplication factor obtained by MCNPX criticality calculations;

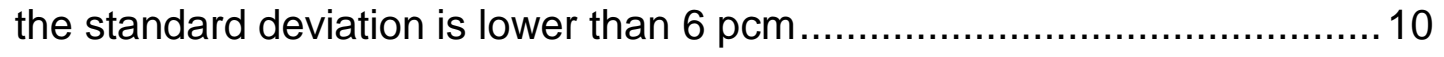

Table II. Position of the irradiation sample that maximizes the specific activity .........11 


\title{
MEDICAL ISOTOPE PRODUCTION ANALYSES IN KIPT NEUTRON SOURCE FACILITY
}

\begin{abstract}
Medical isotope production analyses in Kharkov Institute of Physics and Technology (KIPT) neutron source facility were performed to include the details of the irradiation cassette and the self-shielding effect. An updated detailed model of the facility was used for the analyses. The facility consists of an accelerator driven system (ADS), which has a subcritical assembly using low enriched uranium fuel elements with a beryllium-graphite reflector. The beryllium assemblies of the reflector have the same outer geometry as the fuel elements, which permits loading the subcritical assembly with different number of fuel elements without impacting the reflector performance. The subcritical assembly is driven by an external neutron source generated from the interaction of $100-\mathrm{kW}$ electron beam with a tungsten target. The facility construction was completed at the end of 2015, and it is planned to start the operation during the year of 2016. It is the first ADS in the world, which has a coolant system for removing the generated fission power. Argonne National Laboratory has developed the design concept and performed extensive design analyses for the facility including its utilization for the production of different radioactive medical isotopes. ${ }^{99} \mathrm{Mo}$ is the parent isotope of ${ }^{99 m} \mathrm{Tc}$, which is the most commonly used medical radioactive isotope. Detailed analyses were performed to define the optimal sample irradiation location and the generated activity, for several radioactive medical isotopes, as a function of the irradiation time.
\end{abstract}




\section{MEDICAL ISOTOPE PRODUCTION ANALYSES IN KIPT NEUTRON SOURCE FACILITY}

\section{Introduction}

Argonne National Laboratory (ANL) and Kharkov Institute of Physics and Technology (KIPT) have cooperated on the construction of the Neutron Source Facility (NSF) at KIPT. The NSF facility has an accelerator driven system (ADS) with 100-kW electron accelerator for multiple applications including medical isotope production. ANL performed extensive analyses including medical isotopes production, ${ }^{1,2}$ reactivity monitoring, ${ }^{3}$ operations and control, ${ }^{4,5}$ refueling, ${ }^{6}$ cold neutron source design, ${ }^{7}$ target design, ${ }^{8}$ and radiation shielding. ${ }^{9}$

The present report focuses on the use of the KIPT ADS for medical isotope production. ${ }^{10-18}$ Medical isotopes are radioactive isotopes with short half-lives used in diagnostic and therapeutic procedures. For example, brain cancer is difficult to treat by ordinary surgery and only brachytherapy with ${ }^{131} \mathrm{Cs}$, which has 9.7 days half-life, has shown effective results on the patients. ${ }^{19}$

${ }^{99 m}$ Tc is the most commonly used medical isotope in diagnoses because the wavelength of its gamma ray (8.8 pm wave length) is about the same as the conventional X-ray diagnostic devices. ${ }^{99 m}$ Tc has 6 hours half-life, therefore it cannot be stored because it quickly decays into ${ }^{99} \mathrm{Tc}$. The parent of ${ }^{99 \mathrm{~m}} \mathrm{Tc}$ is ${ }^{99} \mathrm{Mo}$, which has 66 hours half-life. Consequently, the delivery of ${ }^{99 m} \mathrm{Tc}$ occurs through shipping ${ }^{99} \mathrm{Mo}$ samples to the medical facilities. The present analyses investigated the ${ }^{99}$ Mo production at the NSF of KIPT due to the importance of ${ }^{99 \mathrm{~m}} \mathrm{Tc}$ in medical applications. In recent years, ANL has a lot of activities researching the ${ }^{99} \mathrm{Mo}$ production without using highenriched uranium. ${ }^{20-23}$

\section{Computational Model}

Reference 1 discusses in detail the medical isotope production in the NSF of KIPT. The calculations of this report used an updated detailed MCNPX ${ }^{24}$ model of the NSF facility and the more recent ENDF/B-VII.O nuclear data library. Only some of the results of Section III.A are based on the ENDF/B-VII.1 nuclear data library. The analyses considered three irradiation positions in the subcritical assembly. The first position is next to the target, the third position is next to the beryllium reflector, and the second position is between the other two positions. Figures 1 to 9 show different MCNPX cross sections of the KIPT NSF model highlighting the irradiation locations. In Figures 1 to 9 , each color corresponds to a different material as follows:

- Orange

- Blue fuel

aluminum 
- Cyan water

- Pink uranium target

- Purple beryllium

- Wheat graphite

- Pale-green concrete

- Yellow air

- Red molybdenum (irradiation sample)

The tally multiplier option of MCNPX allowed calculating the average reaction rate in each of the three positions for more than forty different reactions. This part of the analyses aimed at identifying the isotopes suitable for production and their optimal location. In the simulations of Sections III.B to III.D, the reaction rate tallies refer to neutron and gamma fluxes averaged in a cylindrical volume with $0.75 \mathrm{~cm}$ radius and 10 $\mathrm{cm}$ height. Unless otherwise specified, the KIPT NSF is loaded with 37 fuel assemblies and the computational model does not include the irradiation target material. The analyses with self-shielding (Section III.D), for configurations with 37 and 38 fuel assemblies, took into consideration the modeling of the molybdenum trioxide powder, $\mathrm{MoO}_{3}$ with $4.69 \mathrm{~g} / \mathrm{cm}^{3}$ density. The configurations with 37 and 38 fuel assemblies use uranium and tungsten targets, respectively. The computational model included the aluminum cassette of the irradiation sample.

Equation 1 gives the initial atomic density of the parent nuclide $N_{p}^{0}$ using: the mass density (in $\mathrm{g} / \mathrm{cm}^{3}$ units) of the parent material $d_{\text {nat }}$, the Avogadro's number $A$, the natural abundance of the parent nuclide in the parent material $f$, and the atomic weight of the parent material $W$.

$$
N_{p}^{0}=\frac{d_{\text {nat }} \cdot A \cdot f}{W}
$$

Equation $2 \mathrm{~b}$ is the solution of Equation set $2 \mathrm{a}$ and it gives the atomic density $N$ of the daughter nuclides (medical isotopes) as a function of time.

$$
\begin{aligned}
& \left\{\begin{array}{c}
\frac{d N}{d t}=-(\lambda+\sigma \Phi) N+\sigma_{p} N_{p} \Phi \\
\frac{d N_{p}}{d t}=-\sigma_{p} N_{p} \Phi
\end{array}\right. \\
& N(t)=\sigma_{p} \Phi N_{p}^{0} \frac{e^{-\sigma_{p} \Phi t}-e^{-(\lambda+\sigma \Phi) t}}{\lambda+\sigma \Phi-\sigma_{p} \Phi}
\end{aligned}
$$

In Eqs. $2 \mathrm{a}$ and $2 \mathrm{~b}, \lambda$ is the decay constant of the daughter nuclide, $N_{p}$ is the density of the parent nuclide, and $\sigma_{p} \Phi$ is the parent reaction rate. The reaction rate per source particle (electron), from the MCNPX output file, multiplied by the number of electrons per second, obtained by assuming $100 \mathrm{~kW}$ beam power and $100 \mathrm{MeV}$ electron energy (in 
Ref. 1 the electron energy is $200 \mathrm{MeV}$ ), gives $\sigma_{p} \Phi$. The standard deviation of the MCNPX reaction rate values per source particle is generally lower than $1.4 \%$; for $(n, 2 n)$ reactions, the standard deviation value increases up to $4.5 \%$. The daughter reaction rate $(\sigma \Phi)$ has a small value relative to the decay constant, because medical isotopes have a short half-life; consequently, this term has been neglected in the equations.

Equations $3 \mathrm{~b}$ are the solution of Equation set $3 \mathrm{a}$ and give the atomic density of daughter nuclides $N$ generated by a grandparent, with density $N_{g p}$, and a parent, with density $N_{p}$. In the case of a stable parent, Eqs. $3 \mathrm{~b}$ hold by setting $\lambda_{p}$ equal to zero; in the case of a decaying parent (as for ${ }^{47} \mathrm{Sc}$ and ${ }^{188} \mathrm{~W}$ production), they do by setting $N_{p}^{0}$ equal to zero.

$$
\begin{gathered}
\left\{\begin{array}{c}
\frac{d N}{d t}=-(\lambda+\sigma \Phi) N+\sigma_{p} N_{p} \Phi \\
\frac{d N_{p}}{d t}=-\left(\lambda_{p}+\sigma_{p} \Phi\right) \cdot N_{p}+\sigma_{g p} N_{g p} \Phi \\
\frac{d N_{g p}}{d t}=-\sigma_{g p} N_{g p} \Phi
\end{array}\right. \\
\left\{\begin{array}{c}
N=\sigma_{p} \Phi N_{p}^{0} \frac{e^{-\left(\lambda_{p}+\sigma_{p} \Phi\right) t}-e^{-(\lambda+\sigma \Phi) t}}{\lambda+\sigma \Phi-\lambda_{p}-\sigma_{p} \Phi}+\frac{\sigma_{p} \Phi N_{g p}^{0} \sigma_{g p} \Phi}{\lambda_{p}+\sigma_{p} \Phi-\sigma_{g p} \Phi}\left[\frac{e^{-\sigma_{g p} \Phi t}-e^{-(\lambda+\sigma \Phi) t}}{\lambda+\sigma \Phi-\sigma_{g p} \Phi}-\frac{e^{-\left(\lambda_{p}+\sigma_{p} \Phi\right) t}-e^{-(\lambda+\sigma \Phi) t}}{\lambda+\sigma \Phi-\lambda_{p}-\sigma_{p} \Phi}\right] \\
N_{p}=N_{p}^{0} e^{-\left(\lambda_{p}+\sigma_{p} \Phi\right) t}+\sigma_{g p} \Phi N_{g p}^{0} \frac{e^{-\sigma_{g p} \Phi t}-e^{-\left(\lambda_{p}+\sigma_{p} \Phi\right) t}}{\lambda_{p}+\sigma_{p} \Phi-\sigma_{g p} \Phi} \\
N_{g p}=N_{g p}^{0} e^{-\sigma_{g p} \Phi t}
\end{array}\right.
\end{gathered}
$$

Equation 6 gives the specific activity, using the atomic densities obtained from the previous formulas.

$$
\text { specific activity }=\frac{\lambda N}{d_{n a t}}
$$

\section{Results}

\section{III.A. Effective Multiplication Factor}

Table I gives the effective multiplication factor $\left(k_{\text {eff }}\right)$ obtained from criticality calculations for different fuel loadings and nuclear data libraries. The impact of nuclear data on the $k_{\text {eff }}$ value is small, lower than $150 \mathrm{pcm}\left(1 \mathrm{pcm}=1 \times 10^{-5}\right)$. The configuration with 38 fuel assemblies and the tungsten target has a much lower multiplication factor than the configuration with 37 fuel assemblies and the uranium target. 


\section{III.B. Neutron and Photon Spectra}

Figures 10 and 11 show the neutron and photon spectra in different irradiation positions; the fluxes have been normalized first to unity and then to lethargy. The irradiation position 3 , next to the beryllium reflector, has the largest thermal neutron flux and the lowest fast neutron flux compared to the other two positions.

The photon spectrum has a smooth profile, as expected from the Bremsstrahlung effect, with exception of some isolated peaks caused by $(n, \gamma)$ reactions. The peaks at $0.5-0.6,2.2$, and $7.7 \mathrm{MeV}$ are caused by the $(n, \gamma)$ reaction with ${ }^{238} \mathrm{U}$, hydrogen, and aluminum nuclei, respectively. ${ }^{25}$

III.C. Specific Activities of Radioactive Isotopes without Considering Self-Shielding Effect

Figures 12 to 39 show the specific activities for the medical isotopes produced by incident neutrons. After 20 irradiation days, ${ }^{82} \mathrm{Br},{ }^{64} \mathrm{Cu},{ }^{165} \mathrm{Dy},{ }^{166} \mathrm{Ho},{ }^{192} \mathrm{Ir},{ }^{194} \mathrm{Ir},{ }^{186} \mathrm{Re}$, ${ }^{188} \mathrm{Re}$ and ${ }^{153} \mathrm{Sm}$ have specific activities larger than $100 \mathrm{MBq} / \mathrm{mg} ;{ }^{60} \mathrm{Co},{ }^{51} \mathrm{Cr},{ }^{159} \mathrm{Gd},{ }^{24} \mathrm{Na}$, ${ }^{32} \mathrm{P}$, and ${ }^{90} \mathrm{Y}$ have specific activities between 10 and $100 \mathrm{MBq} / \mathrm{mg} ;{ }^{111} \mathrm{Ag},{ }^{58} \mathrm{Co},{ }^{125} \mathrm{I},{ }^{42} \mathrm{~K}$, ${ }^{99} \mathrm{Mo}$, and ${ }^{32} \mathrm{P}$ (via (n,p)) have specific activities between 1 and $10 \mathrm{MBq} / \mathrm{mg}$; and ${ }^{58} \mathrm{Co}$ (via $(\mathrm{n}, 2 \mathrm{n})),{ }^{59} \mathrm{Fe},{ }^{33} \mathrm{P},{ }^{103} \mathrm{Pd},{ }^{35} \mathrm{~S},{ }^{47} \mathrm{Sc}$, and ${ }^{188} \mathrm{~W}$ have specific activities $<1 \mathrm{MBq} / \mathrm{mg}$. Figure 26 shows the specific activity of ${ }^{99} \mathrm{Mo}$ obtained from irradiating natural molybdenum in metallic and trioxide forms.

Table II reports the best positions for generating these isotopes; these positions may change if self-shielding effect is included. ${ }^{1,2}$ In general, the results show that isotopes generated through large thermal cross sections are better produced in the third position next to the beryllium reflector because of the highest thermal neutron flux at this location. The first position next to the target enhances the production of isotopes generated through resonances or by threshold reactions due to higher epithermal and fast neutron fluxes. The specific activities of the medical isotopes generated through photonuclear reactions are small ${ }^{1}$ and therefore they have not been considered in the present study.

III.D. Specific Activity of ${ }^{99}$ Mo with Self-Shielding effect

The self-shielding effect can change the results obtained in Section III.C, for example the ${ }^{99}$ Mo production. Figures 40 and 41 show the specific activity of ${ }^{99} \mathrm{Mo}$ obtained by $(n, \gamma)$ and $(\gamma, n)$ reactions after modeling the parent material (molybdenum trioxide $\left.\mathrm{MoO}_{3}\right)$ in the irradiation sample. The values obtained by the $(\mathrm{n}, \gamma)$ reactions with self-shielding, shown in Fig. 40 are lower than those obtained without self-shielding, shown in Fig. 26, by a factor of 1.4. The specific activities of ${ }^{99}$ Mo obtained by the ${ }^{100} \mathrm{Mo}(\gamma, \mathrm{n})$ reaction shown in Fig. 41 are 40 and 12 times smaller than those obtained by the ${ }^{98} \mathrm{Mo}(\mathrm{n}, \gamma)$ reaction shown in Fig. 40 for the configurations with 37 and 38 fuel assemblies, respectively. The configuration with 37 fuel assemblies and the uranium target produces higher specific activities, relative to the configuration with 38 fuel assemblies and the tungsten target, because it has a higher neutron multiplication as 
shown in Table I. The insertion of the molybdenum trioxide irradiation sample, a cylinder with $0.75 \mathrm{~cm}$ radius and $10 \mathrm{~cm}$ height, has negligible effect on the effective multiplication factor as shown in Table I.

\section{III.E. Specific Activity of Strong Neutron Absorbers with Self-Shielding}

The analysis of this section evaluates the self-shielding effect when the irradiation samples have high absorption neutron cross section values. In this set of simulations, four cylindrical samples have been simultaneously loaded into the aluminum cassette. Each irradiation sample has $0.1 \mathrm{~cm}$ radius and $10 \mathrm{~cm}$ height. Figures 3 to 8 show position 1, 2, and 3 of the aluminum cassette without the irradiation samples. Figures 42 and 43 show the four locations, $A, B, C$, and $D$, of the irradiation samples inside the aluminum cassette. The sample locations A, B, C, and D have cobalt, copper, gadolinium, and holmium irradiation samples, respectively. In other simulations, the previously listed four materials have been replaced first by iridium, rhenium, samarium, and tungsten, and then by bromine, dysprosium, sodium, and yttrium, respectively. Figures 44 to 57 show the specific activity of ${ }^{60} \mathrm{Co},{ }^{64} \mathrm{Cu},{ }^{159} \mathrm{Gd},{ }^{166} \mathrm{Ho},{ }^{192} \mathrm{Ir},{ }^{194} \mathrm{Ir},{ }^{186} \mathrm{Re}$, ${ }^{188} \mathrm{Re},{ }^{153} \mathrm{Sm},{ }^{188} \mathrm{~W},{ }^{82} \mathrm{Br},{ }^{165} \mathrm{Dy},{ }^{24} \mathrm{Na}$, and ${ }^{90} \mathrm{Y}$, respectively, as a function of the irradiation time. For the previously listed isotopes, the self-shielding effect reduces the specific activity by a factor of 1.9, 1.4, 2.8, 2.3 . 7.3, 8.0, 4.1, 2.6, 13.3, 4.5, 1.9, 4.9, 1.1, and 1.1, respectively. The self-shielding effect is proportional to the magnitude of the capture cross section of the irradiated sample material. Figures 58 and 59 plot the microscopic capture cross section $\left(\sigma_{\gamma}\right)$ of the parent nuclides producing the medical isotopes shown in Figs. 12 to 39 through $(n, \gamma)$ reactions. The parents analyzed in this Section have $\sigma_{\gamma}$ higher than $30 \mathrm{~b}$ at $0.02 \mathrm{eV}$, a value close to the thermal neutron energy $(0.025 \mathrm{eV})$.

For all isotopes, the optimum irradiation positions for producing the maximum possible activity are the ones found and discussed in Section III.C and listed in Table II, with exception of ${ }^{153} \mathrm{Sm}$. The insertion of the irradiation samples may lower the effective multiplication factor by $200 \mathrm{pcm}$ as shown in Table I; this reduction also contributes in lowering the specific activity from the analyses with the self-shielding effect.

\section{Conclusions}

The NSF of KIPT is the first ADS in the world operating at non-zero power and allows producing several isotopes for medical applications. After 20 irradiation days, ${ }^{82} \mathrm{Br},{ }^{64} \mathrm{Cu},{ }^{165} \mathrm{Dy},{ }^{166} \mathrm{Ho},{ }^{192} \mathrm{Ir},{ }^{194} \mathrm{Ir},{ }^{186} \mathrm{Re},{ }^{188} \mathrm{Re}$ and ${ }^{153} \mathrm{Sm}$ have specific activities, larger than $100 \mathrm{MBq} / \mathrm{mg}$ without taking into account the self-shielding effect and therefore they are good candidates for production. The self-shielding effect plays an important role for all parents that have a large microscopic capture cross section. This effect reduces the reaction rate and therefore the specific activity. For instance, the analyses of molybdenum trioxide irradiation samples have shown that the self-shielding effect may reduce the specific activity by a factor of 1.4 . The specific activity of ${ }^{99} \mathrm{Mo}$, produced 
from ${ }^{100} \mathrm{Mo}$ by incident photon reactions with natural molybdenum trioxide is small. For ${ }^{60} \mathrm{Co},{ }^{64} \mathrm{Cu},{ }^{159} \mathrm{Gd},{ }^{166} \mathrm{Ho},{ }^{192} \mathrm{Ir},{ }^{194} \mathrm{Ir},{ }^{186} \mathrm{Re},{ }^{188} \mathrm{Re},{ }^{153} \mathrm{Sm},{ }^{188} \mathrm{~W},{ }^{82} \mathrm{Br},{ }^{165} \mathrm{Dy},{ }^{24} \mathrm{Na}$, and ${ }^{90} \mathrm{Y}$ the self-shielding effect reduces the specific activity by a factor of 1.9, 1.4, 2.8, 2.3, 7.3, $8.0,4.1,2.6,13.3,4.5,1.9,4.9,1.1$, and 1.1, respectively.

\section{Acknowledgments}

This work is supported by the U.S. Department of Energy, National Nuclear Security Administration, Office of Material Management and Minimization (M3), under Contract No. DE-AC02-06CH11357. 


\section{References}

[1] A. TALAMO and Y. GOHAR, Radioactive Isotope Production for Medical Applications Using Kharkov Electron Driven Subcritical Assembly Facility, Argonne National Laboratory, ANL-07/18, 2007.

[2] A. TALAMO and Y. GOHAR, Production of Medical Radioactive Isotopes Using KIPT Electron Driven Subcritical Facility, Applied Radiation and Isotopes 66, pp. 577-586, 2008.

[3] Y. CAO et al., Measuring and Monitoring KIPT Neutron Source Facility Reactivity, Argonne National Laboratory, ANL-15/15, 2015.

[4] A.L. GRELLE et al., Neutron Source Facility Simulator (NSFS), Argonne National Laboratory, ANL-14/07, 2014.

[5] Y. GOHAR et al., Control and Protection System Conceptual Design Logic Diagrams for Neutron Source Facility at the Kharkov Institute of Physics and Technology, Argonne National Laboratory, ANL-13/10, 2013.

[6] Z. ZHONG et al., Burnup Calculations for KIPT Accelerator Driven Subcritical Facility Using Monte Carlo Computer Codes - MCB and MCNPX, Argonne National Laboratory, ANL-09/07, 2009.

[7] Z. ZHONG et al., Physics Design of a Cold Neutron Source for KIPT Neutron Source Facility, Argonne National Laboratory, ANL-08/36, 2008.

[8] T. SOFU et al., Target Design Optimization for an Electron Accelerator Driven Subcritical Facility with Circular and Square Beam Profiles, Argonne National Laboratory, ANL-NE-08/25, 2008.

[9] Z. ZHONG et al., Shielding Analysis and Design of the KIPT Experimental Neutron Source Facility of Ukraine, Argonne National Laboratory, ANL-08/23, 2008.

[10] IAEA, Manual for Reactor Produced Radioisotopes, International Atomic Energy Agency, IAEA-TECDOC-1340, 2003.

[11] COMMITTEE ON MEDICAL ISOTOPES PRODUCTION, Medical Isotope Production without Highly Enriched Uranium, The National Academies Press, ISBN 0-309-13040-9, 2009.

[12] S.J. ADELSTEIN et al., Isotopes for Medicine and Life Science, The National Academies Press, ISBN 0-309-05190-8, 1995.

[13] S. MIRZADEH et al., Projected Medical Radioisotope Production Capabilities of the Advanced Neutron Source (ANS), Oak Ridge National Laboratory, ORNL/TM10210-S, 1994.

[14] V.N. STAROVOITOVA et al., Production of Medical Isotopes with Linear Accelerators, Applied Radiation and Isotopes 85, pp. 39-44, 2014.

[15] B.I. ZHUIKOV, Production of Medical Radionuclides in Russia: Status and Future A Review, Applied Radiation and Isotopes 84, pp. 48-56, 2014.

[16] B. GUÉRIN et al., Cyclotron Production of ${ }^{99 m} T c$ : An Approach to the Medical Isotope Crisis, The Journal of Nuclear Medicine 51/4, 2010.

[17] M. NEVES, A. KLING and R.M. LAMBRECHT, Radionuclide Production for Therapeutic Radiopharmaceuticals, Applied Radiation and Isotopes 57, pp. 657664, 2002.

[18] K. A. Van RIPER, S.G. MASHNIK and W.B. Wilson, A Computer Study of Radionuclide Production in High Power Accelerators for Medical and Industrial 
Applications, Nuclear Instruments \& Methods in Physics Research A 463, pp. 576585, 2001.

[19] ISORAY MEDICAL, URL http://www.isoray.com/press-releasel, 2015.

[20] D.C. STEPINSKI et al., Verification of Column Design for Recovery of Mo from Low-Enriched Uranium Target using Irradiated Target Tracer Solution, Argonne National Laboratory, ANL/CSE-14/14, 2014.

[21] D.C. STEPINSKI et al., Development of Recovery and Purification Processes for Mo-99 from an Accelerator-Driven Subcritical target Solution: Determination of Distribution Coefficients for Competing Components and Micro-SHINE Tracer Column Results, Argonne National Laboratory, ANL/CSE-14/12, 2014.

[22] P. TKAC et al., Recovery of Mo for Accelerator Production of Mo-99 Using $(\gamma, n)$ Reaction on Mo-100, Argonne National Laboratory, ANL/CSE-13/45, 2013.

[23] J. JERDEN et al., Acid-Dissolution Front-End Process for Mo-99 Recovery at Ambient Pressure: Final Design and Results from Full-Scale Tests, Argonne National Laboratory, ANL/CSE-14/15, 2014.

[24] D.B. PELOWITZ et al., MCNPX 2.7A Extensions, LA-UR-08-07182, 2008.

[25] IAEA, Database of Prompt Gamma Rays from Slow Neutron Capture for Elemental Analysis, ISBN 92-0-101306-X, 2007. 
Table I. Effective multiplication factor obtained by MCNPX criticality calculations; the standard deviation is lower than $6 \mathrm{pcm}$

\begin{tabular}{|c|c|c|c|c|}
\hline \multirow{2}{*}{$\begin{array}{c}\text { No. FA } \\
\text { ENDFIB } \\
\text { version }\end{array}$} & \multirow{2}{*}{$\begin{array}{c}\text { Irradiation Sample } \\
\text { Materials }\end{array}$} & \multicolumn{3}{|c|}{ Position of the Irradiation Sample } \\
\cline { 3 - 5 } & & $\mathbf{1}$ & $\mathbf{2}$ & $\mathbf{3}$ \\
\hline $37-$ VII.0 & & 0.97094 & 0.97207 & 0.97138 \\
\hline $37-$ VII.1 & Mo & 0.96948 & 0.97061 & 0.96991 \\
\hline $38-$ VII.0 & & 0.95254 & & 0.95324 \\
\hline $38-$ VII.0 & Mo & 0.95081 & 0.95202 & 0.95137 \\
\hline $38-$ VII.1 & & 0.95133 & & \\
\hline $38-$ VII.1 & Br Dy Na Y & 0.96995 & 0.97122 & 0.97047 \\
\hline $37-$ VII.0 & Co Cu Gd Ho & 0.96952 & 0.97078 & 0.97018 \\
\hline $37-$ VII.0 & Ir Re Sm W & 0.96868 & 0.97003 & 0.96949 \\
\hline $37-$ VII.0 & Br Dy Na Y & 0.95167 & 0.95270 & 0.95194 \\
\hline $38-$ VII.0 & Co Cu Gd Ho & 0.95146 & 0.95230 & 0.95160 \\
\hline $38-$ VII.0 & Ir Re Sm W & 0.95059 & 0.95163 & 0.95078 \\
\hline $38-$ VII.0 & & & & \\
\hline
\end{tabular}


Table II. Position of the irradiation sample that maximizes the specific activity

\begin{tabular}{|c|c|c|}
\hline \multirow{2}{*}{ Medical Isotope } & \multicolumn{2}{|c|}{ Position Number } \\
\hline & Without Self-Shielding & With Self-Shielding \\
\hline${ }^{111} \mathrm{Ag}$ & 1 & - \\
\hline${ }^{82} \mathrm{Br}$ & 1 & 1 \\
\hline${ }^{58}$ Co via $(n, 2 n)$ & 1 & - \\
\hline${ }^{58} \mathrm{Co}$ via $(n, p)$ & 1 & - \\
\hline${ }^{60} \mathrm{Co}$ & 3 & 3 \\
\hline${ }^{51} \mathrm{Cr}$ & 3 & - \\
\hline${ }^{64} \mathrm{Cu}$ & 3 & 3 \\
\hline${ }^{165}$ Dy & 3 & 3 \\
\hline${ }^{59} \mathrm{Fe}$ & 3 & - \\
\hline${ }^{159} \mathrm{Gd}$ & 1 & 1 \\
\hline${ }^{166} \mathrm{Ho}$ & 3 & 3 \\
\hline 125 & 1 & - \\
\hline${ }^{192} \mathrm{Ir}$ & 3 & 3 \\
\hline${ }^{194}$ Ir & 3 & 3 \\
\hline${ }^{42} \mathrm{~K}$ & 3 & - \\
\hline${ }^{99} \mathrm{Mo}$ & 1 & 1 \\
\hline${ }^{24} \mathrm{Na}$ & 3 & 3 \\
\hline${ }^{32} \mathrm{P}$ via $(\mathrm{n}, \gamma)$ & 3 & - \\
\hline${ }^{32} \mathrm{P}$ via $(n, p)$ & 1 & - \\
\hline${ }^{33} \mathrm{P}$ & 1 & - \\
\hline${ }^{103} \mathrm{Pd}$ via $(\mathrm{n}, \gamma)$ & 3 & - \\
\hline${ }^{103} \mathrm{Pd}$ via $(n, 2 n)$ & 1 & - \\
\hline${ }^{186} \mathrm{Re}$ & 3 & 3 \\
\hline${ }^{188} \mathrm{Re}$ & 3 & 3 \\
\hline${ }^{35} \mathrm{~S}$ & 3 & - \\
\hline${ }^{47} \mathrm{Sc}$ & 3 & - \\
\hline${ }^{153} \mathrm{Sm}$ & 3 & 1 \\
\hline${ }^{188} W$ & 1 & 3 \\
\hline${ }^{90} Y$ & 3 & 3 \\
\hline
\end{tabular}



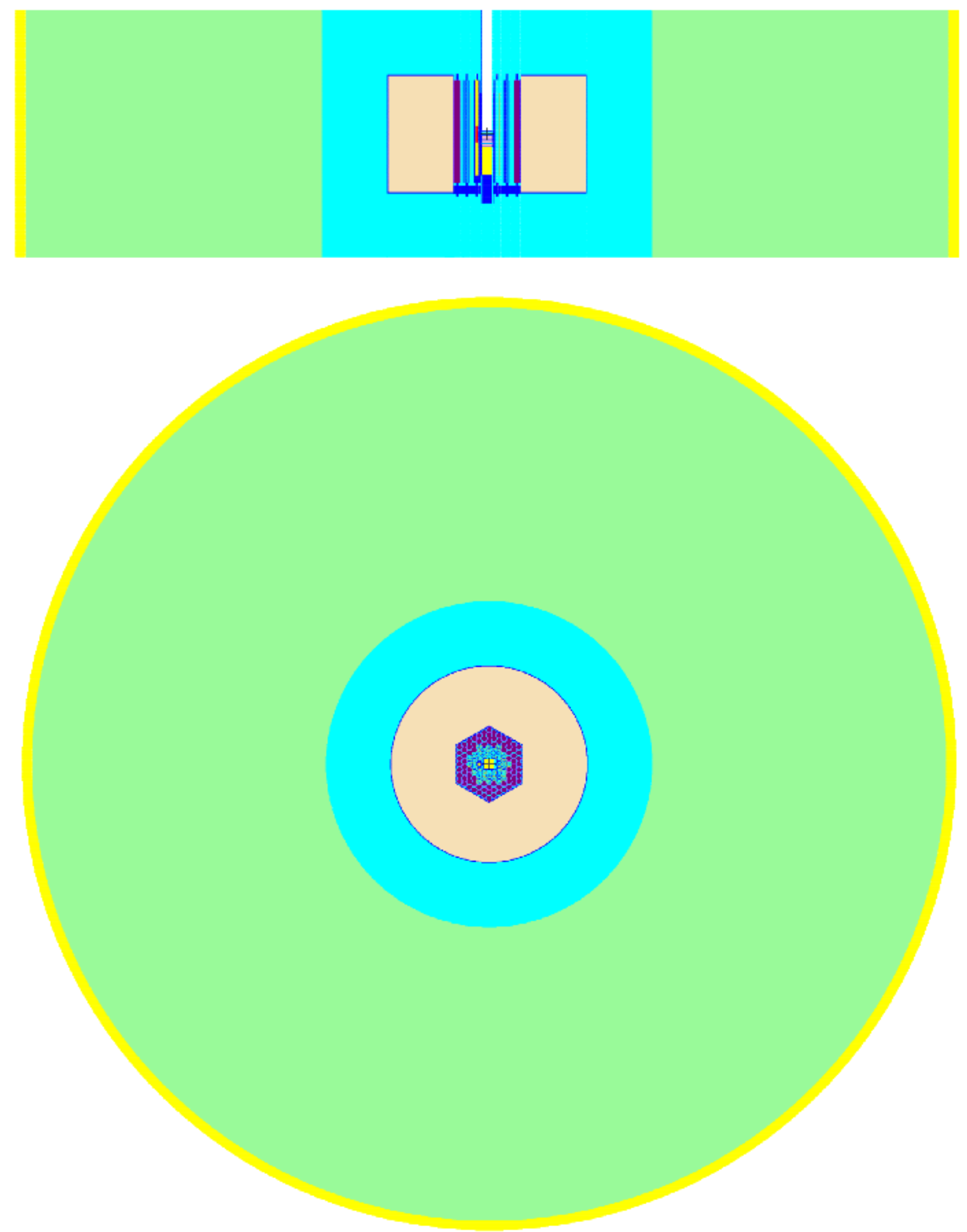

Figure 1. Vertical (top plot) and horizontal (bottom plot) cross sections of the model with 37 fuel assemblies and irradiation sample at position 1 


\section{Electron Beam}

100 kW power; 100 MeV energy

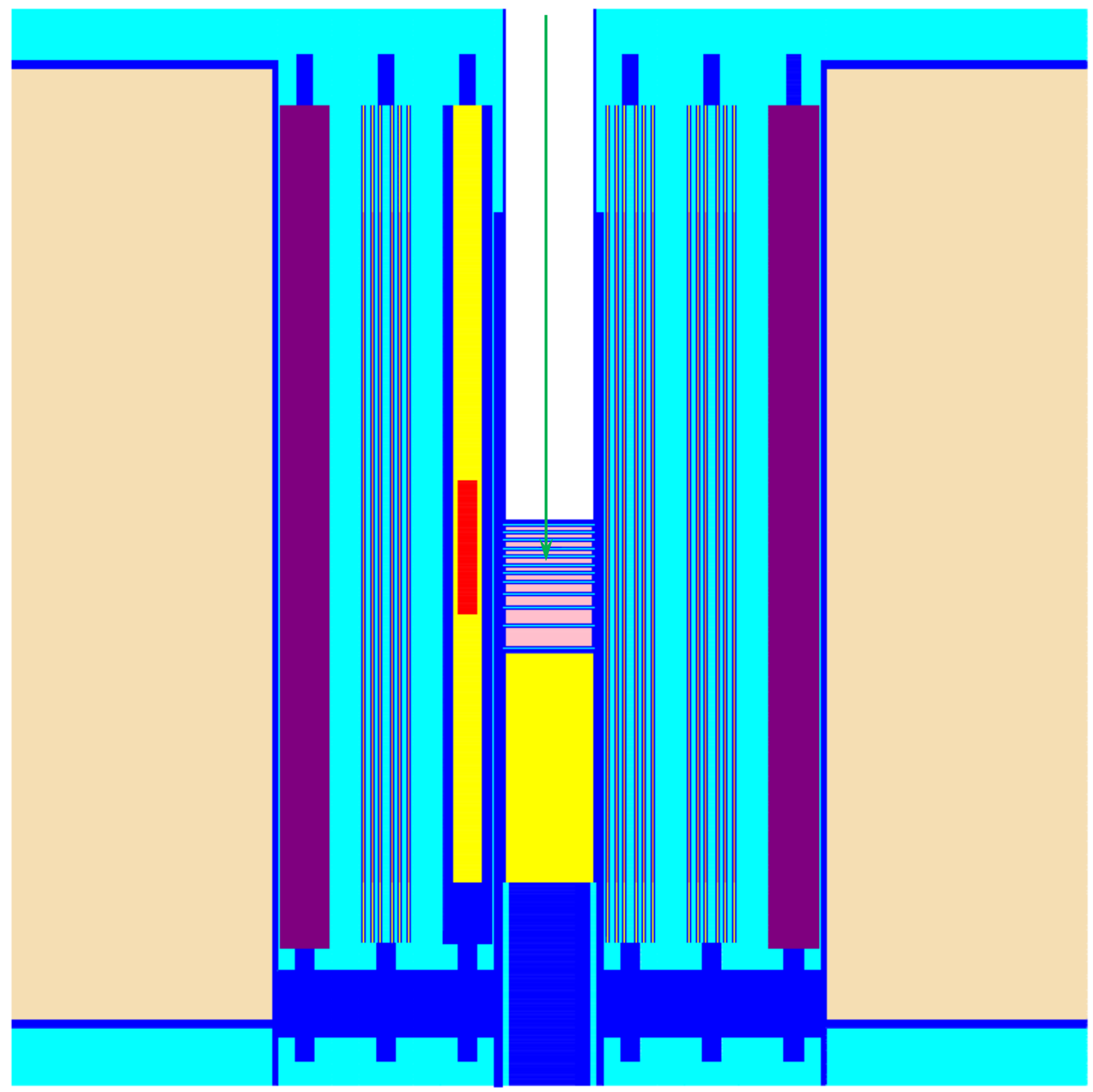

Figure 2. Zoom of the vertical cross section for the configuration with 37 fuel assemblies and irradiation sample at position 1 


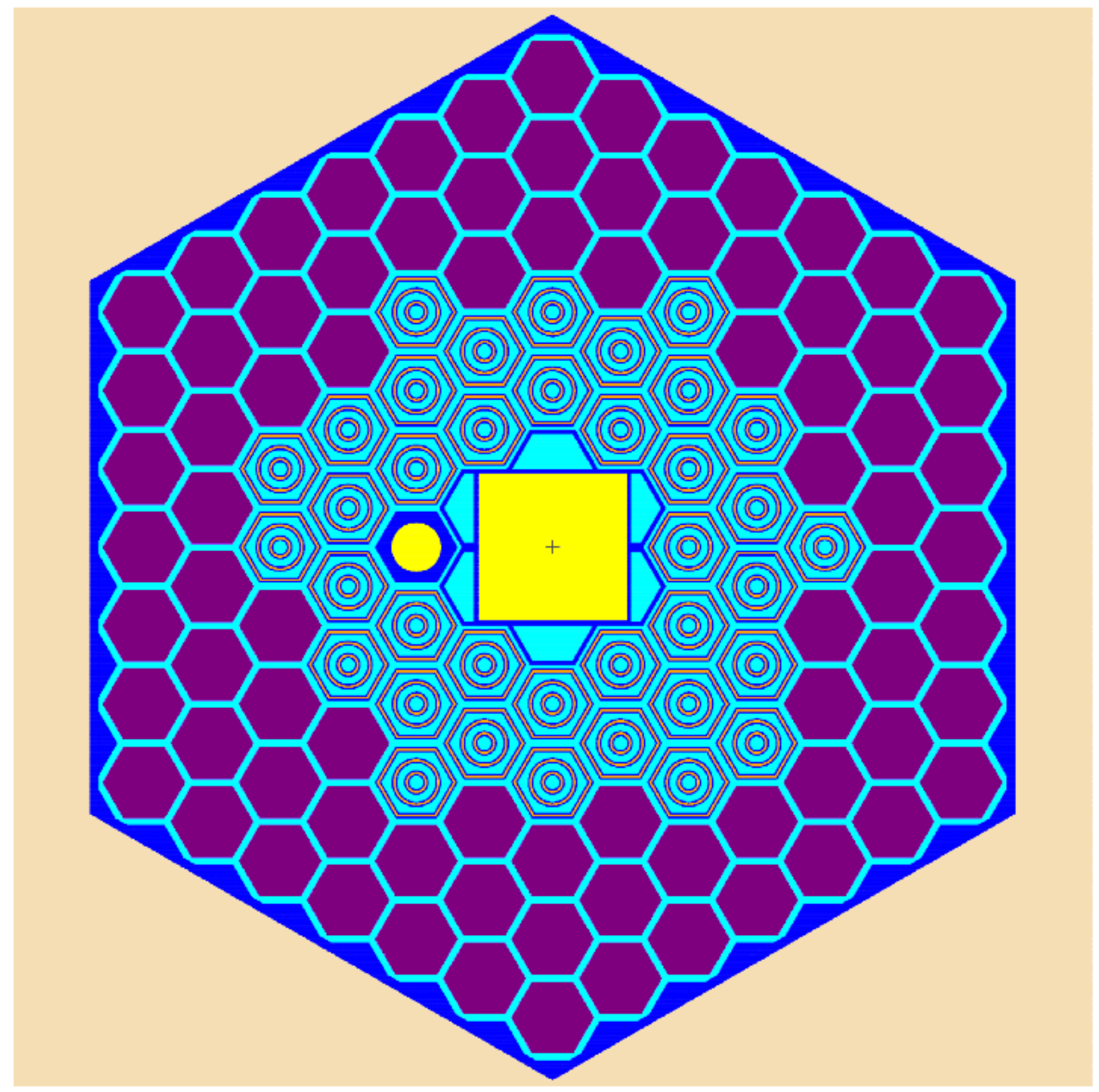

Figure 3. Zoom of the horizontal cross section for the configuration with 37 fuel assemblies and irradiation sample at position 1 


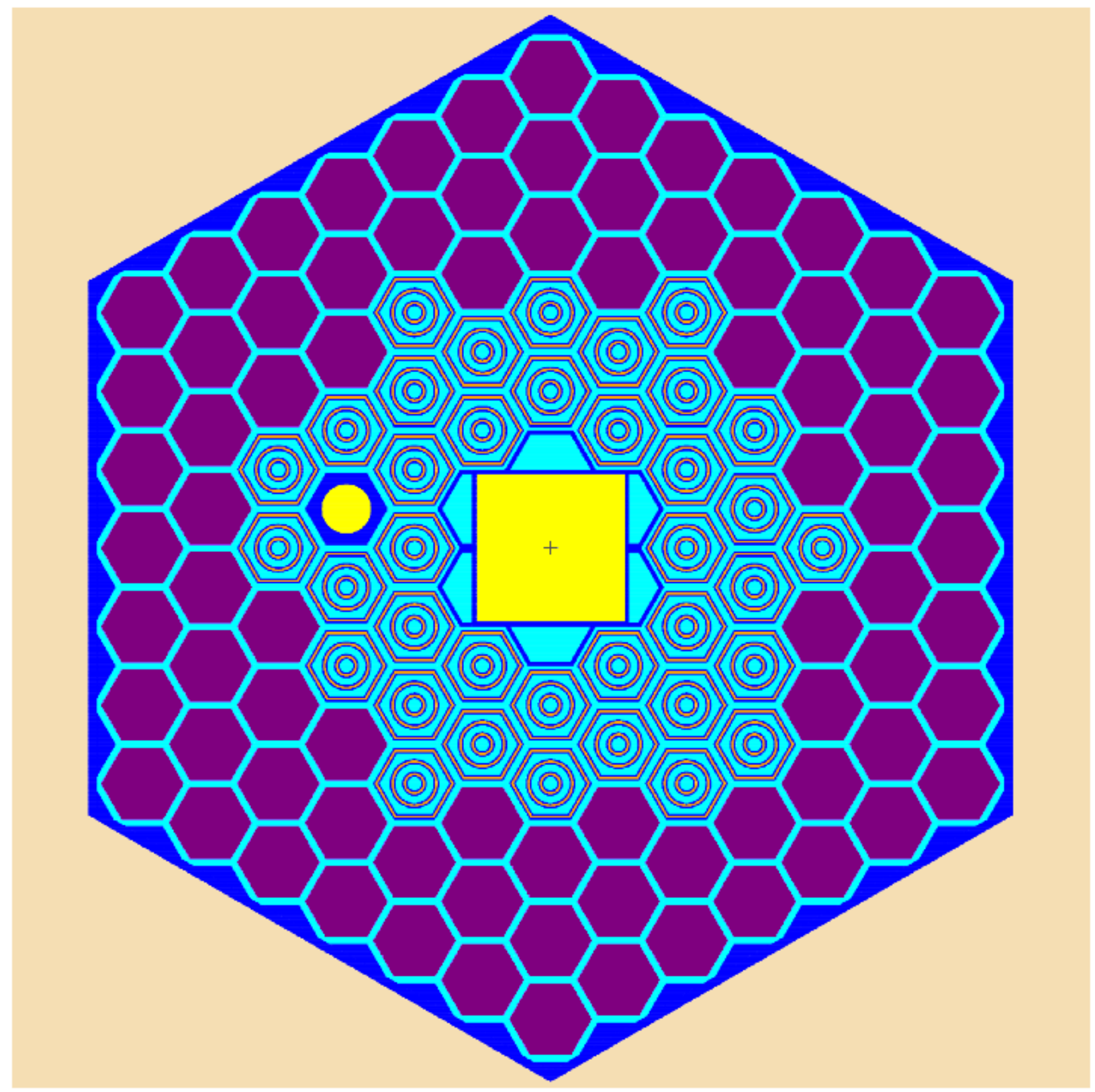

Figure 4. Zoom of the horizontal cross section for the configuration with 37 fuel assemblies and irradiation sample at position 2 


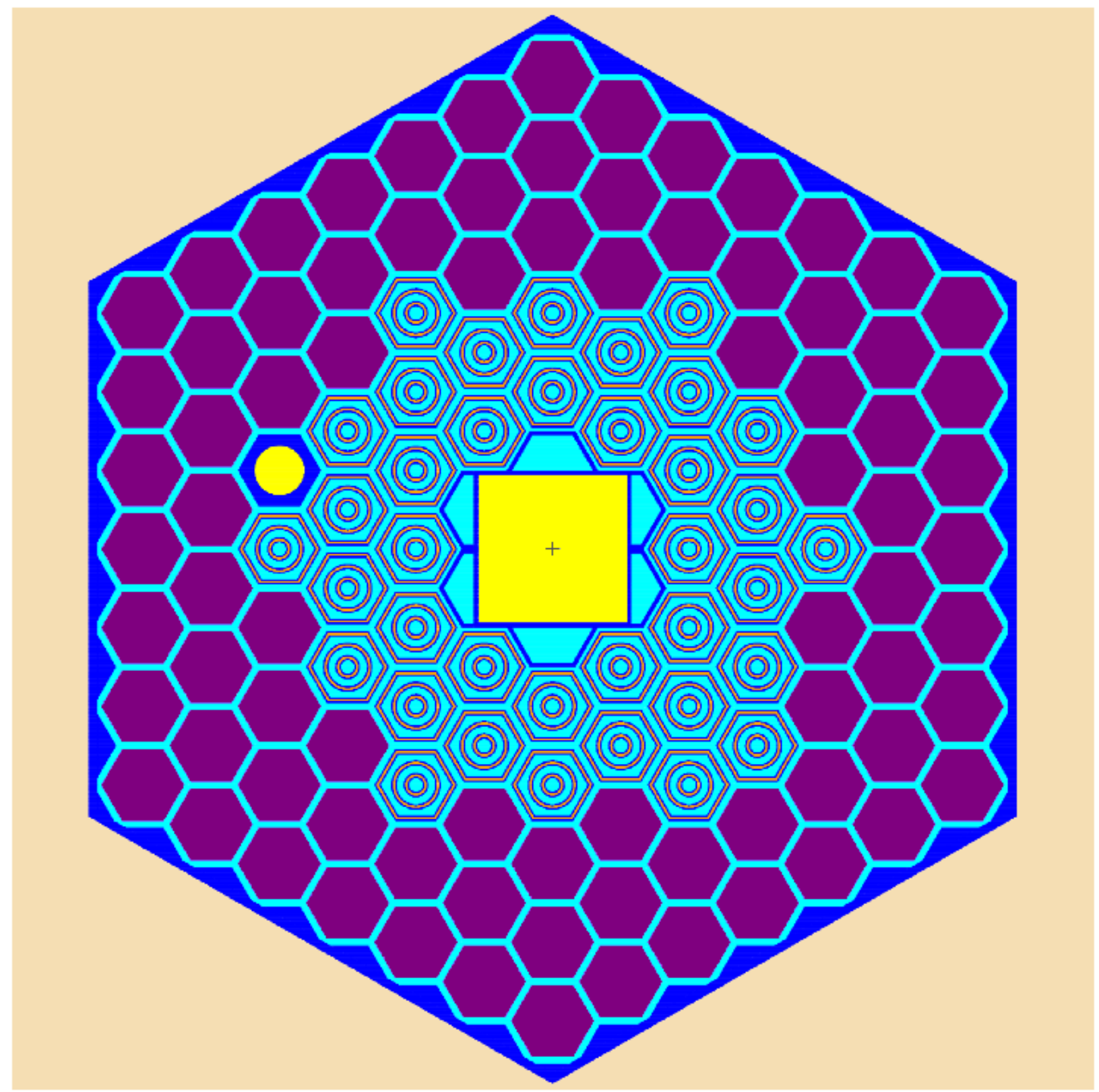

Figure 5. Zoom of the horizontal cross section for the configuration with 37 fuel assemblies and irradiation sample at position 3 


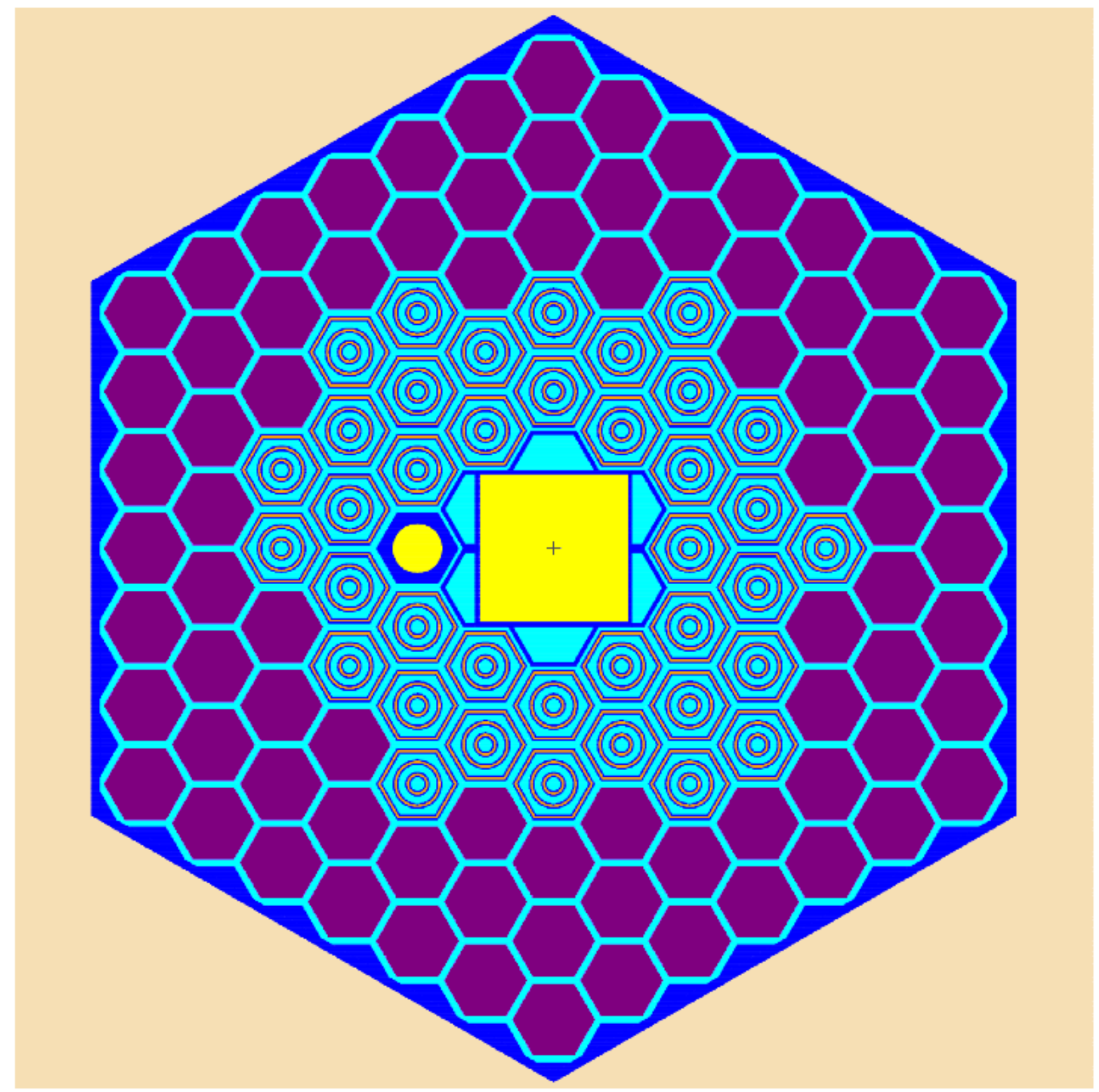

Figure 6. Zoom of the horizontal cross section for the configuration with 38 fuel assemblies and irradiation sample at position 1 


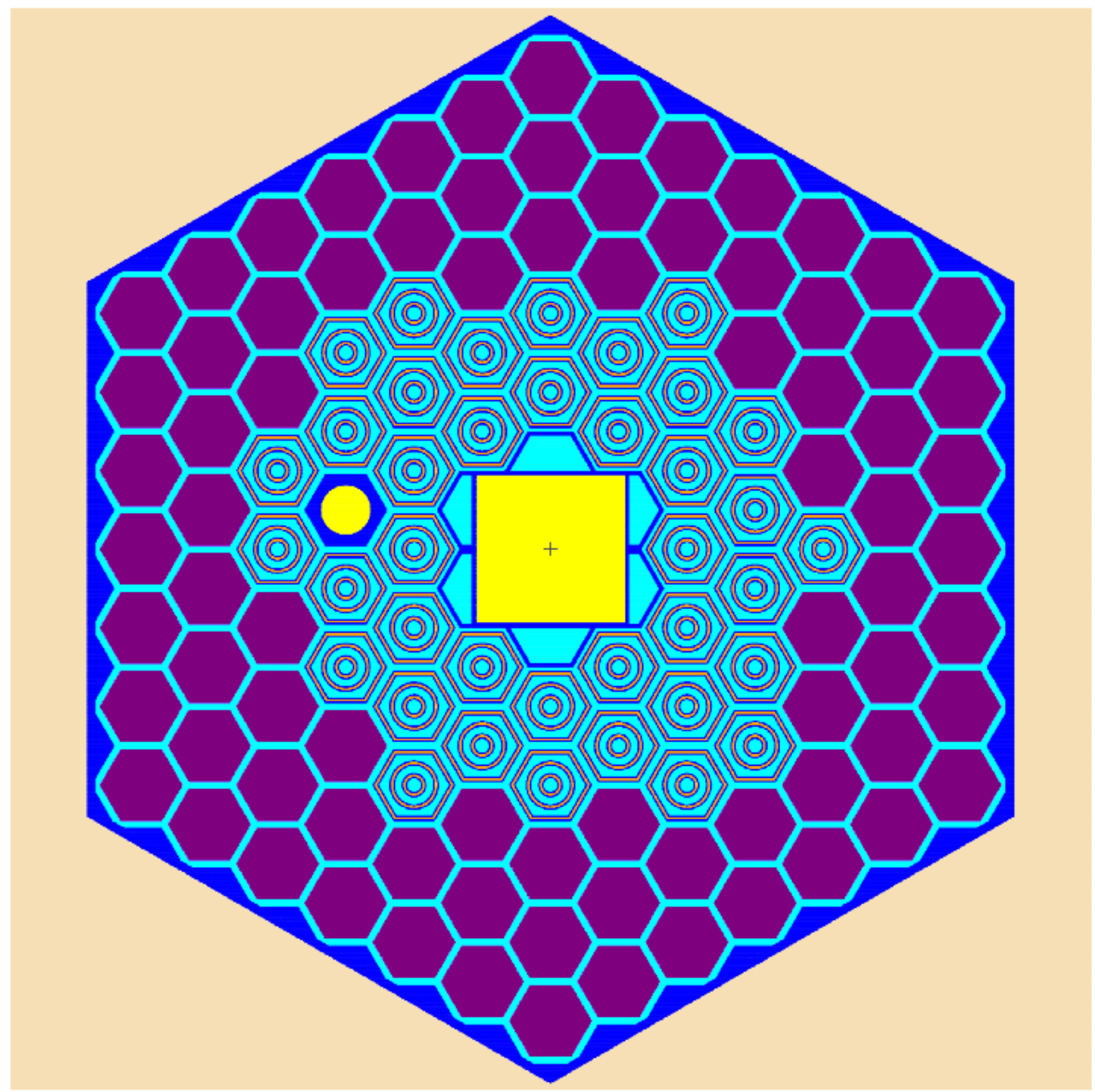

Figure 7. Zoom of the horizontal cross section for the configuration with 38 fuel assemblies and irradiation sample at position 2 


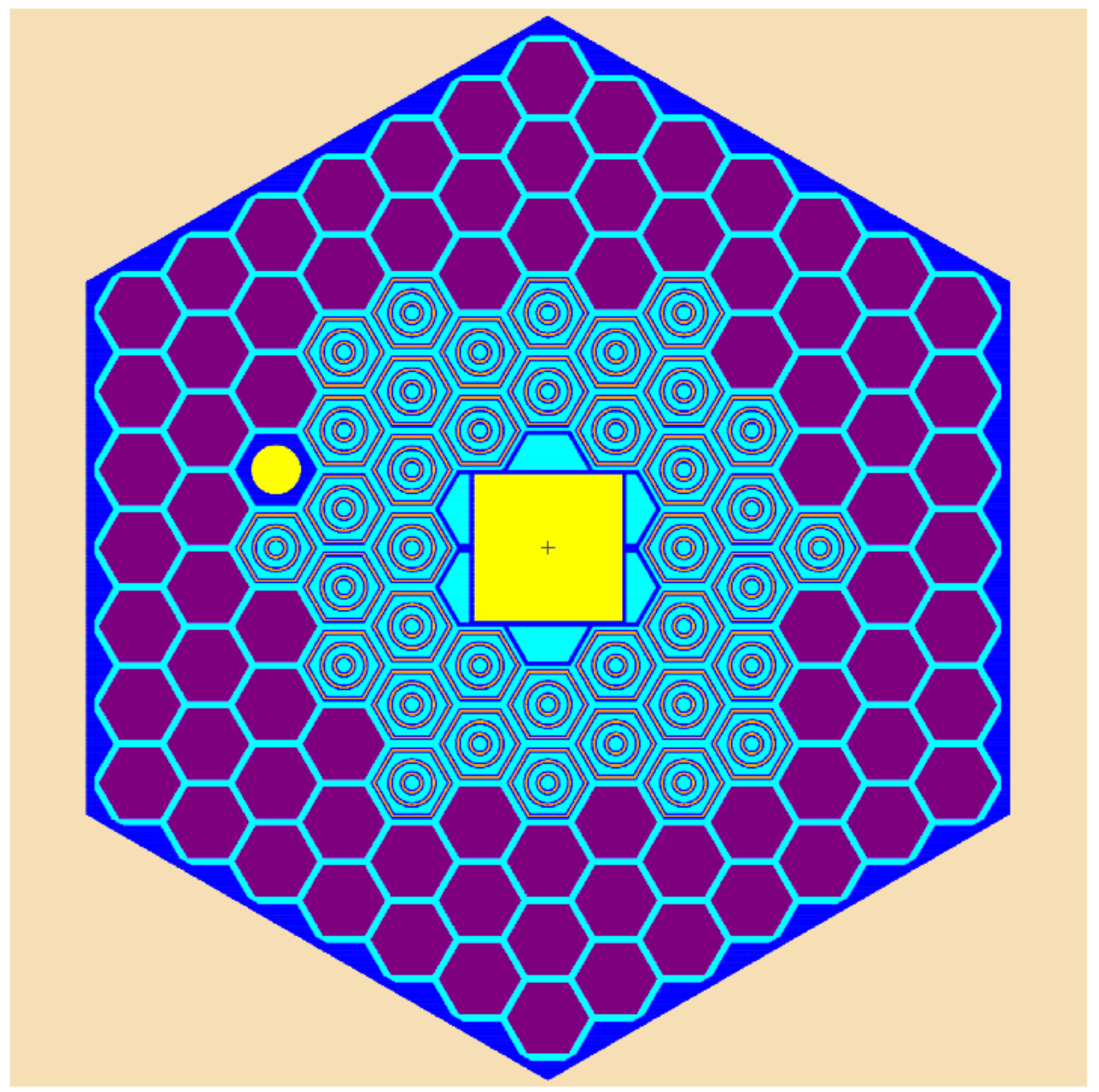

Figure 8. Zoom of the horizontal cross section for the configuration with 37 fuel assemblies and irradiation sample at position 3 


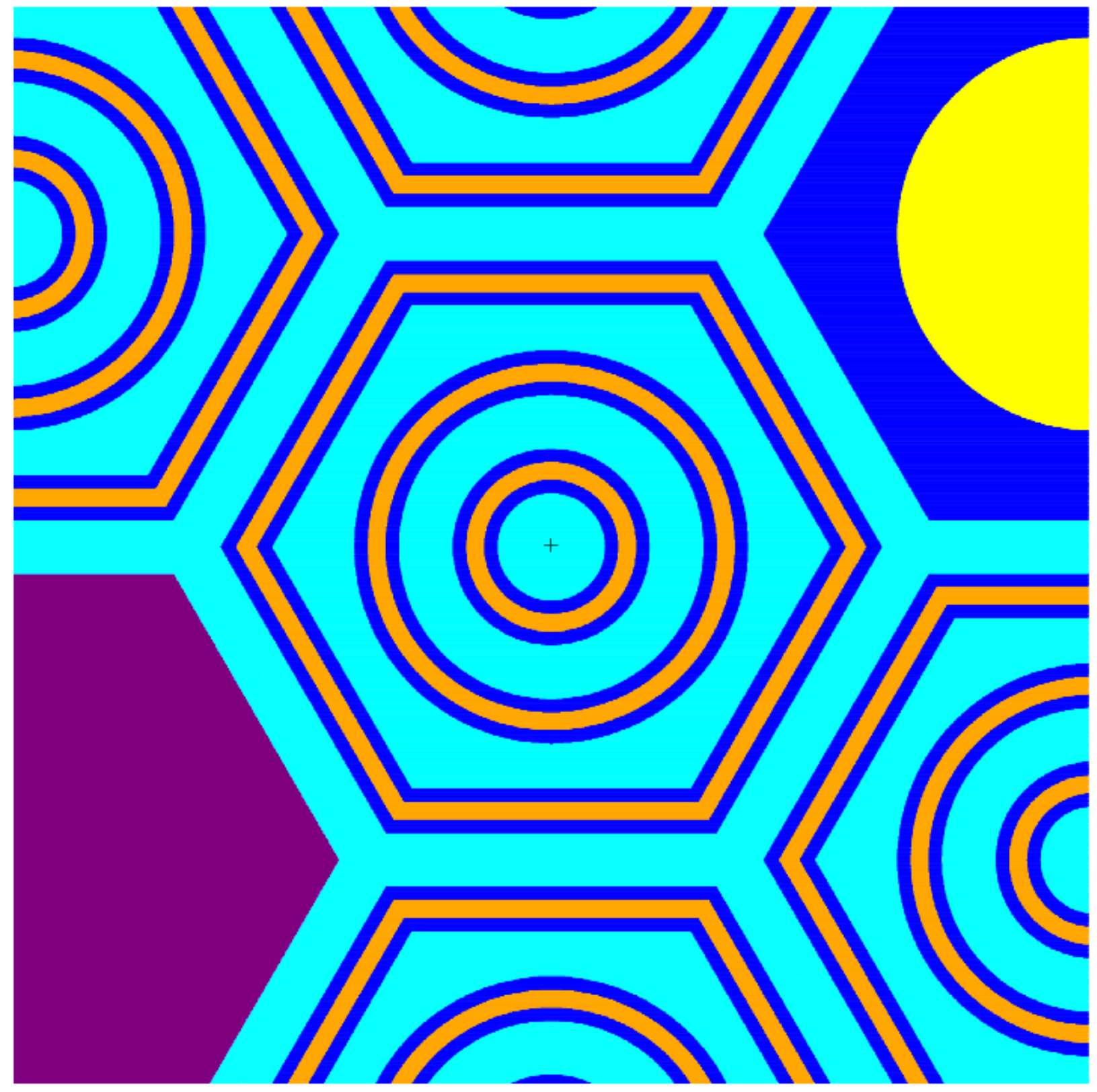

Figure 9. Horizontal cross section of the fuel assembly 


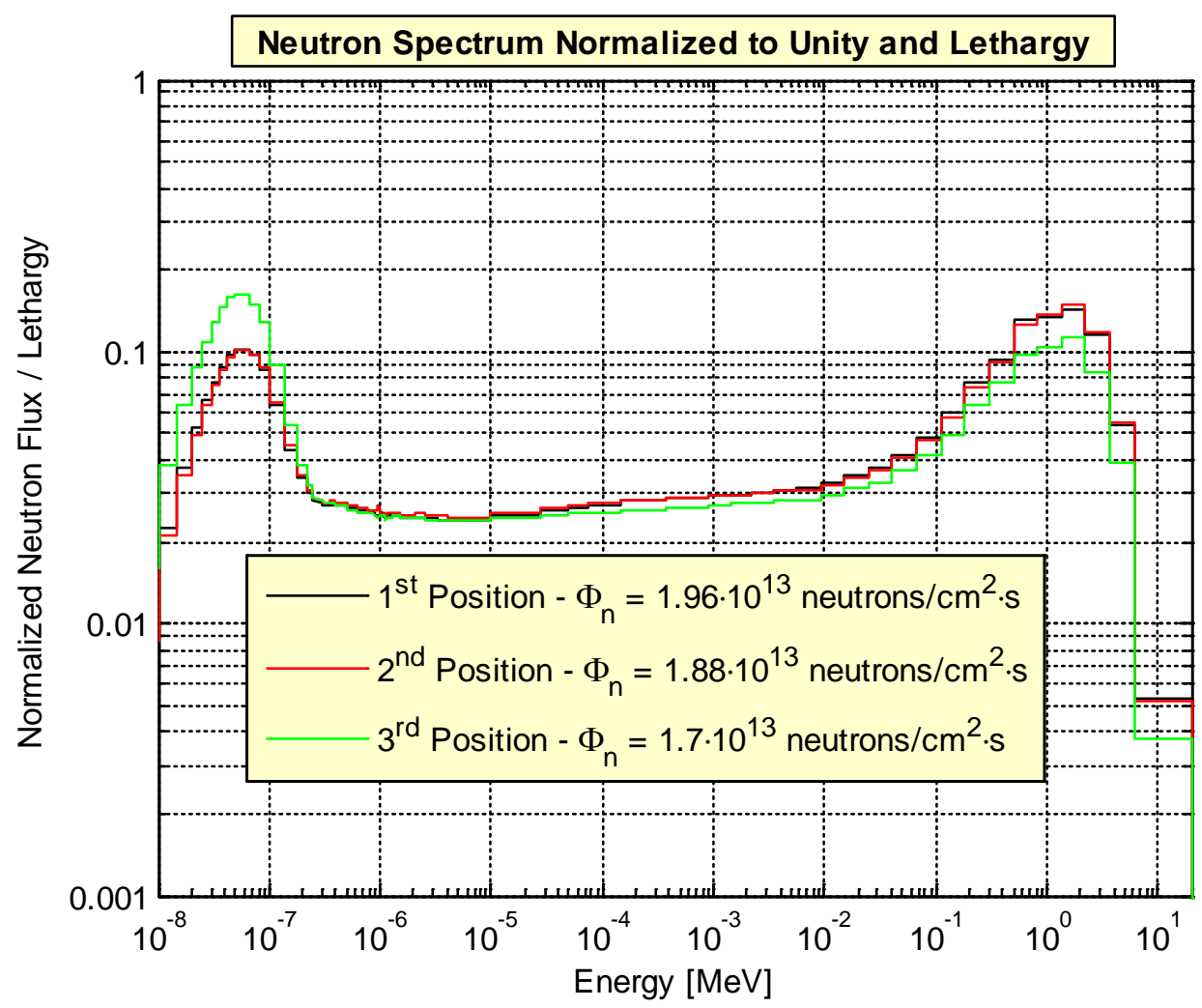

Figure 10. Neutron spectrum in different irradiation positions

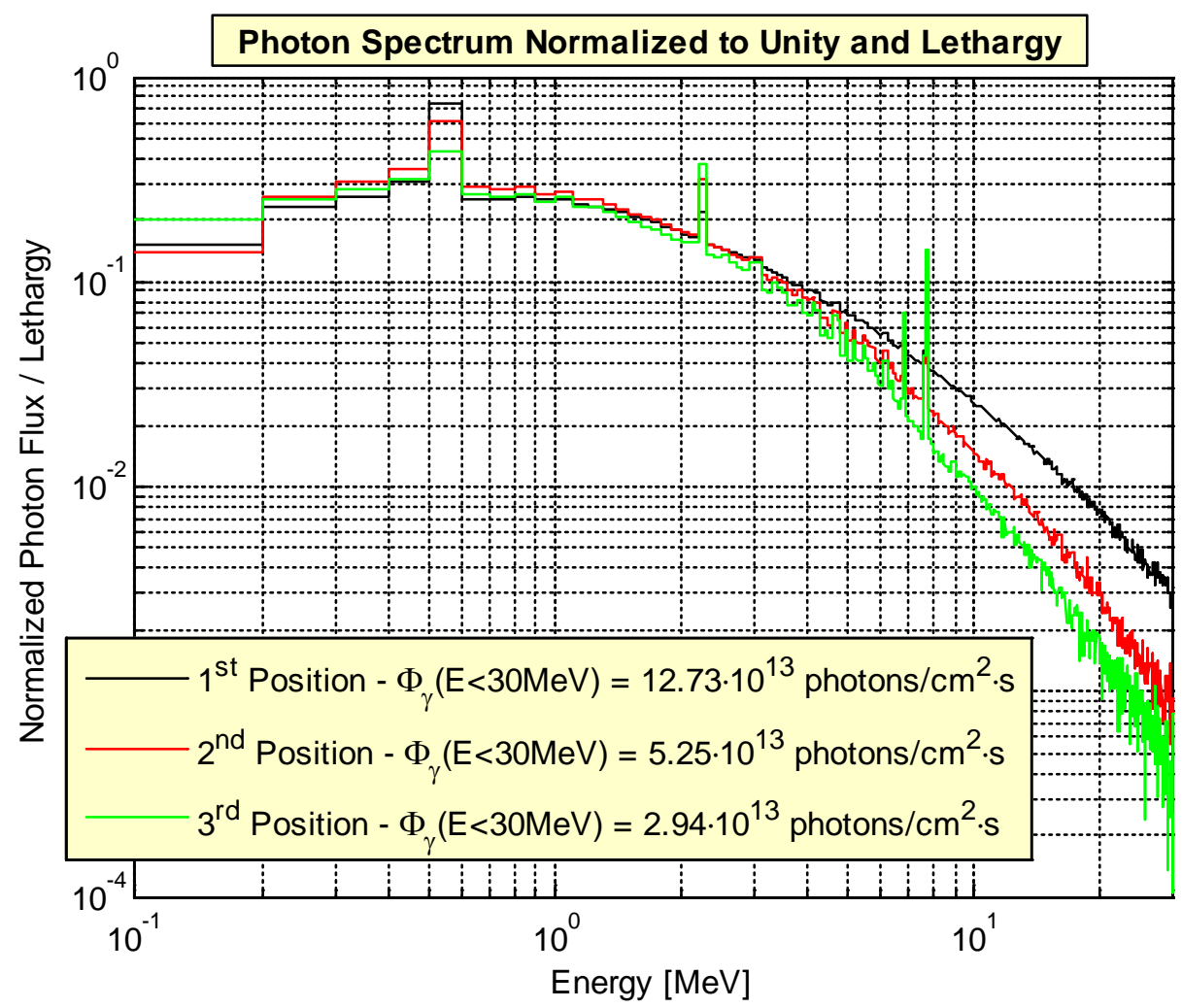

Figure 11. Photon spectrum in different irradiation positions 


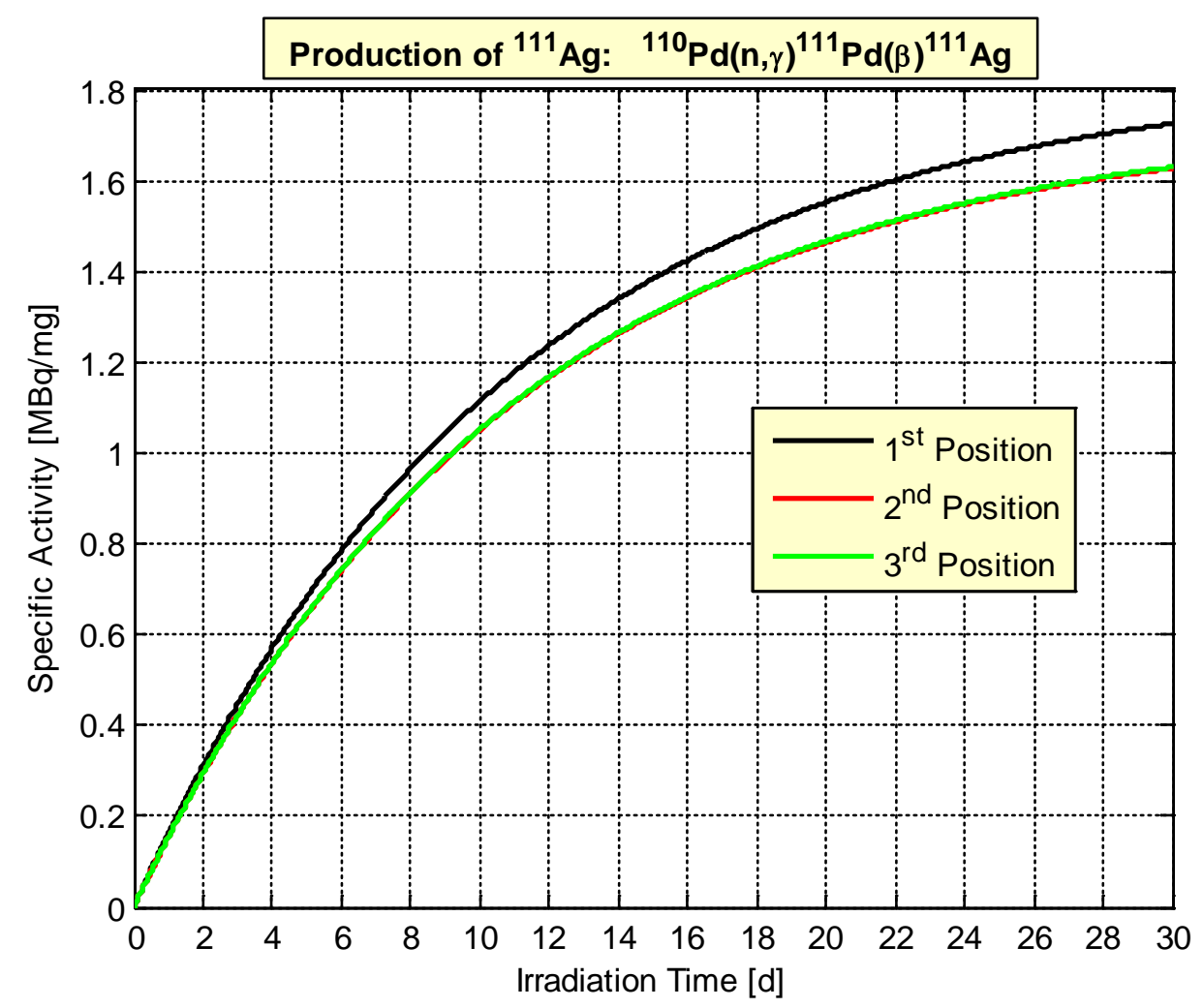

Figure $12 .{ }^{111} \mathrm{Ag}$ specific activity as a function of the irradiation time

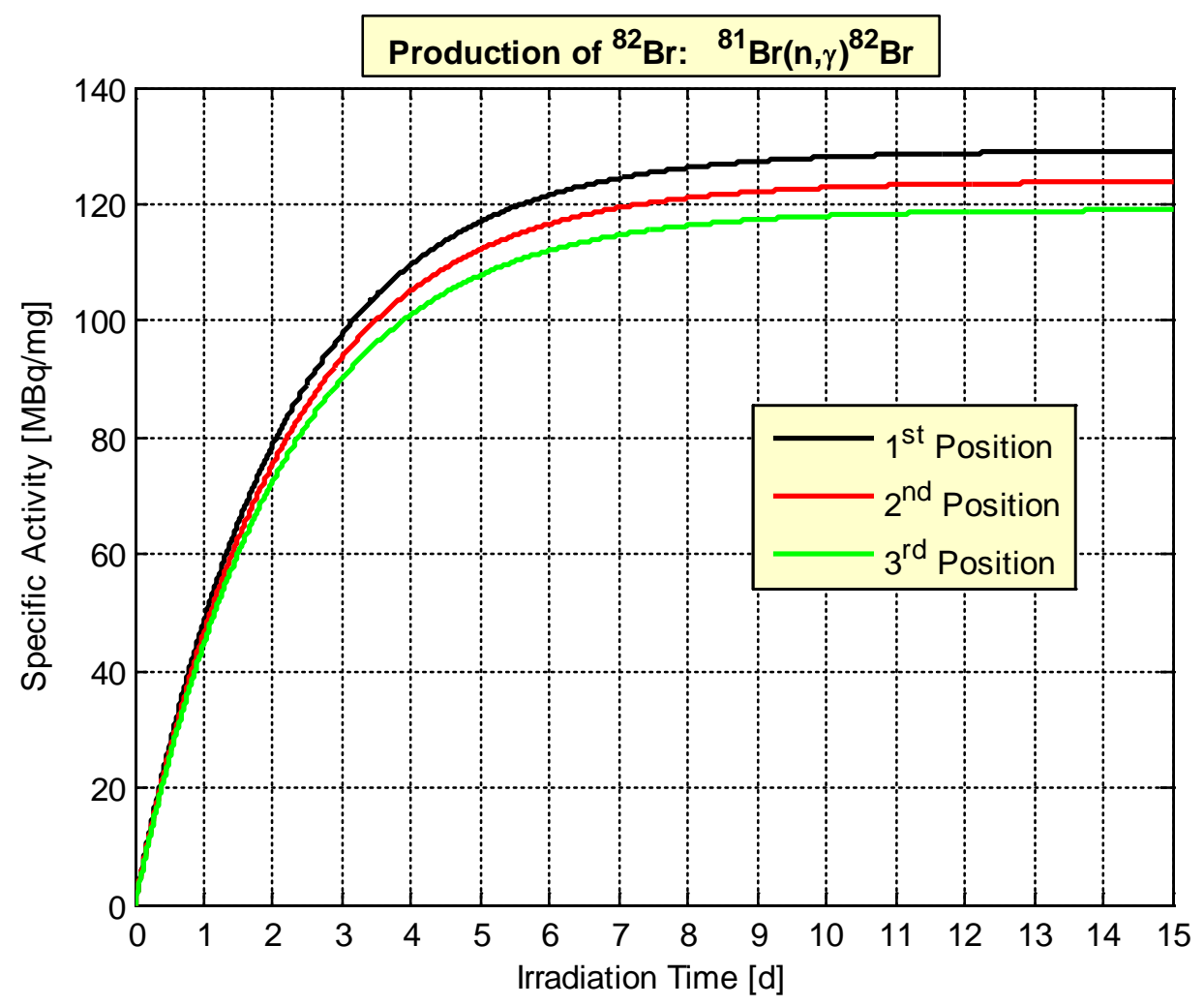

Figure $13 .{ }^{82} \mathrm{Br}$ specific activity as a function of the irradiation time 


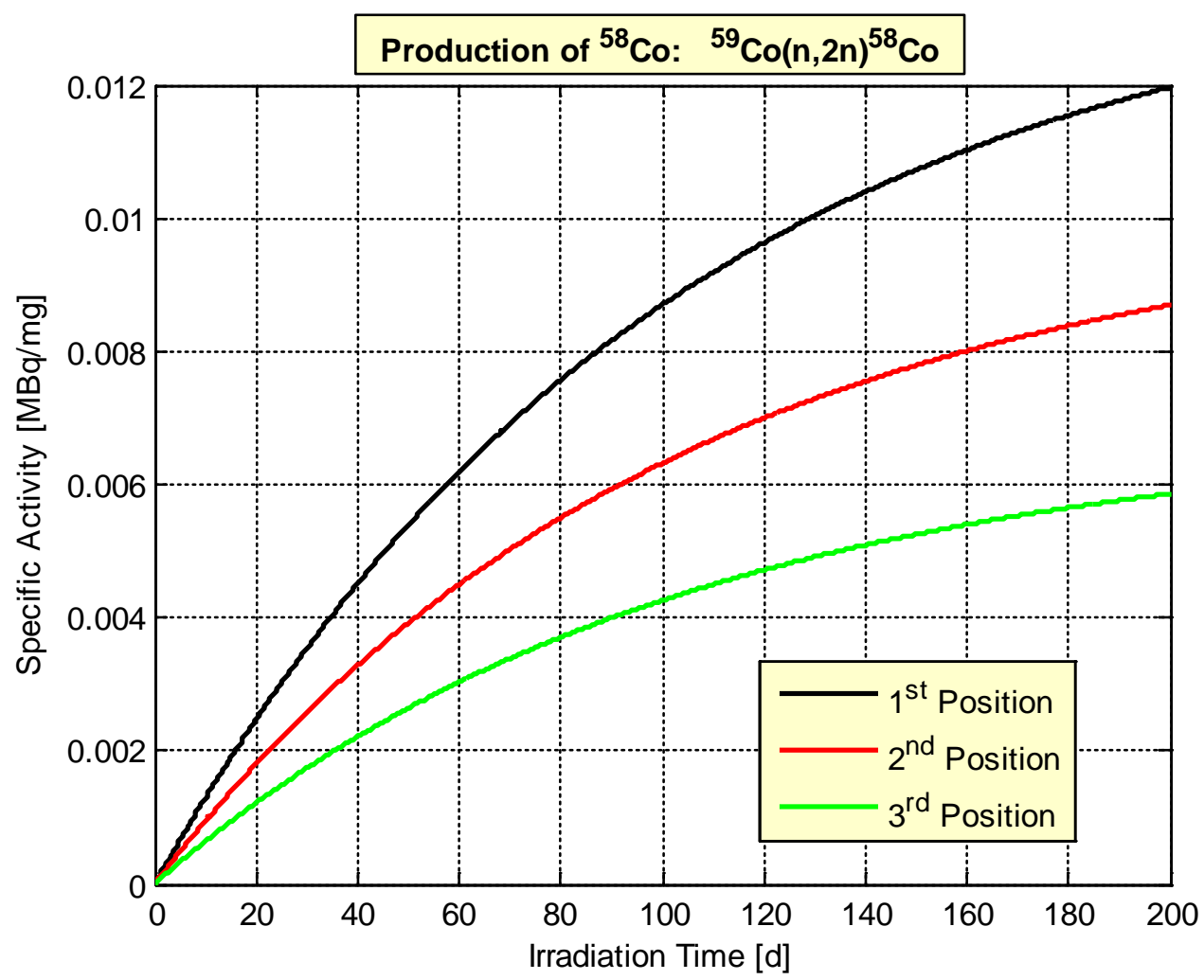

Figure $14 .{ }^{58} \mathrm{Co}$ specific activity as a function of the irradiation time

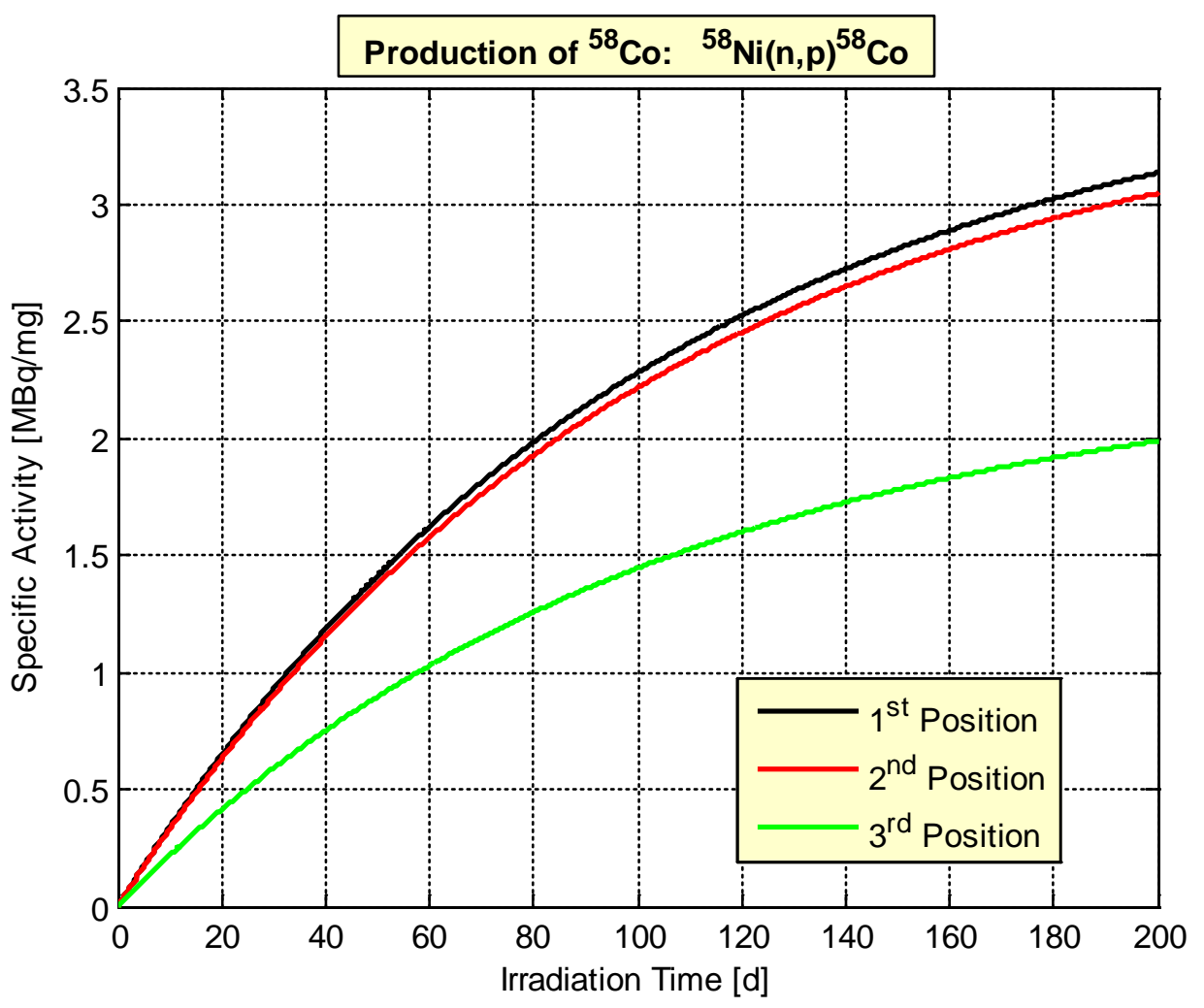

Figure $15 .{ }^{58} \mathrm{Co}$ specific activity as a function of the irradiation time 


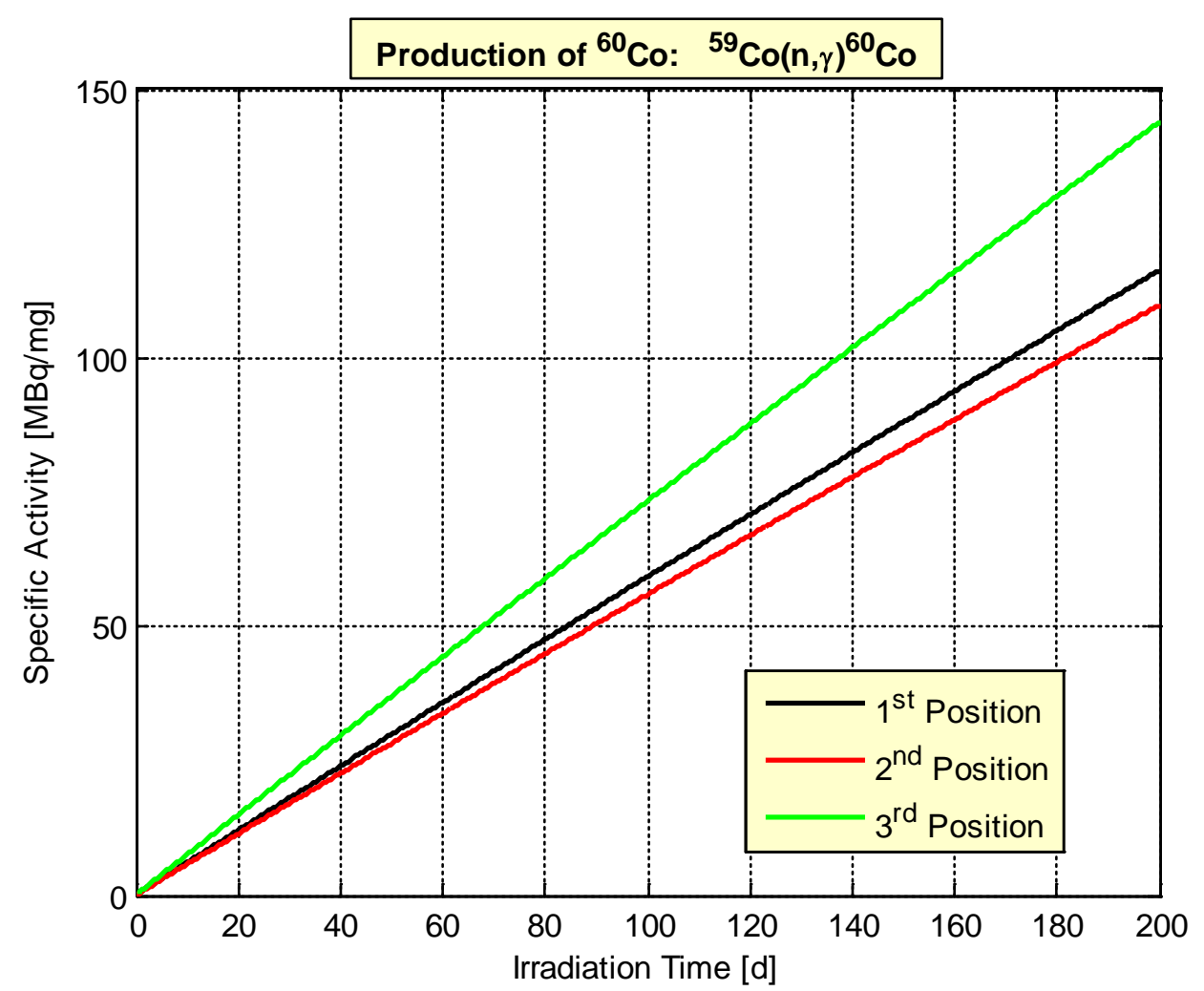

Figure $16 .{ }^{60} \mathrm{Co}$ specific activity as a function of the irradiation time

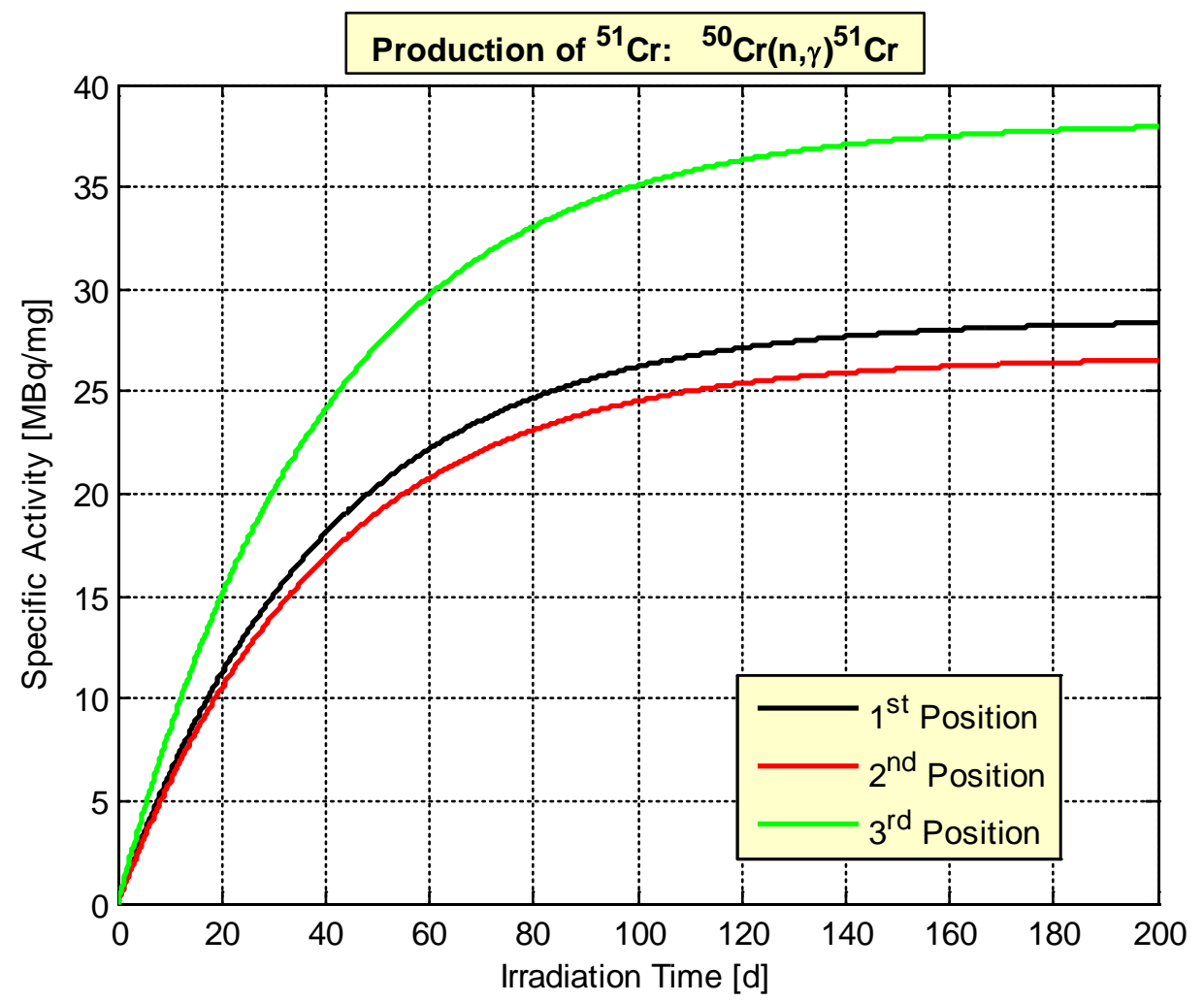

Figure $17 .{ }^{51} \mathrm{Cr}$ specific activity as a function of the irradiation time 


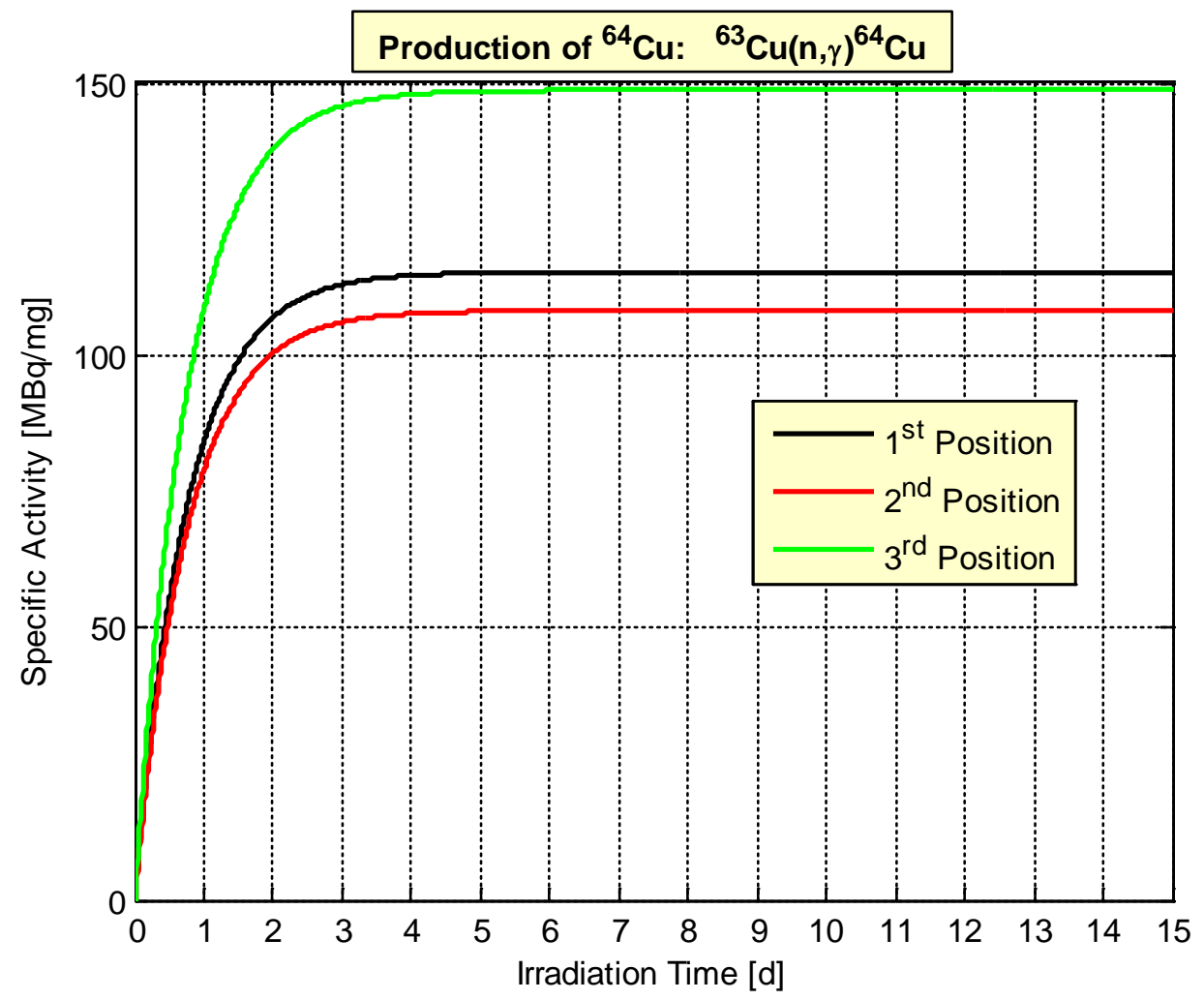

Figure $18 .{ }^{64} \mathrm{Cu}$ specific activity as a function of the irradiation time

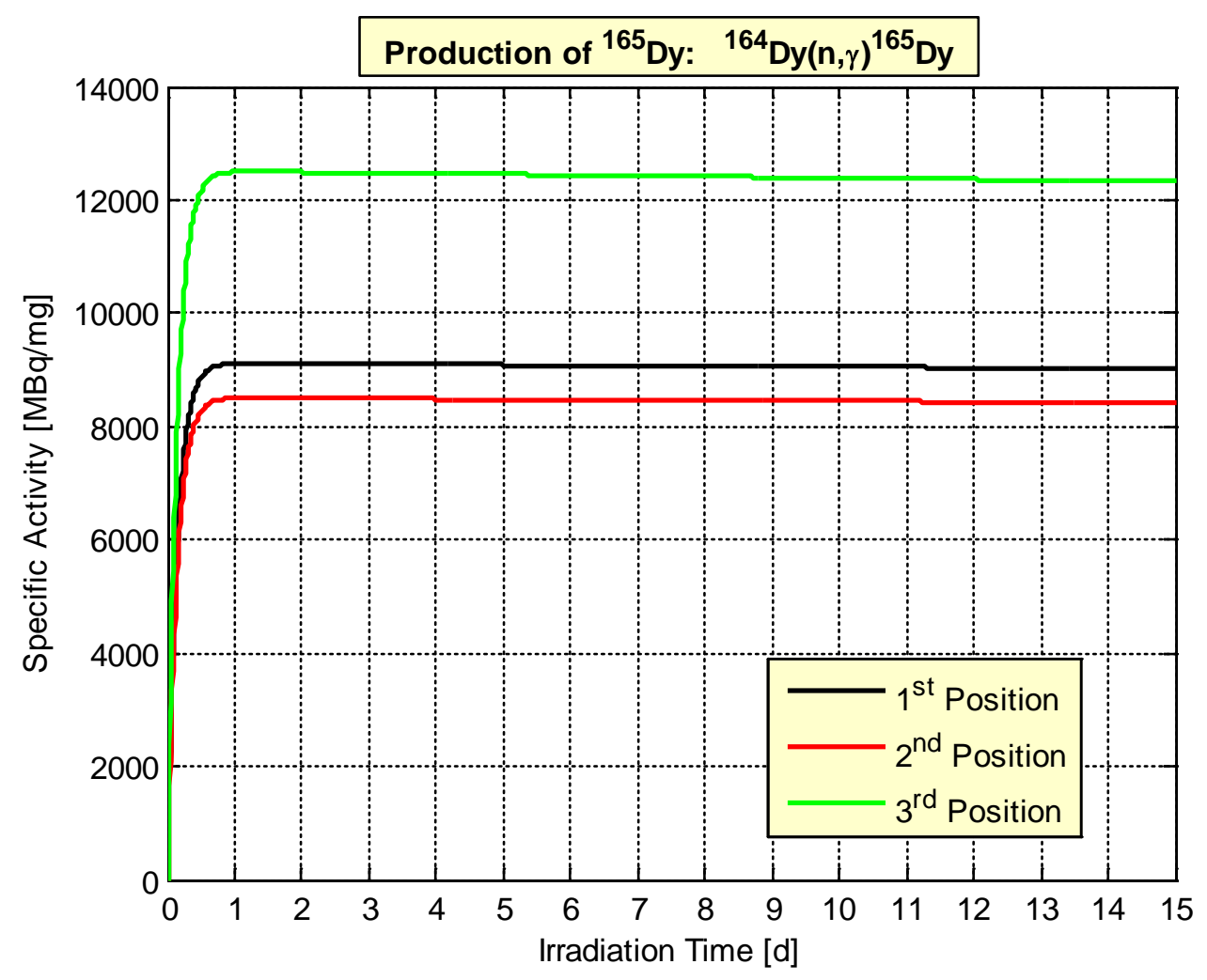

Figure 19. ${ }^{165}$ Dy specific activity as a function of the irradiation time 


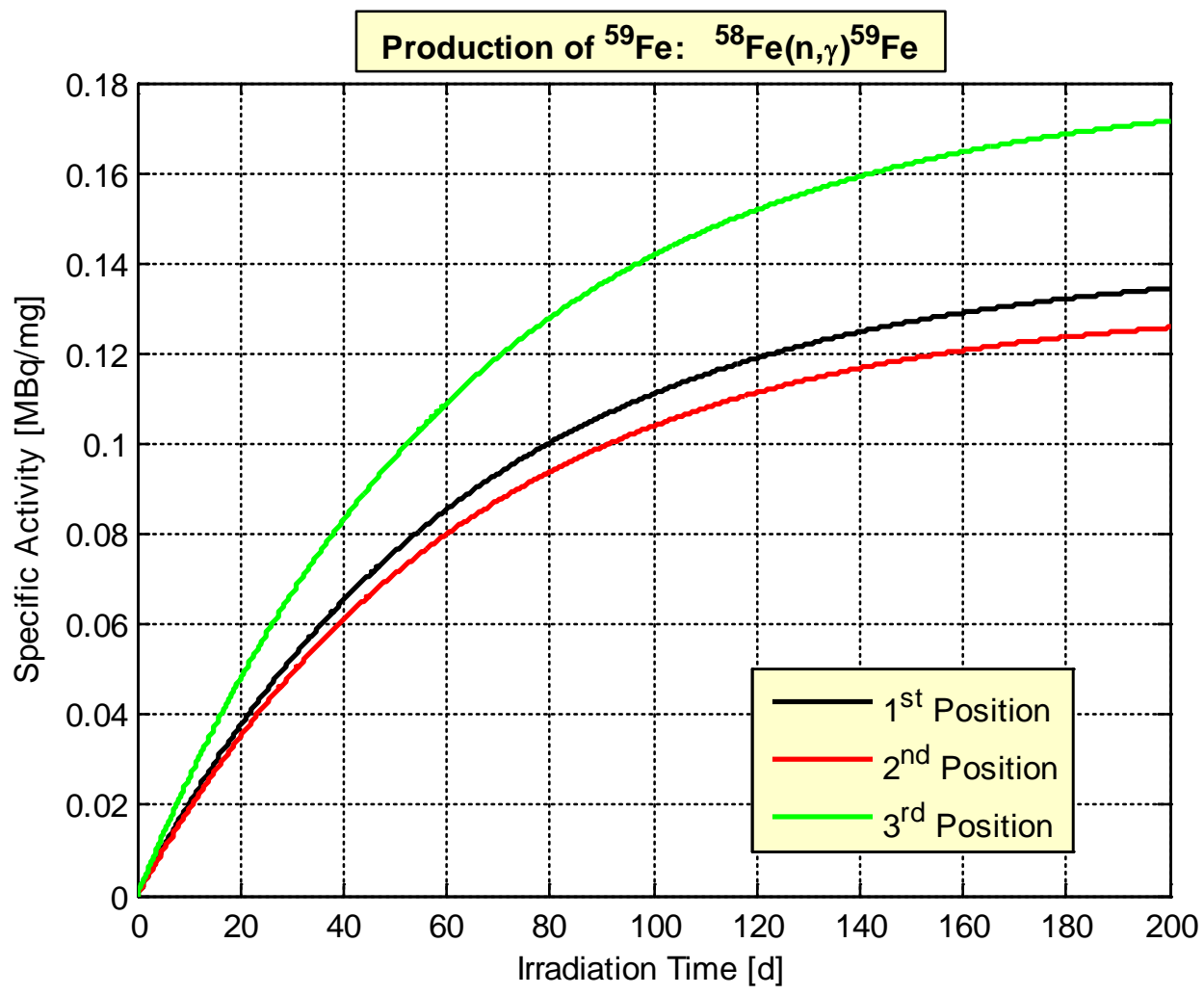

Figure $20 .{ }^{59} \mathrm{Fe}$ specific activity as a function of the irradiation time

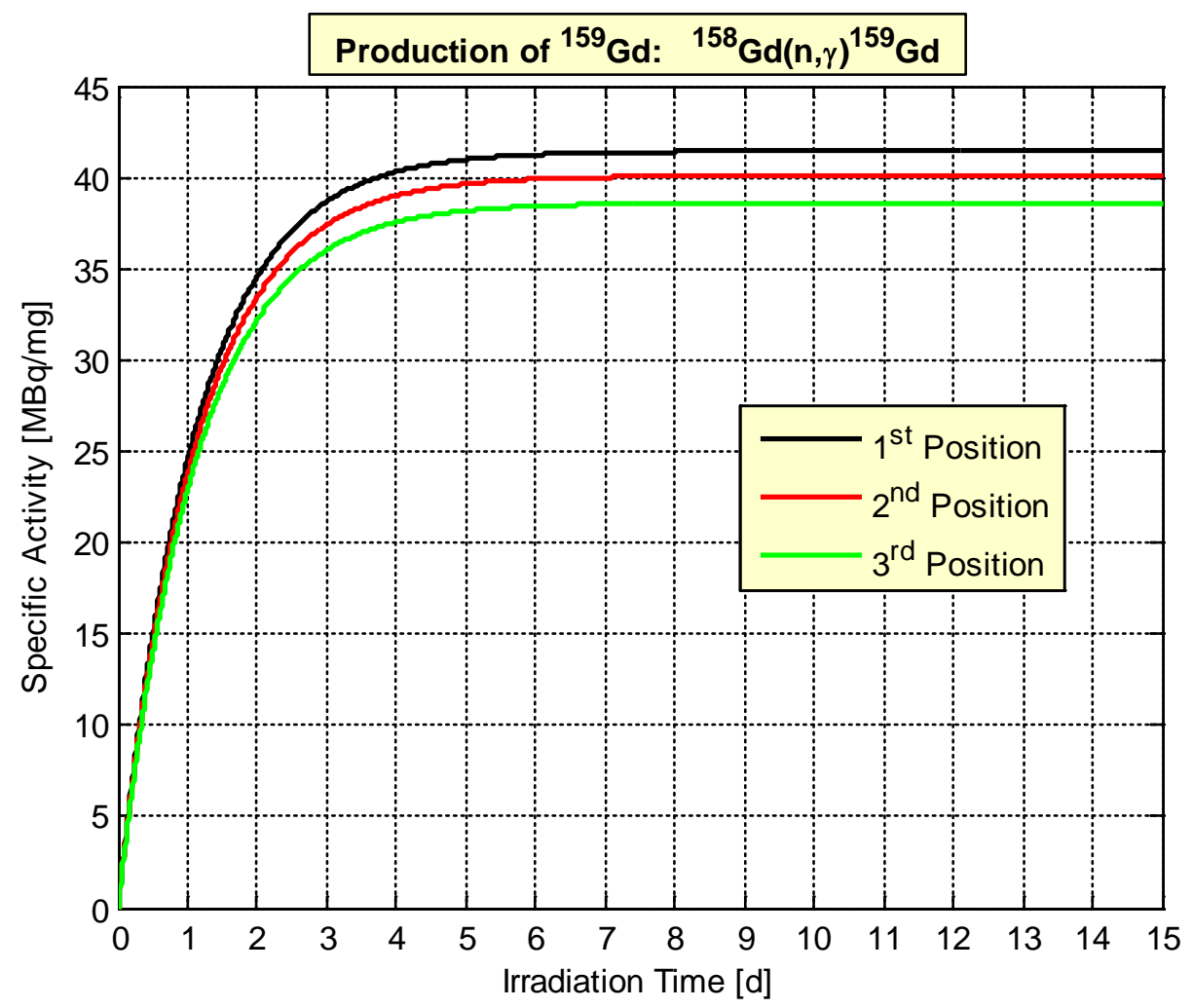

Figure $21 .{ }^{159} \mathrm{Gd}$ specific activity as a function of the irradiation time 


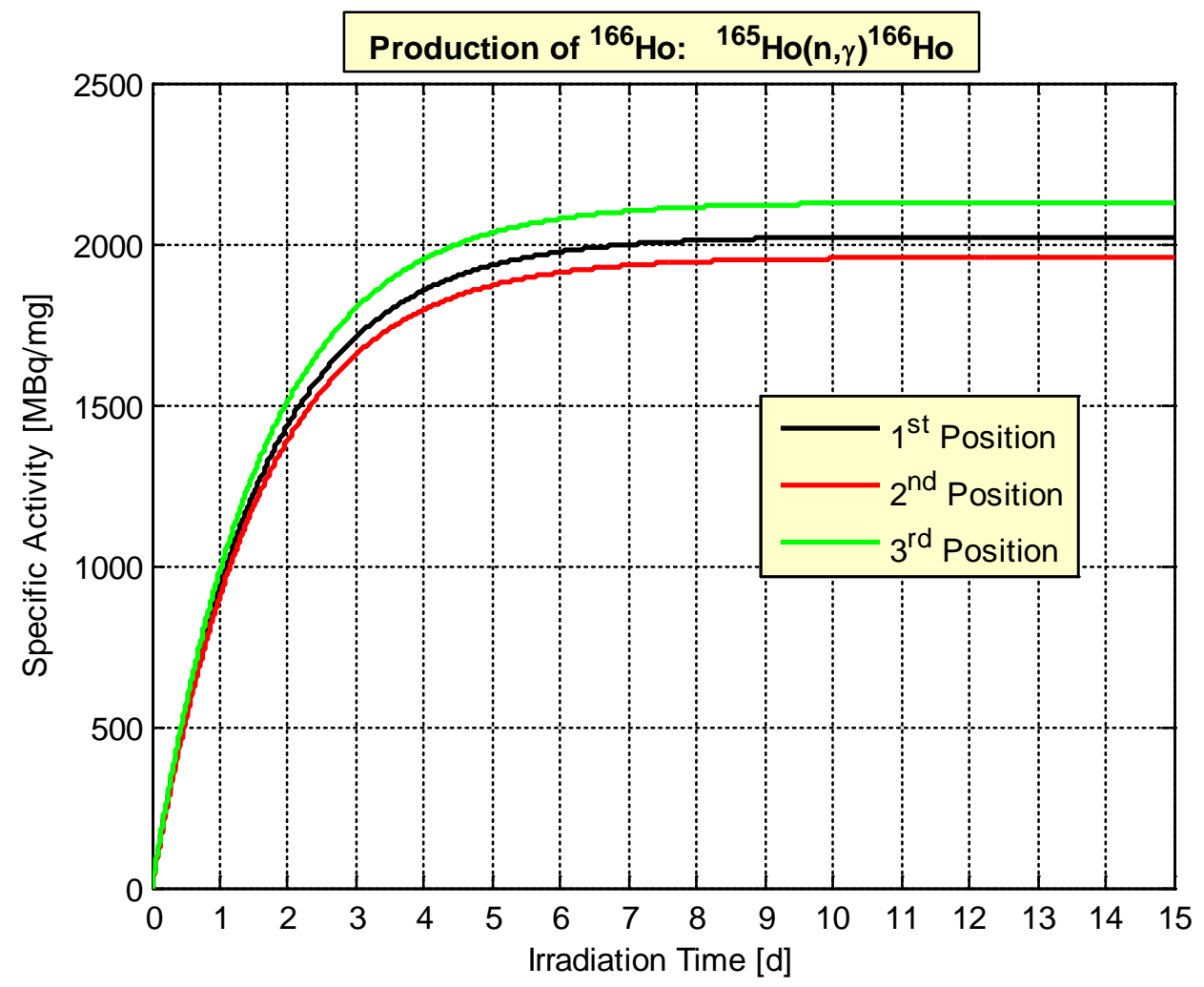

Figure $22 .{ }^{166} \mathrm{Ho}$ specific activity as a function of the irradiation time

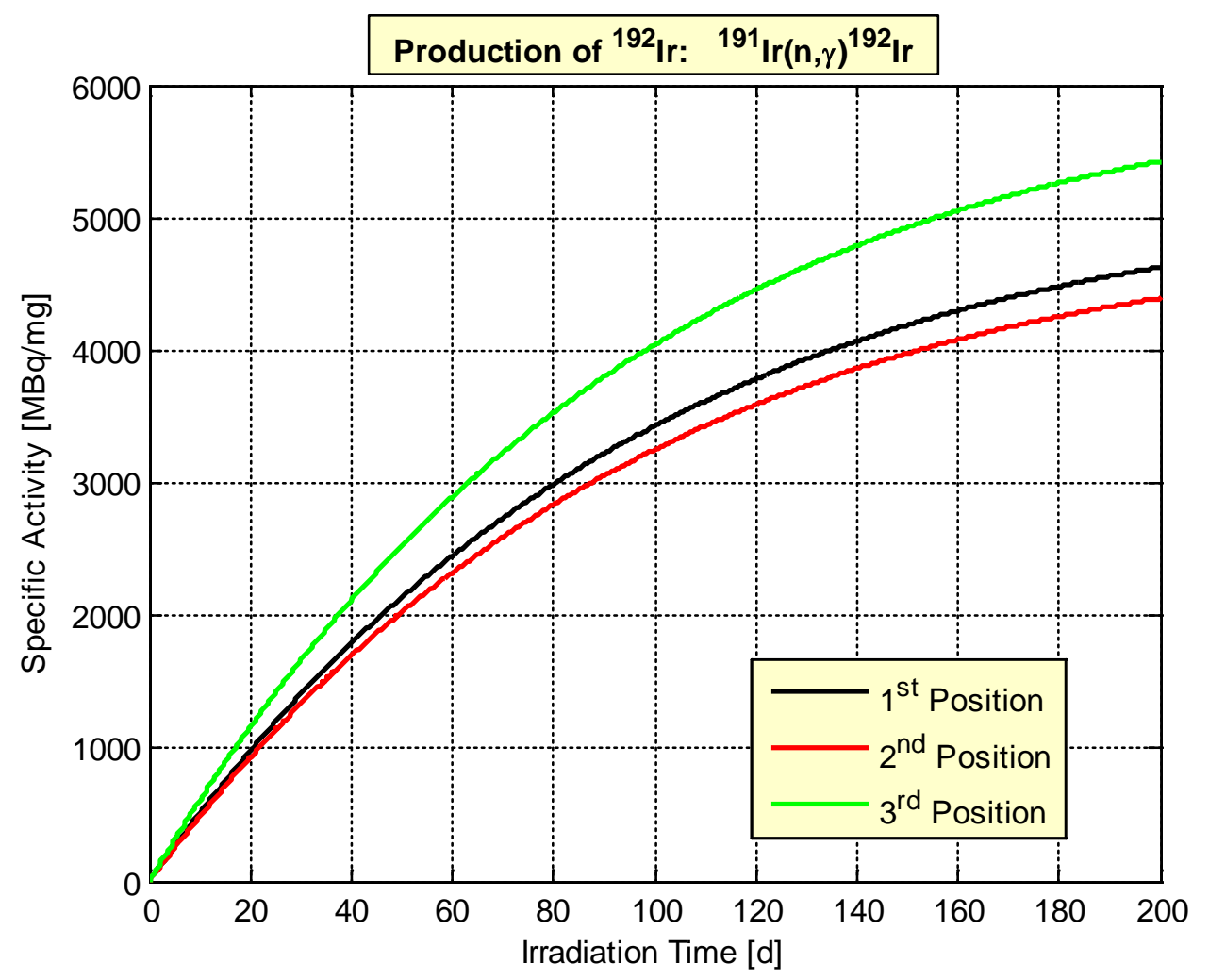

Figure $23 .{ }^{192}$ Ir specific activity as a function of the irradiation time 


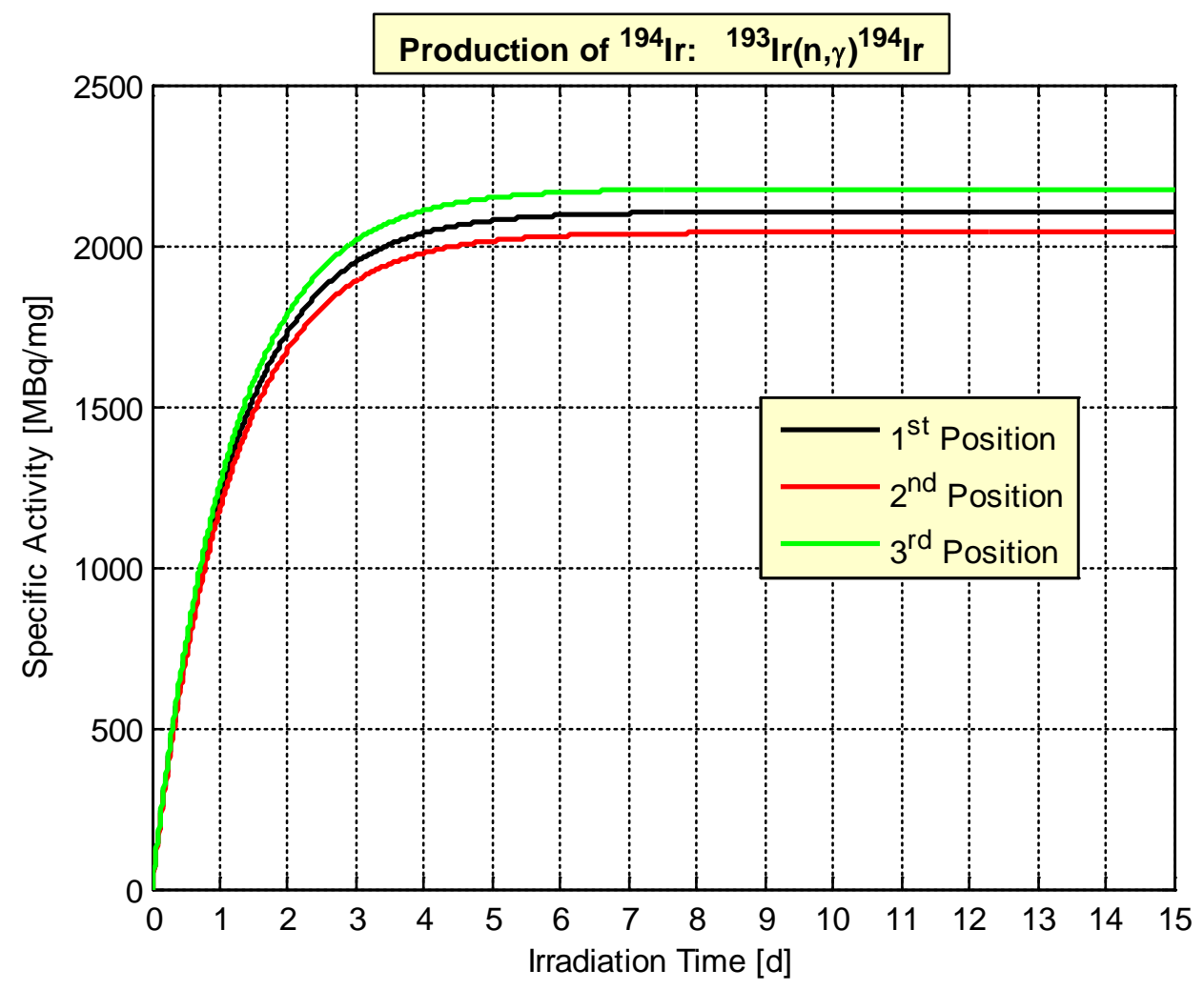

Figure $24 .{ }^{194}$ Ir specific activity as a function of the irradiation time

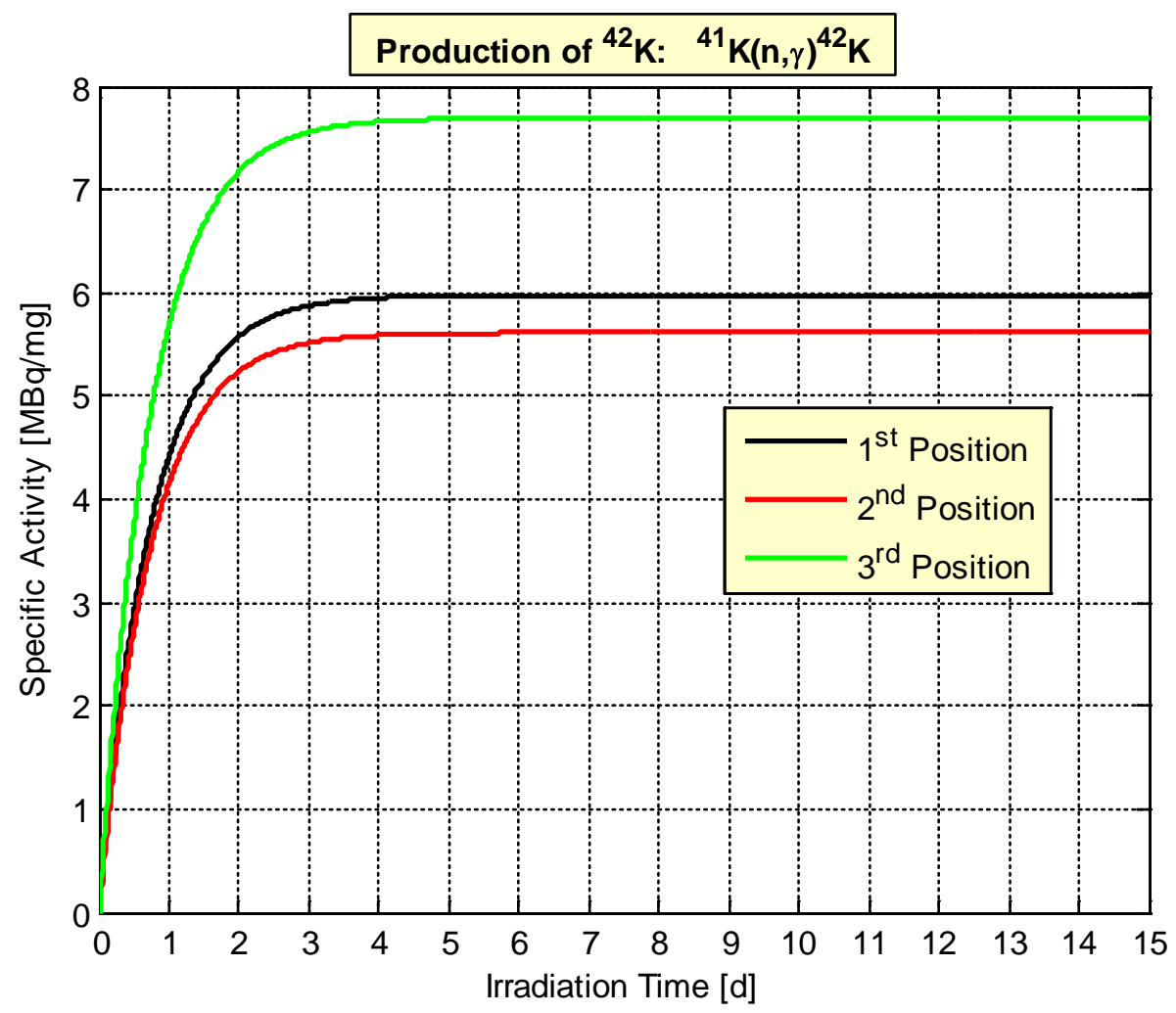

Figure $25 .{ }^{42} \mathrm{~K}$ specific activity as a function of the irradiation time 


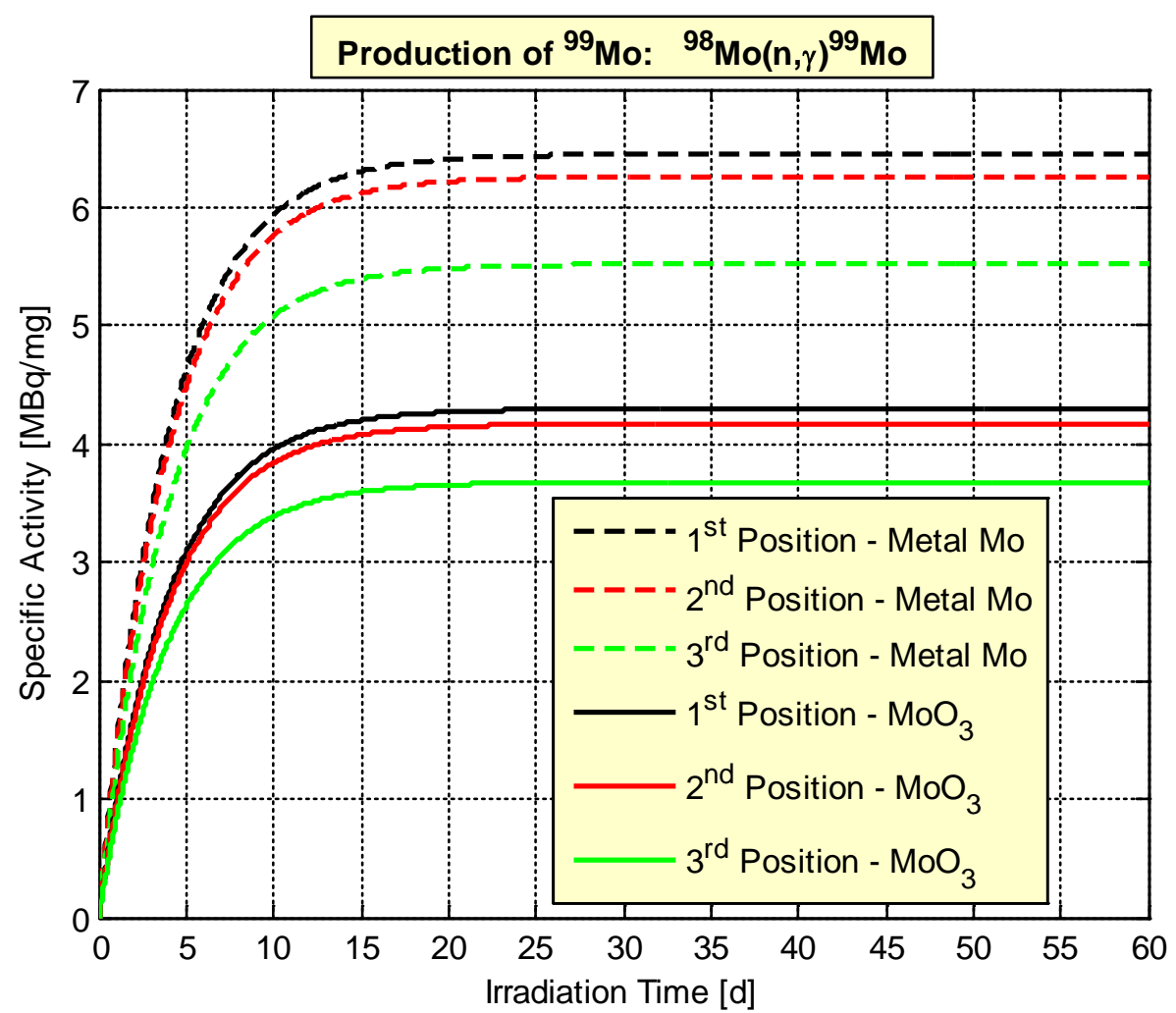

Figure $26 .{ }^{99}$ Mo specific activity as a function of the irradiation time

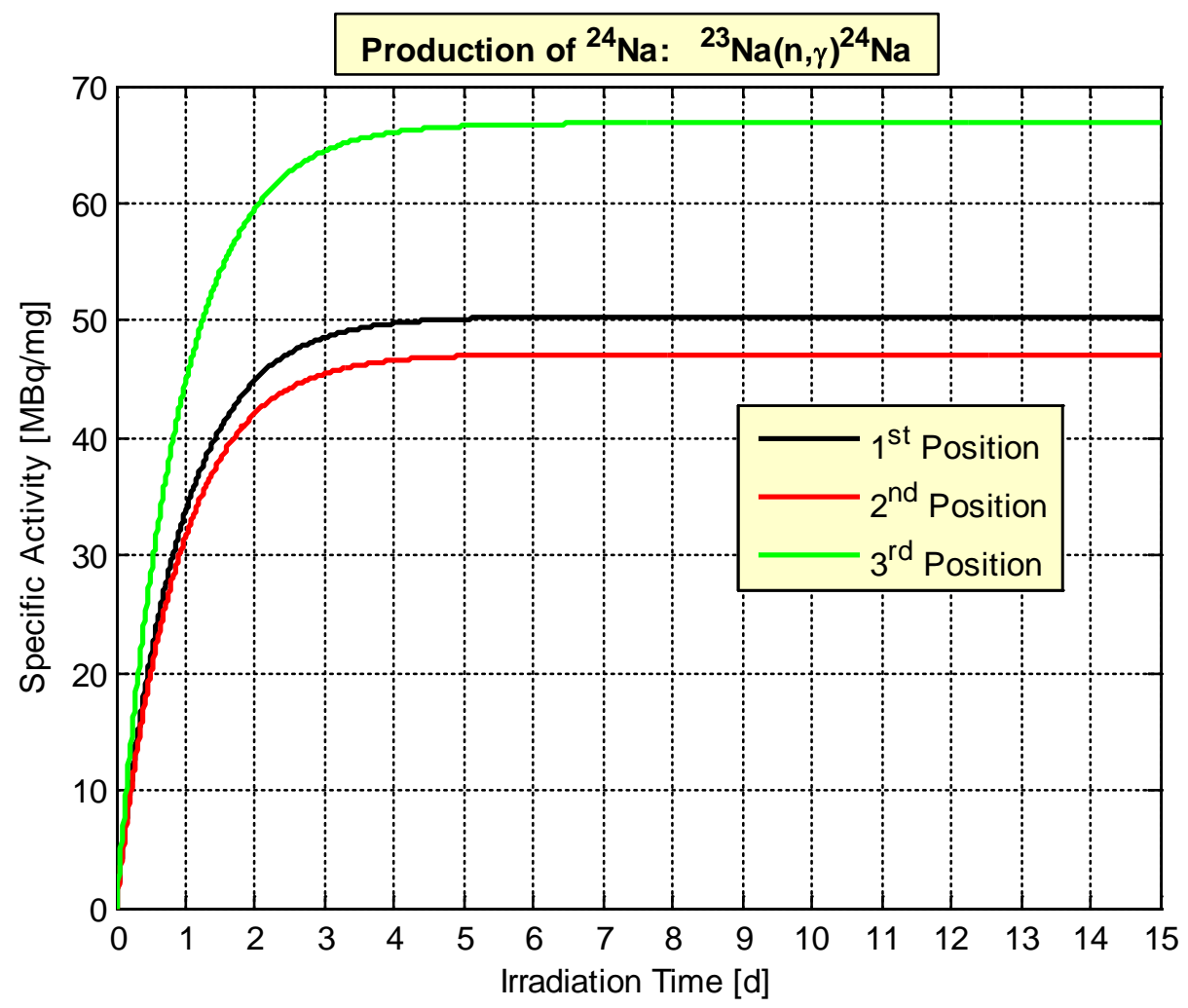

Figure $27 .{ }^{24} \mathrm{Na}$ specific activity as a function of the irradiation time 


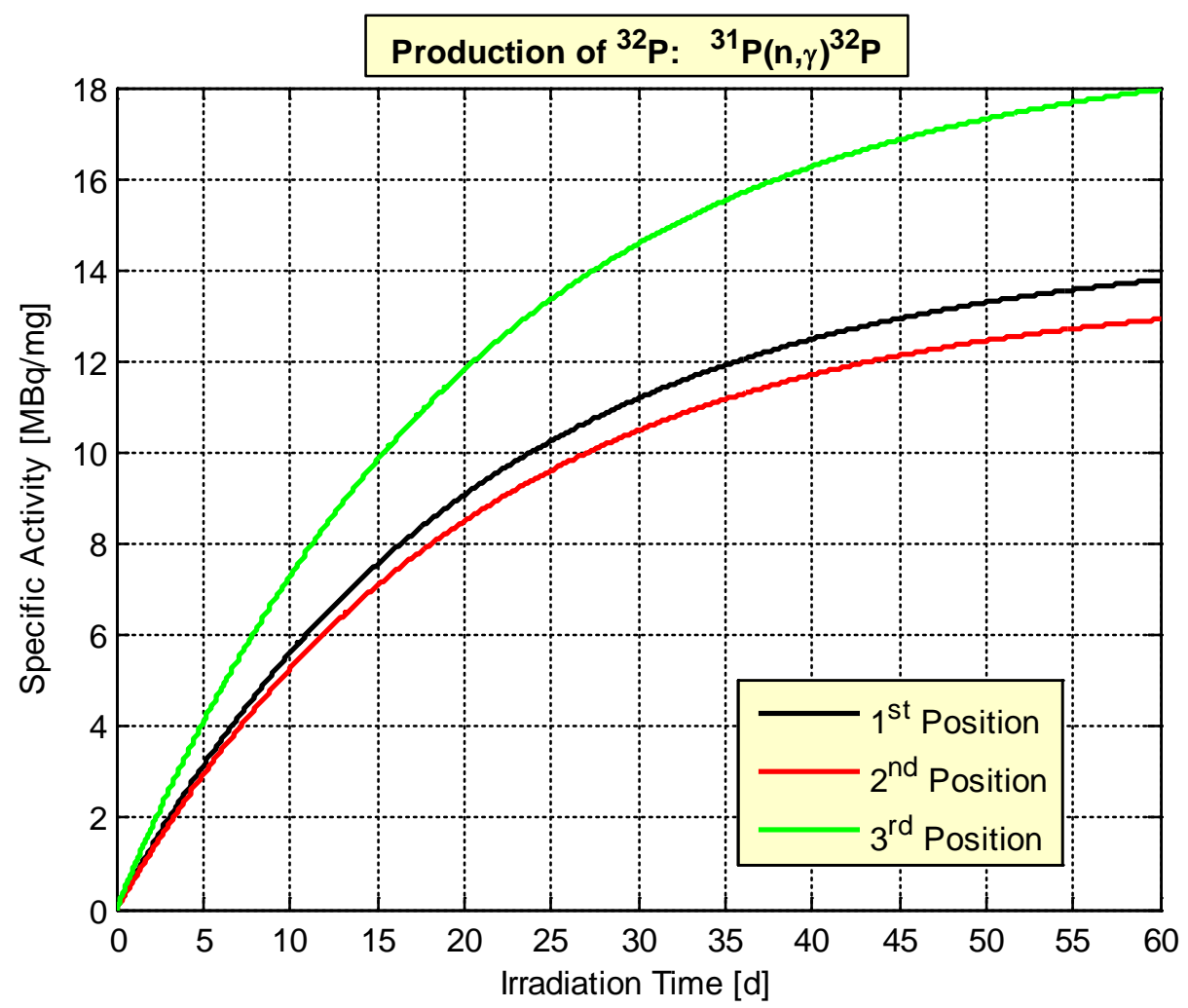

Figure $28 .{ }^{32} \mathrm{P}$ specific activity as a function of the irradiation time

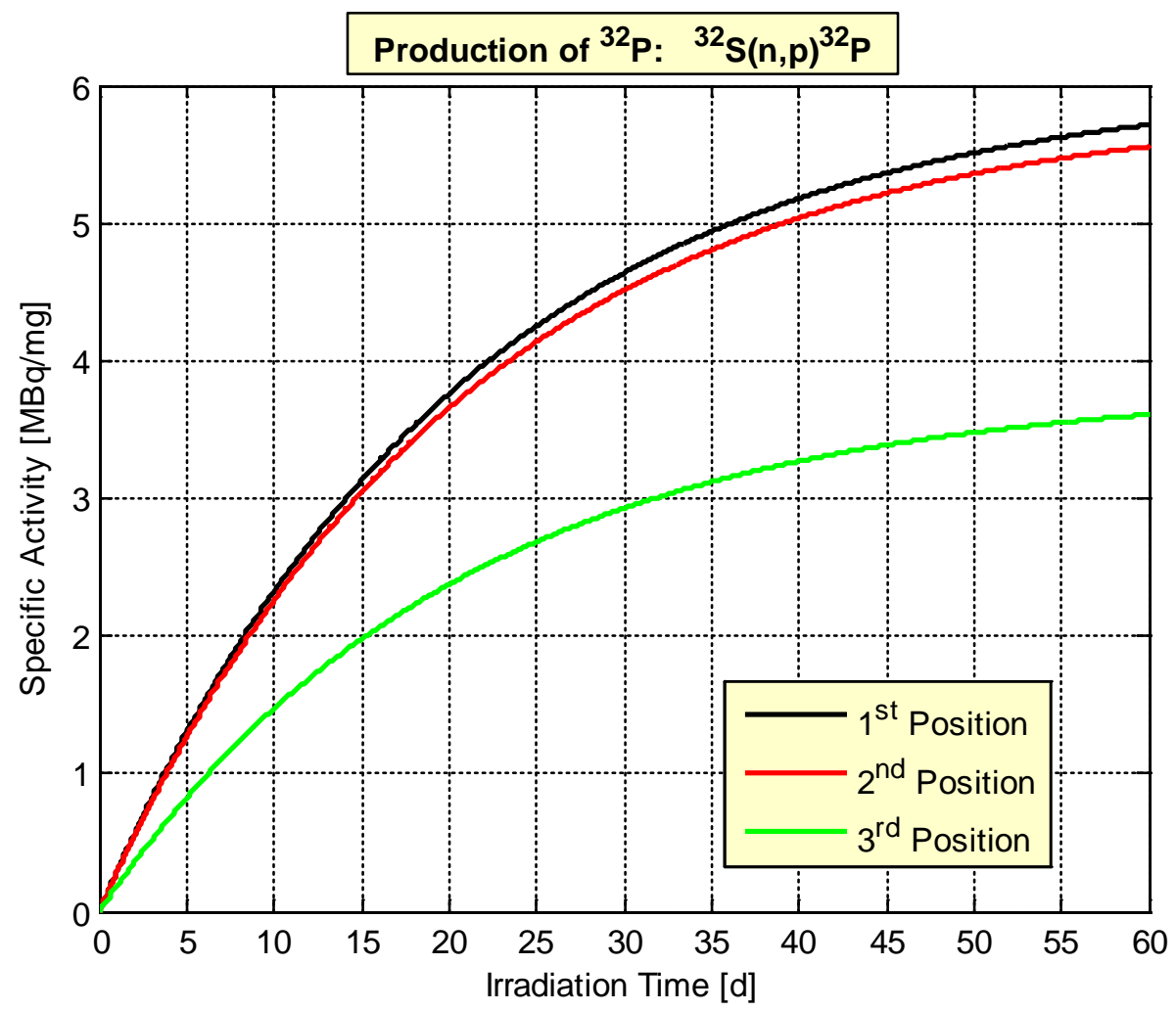

Figure $29 .{ }^{32} \mathrm{P}$ specific activity as a function of the irradiation time 


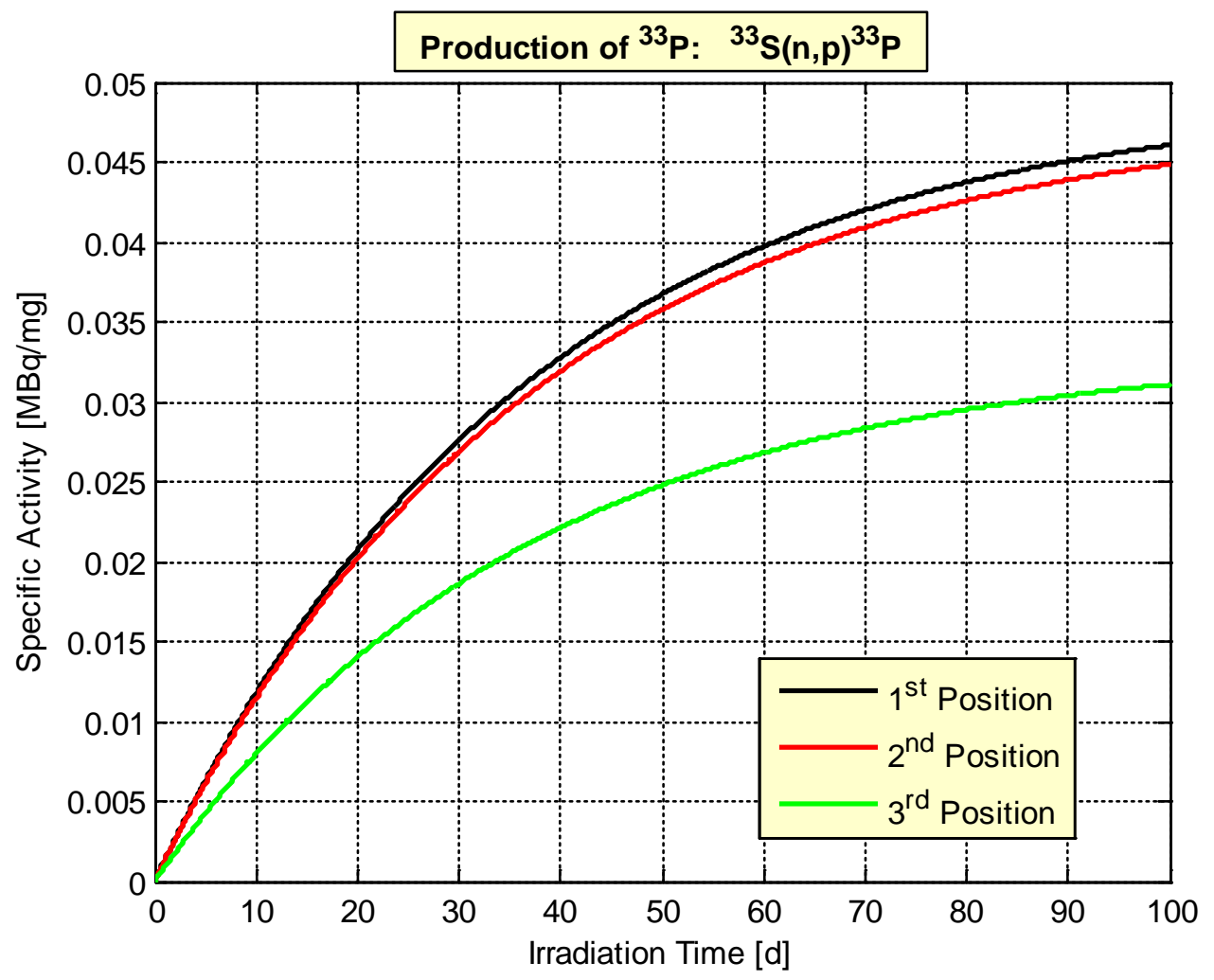

Figure $30 .{ }^{33} \mathrm{P}$ specific activity as a function of the irradiation time

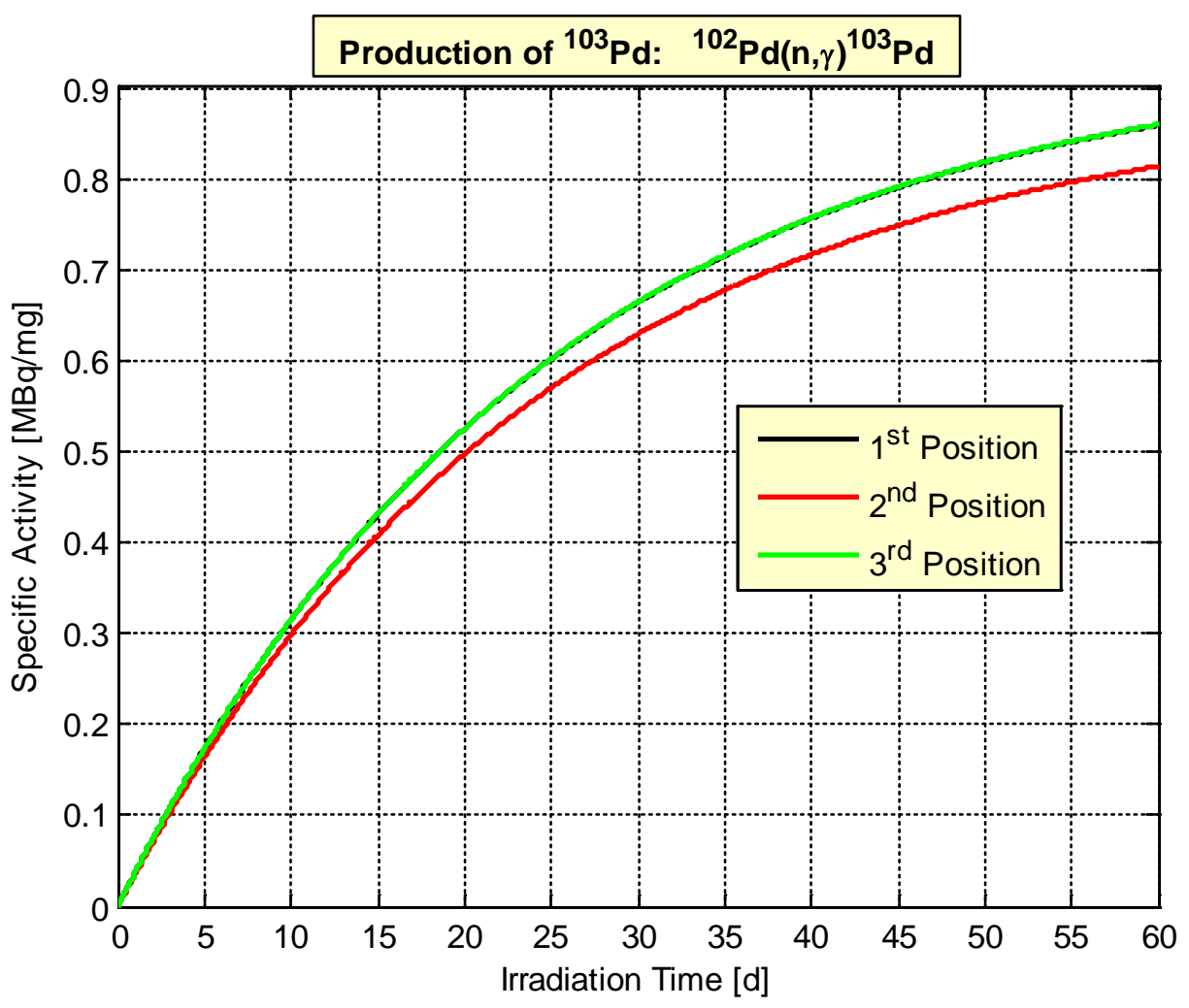

Figure $31 .{ }^{103} \mathrm{Pd}$ specific activity as a function of the irradiation time 


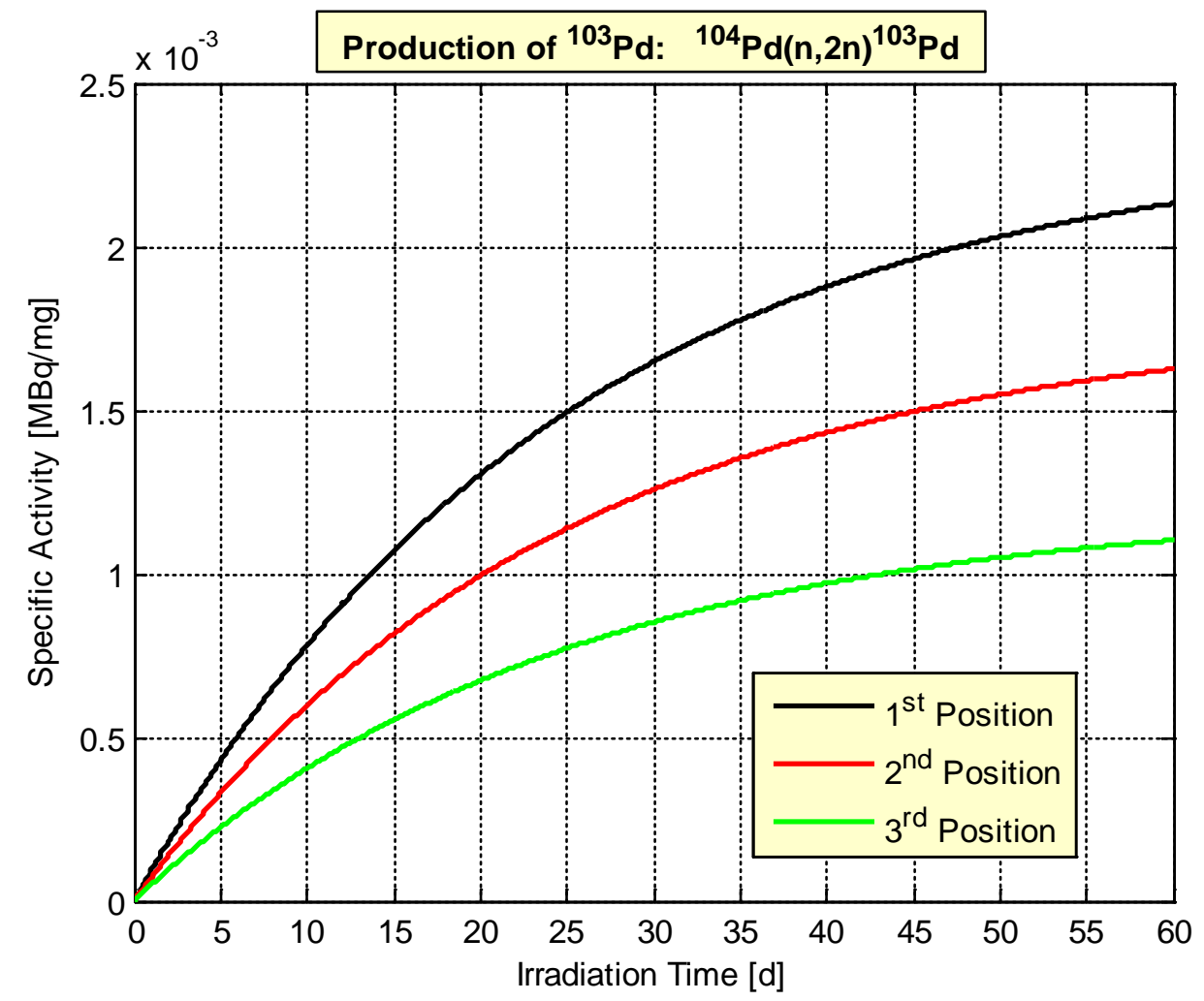

Figure $32 .{ }^{103} \mathrm{Pd}$ specific activity as a function of the irradiation time

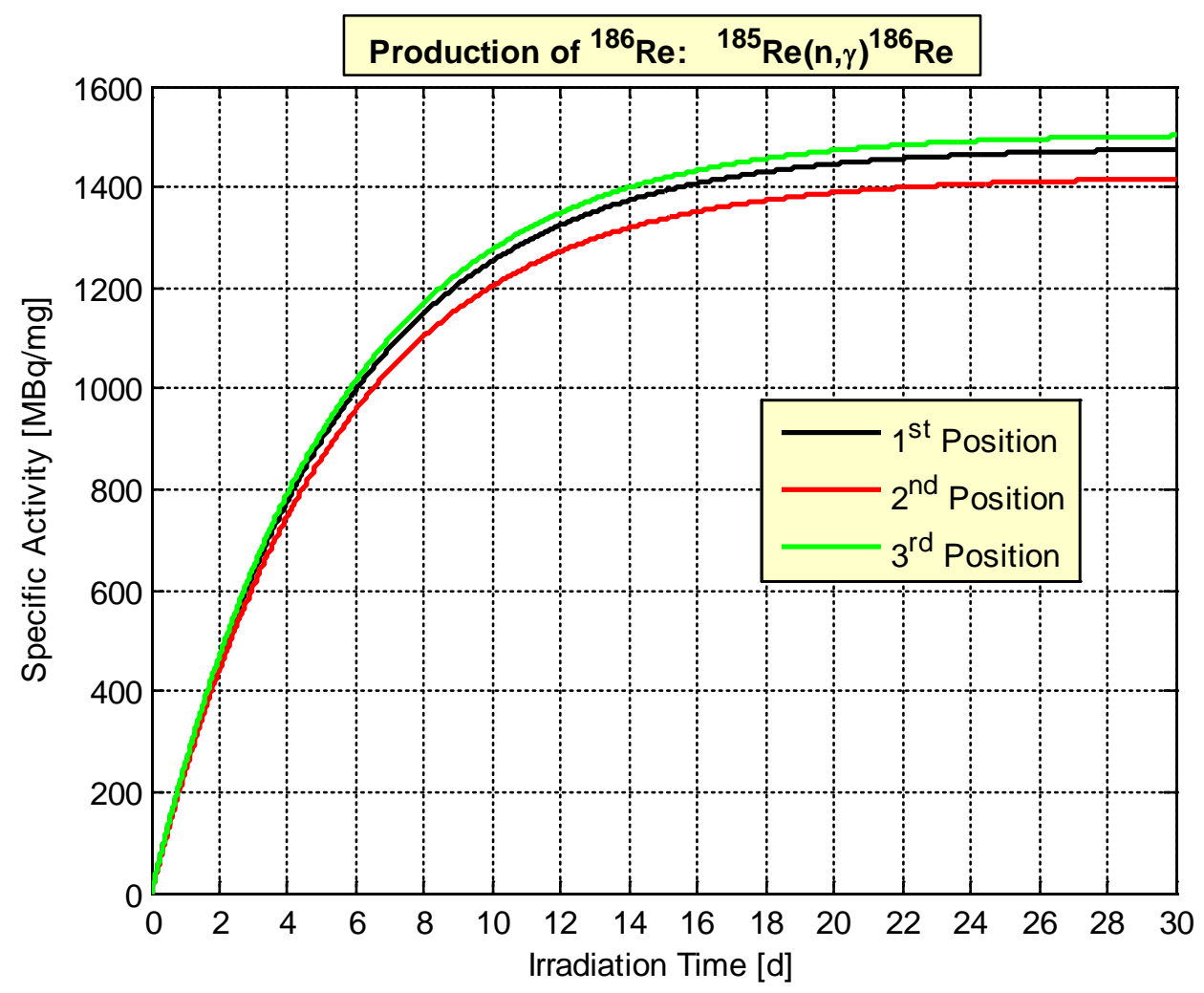

Figure $33 .{ }^{186}$ Re specific activity as a function of the irradiation time 


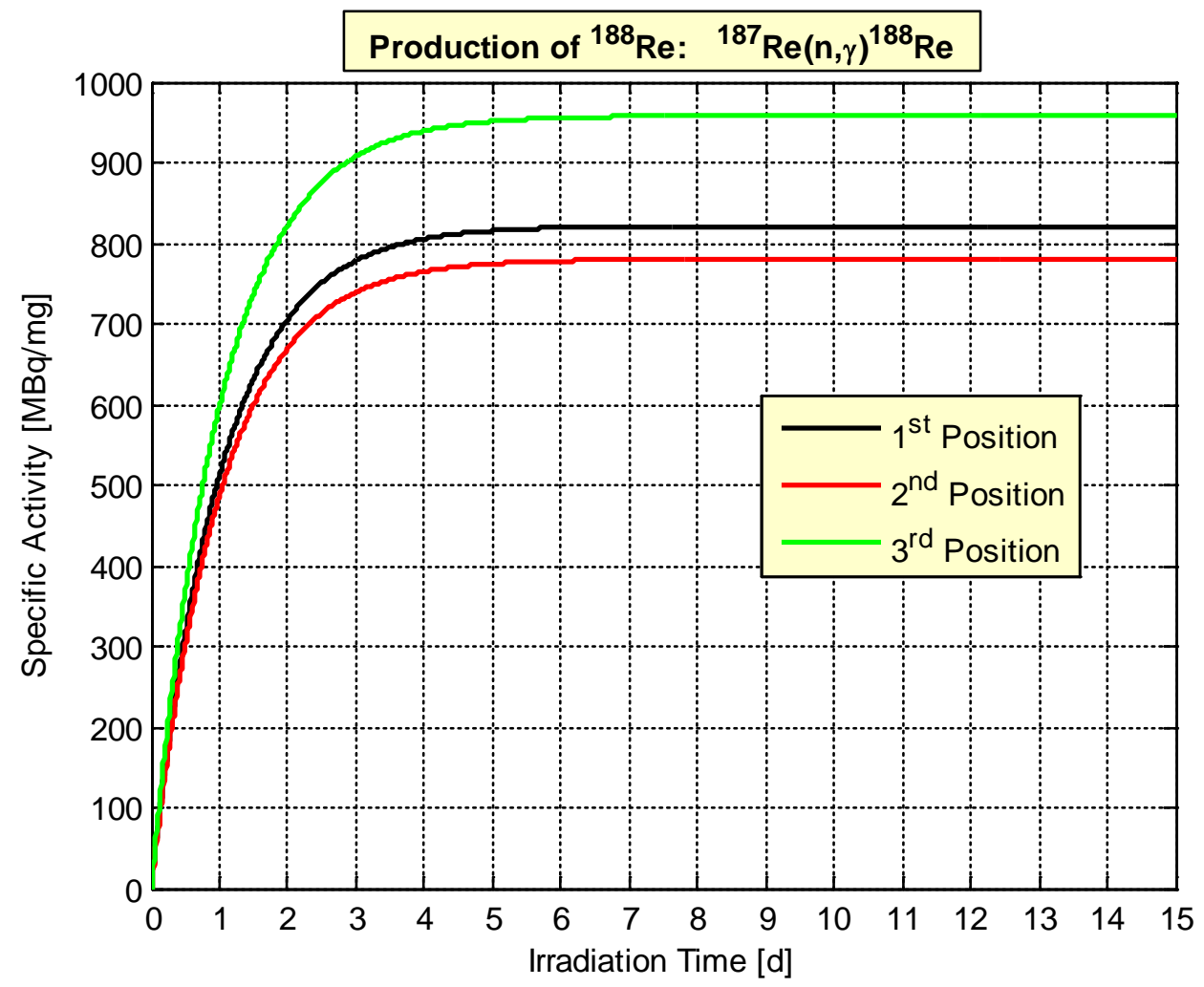

Figure $34 .{ }^{188} \mathrm{Re}$ specific activity as a function of the irradiation time

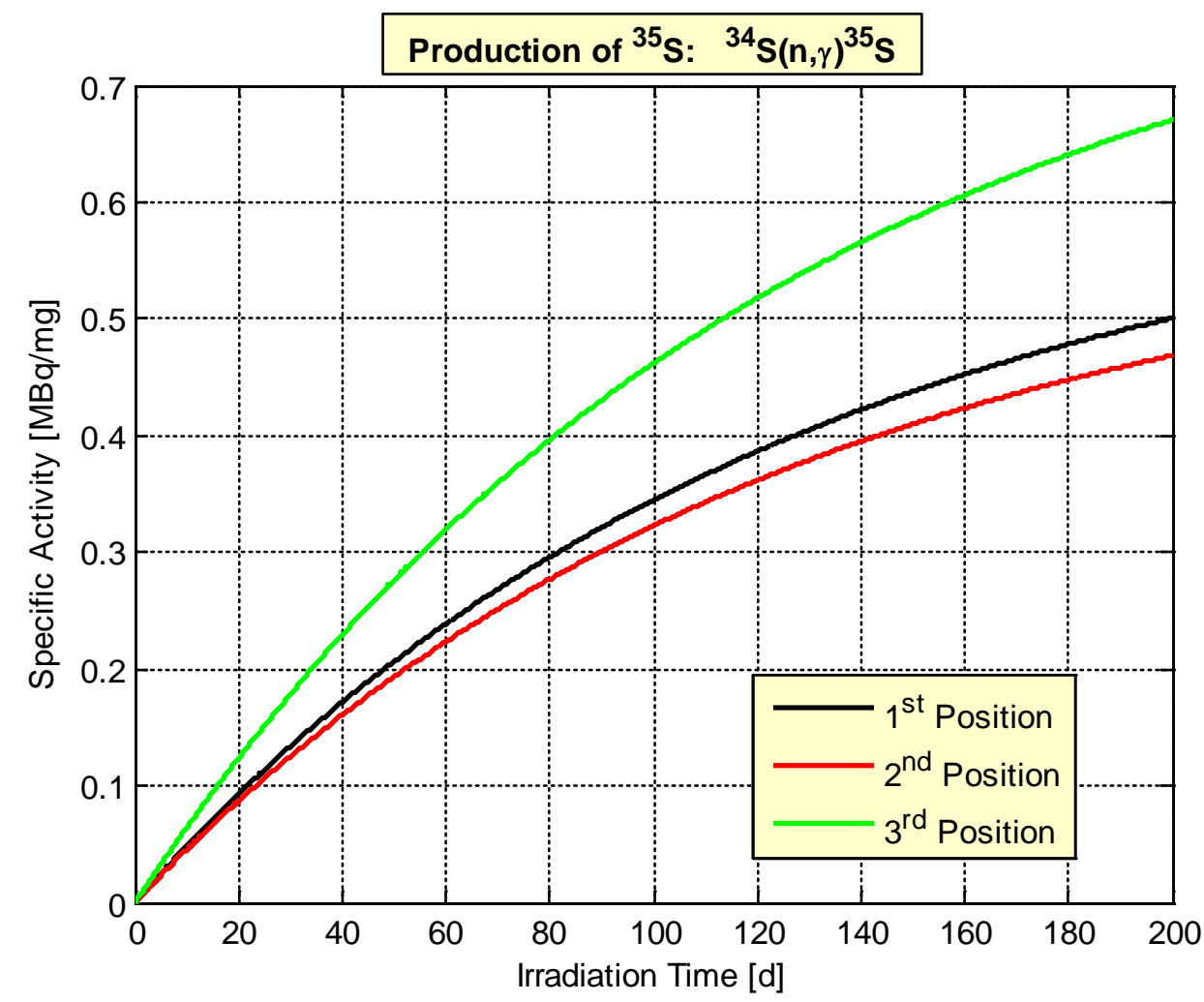

Figure $35 .{ }^{35} \mathrm{~S}$ specific activity as a function of the irradiation time 


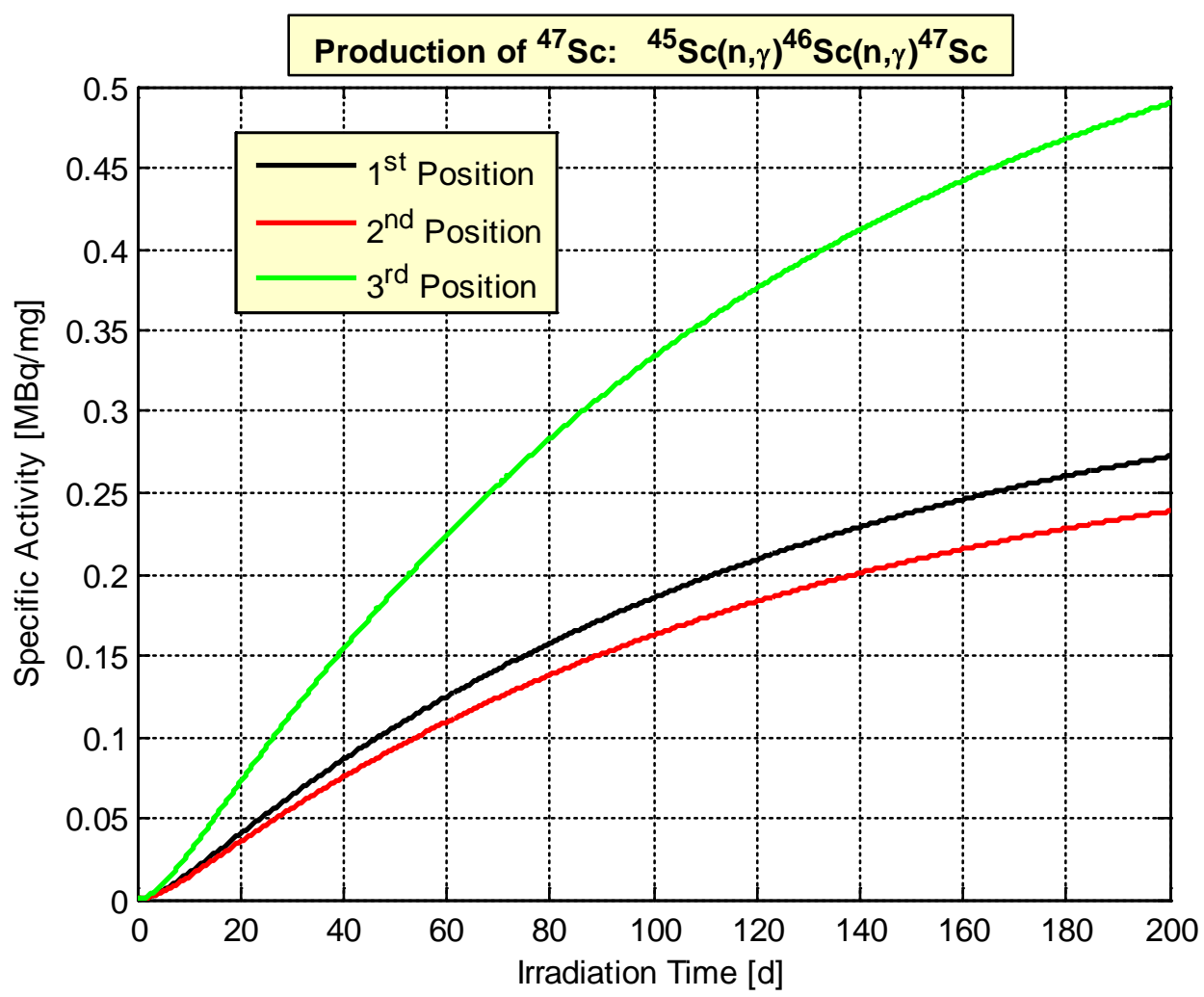

Figure $36 .{ }^{47} \mathrm{Sc}$ specific activity as a function of the irradiation time

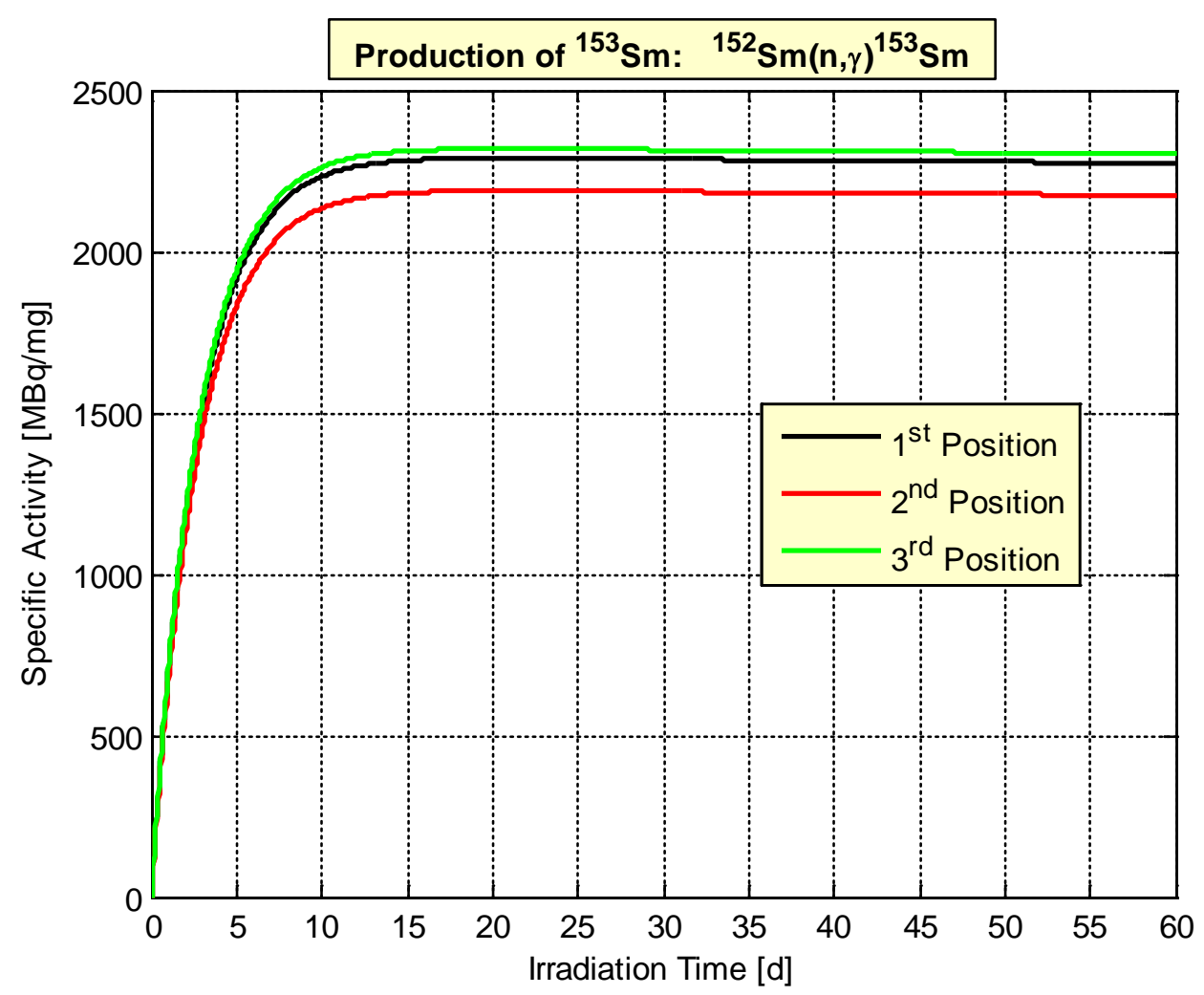

Figure $37 .{ }^{153} \mathrm{Sm}$ specific activity as a function of the irradiation time 


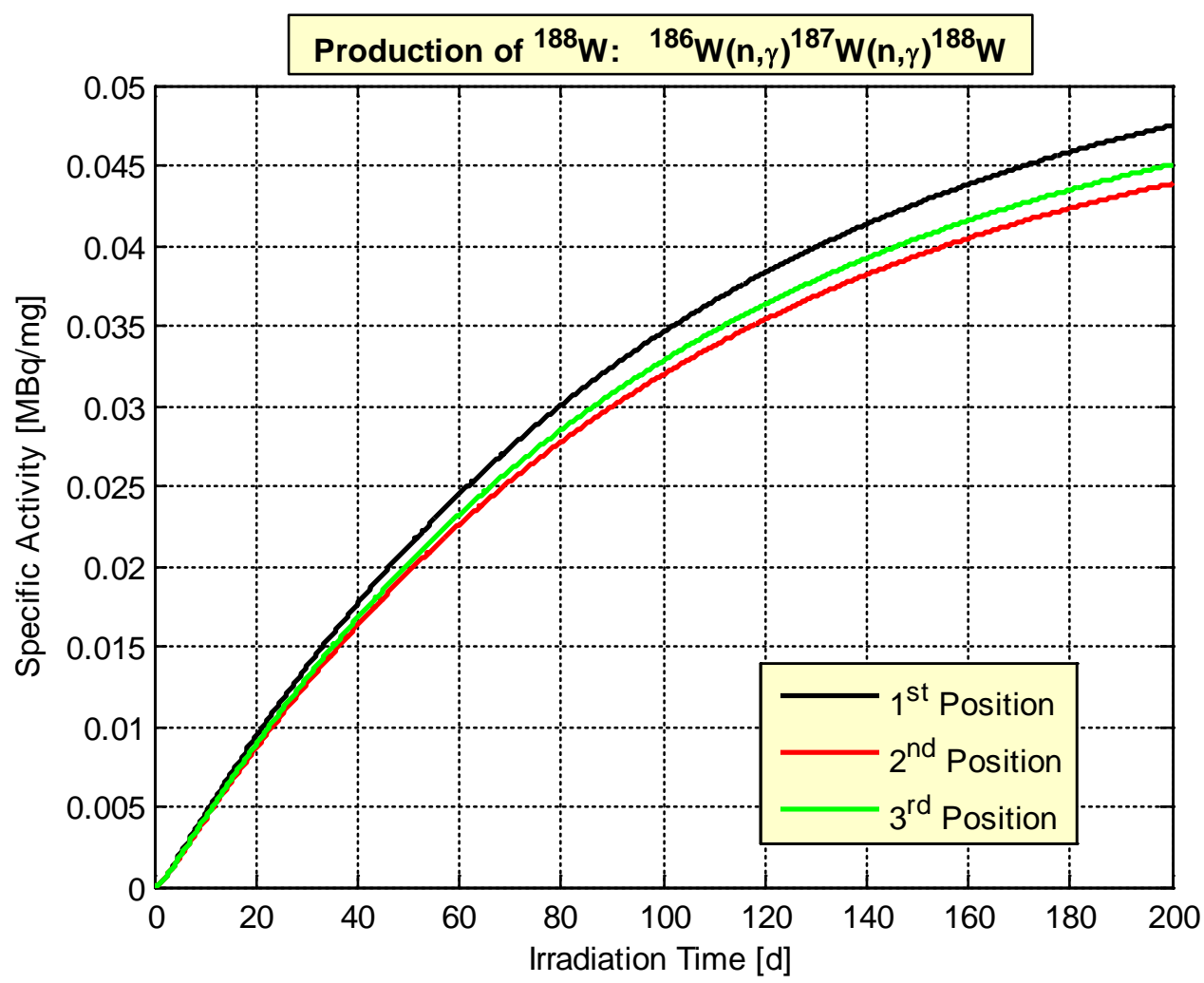

Figure $38 .{ }^{188} \mathrm{~W}$ specific activity as a function of the irradiation time

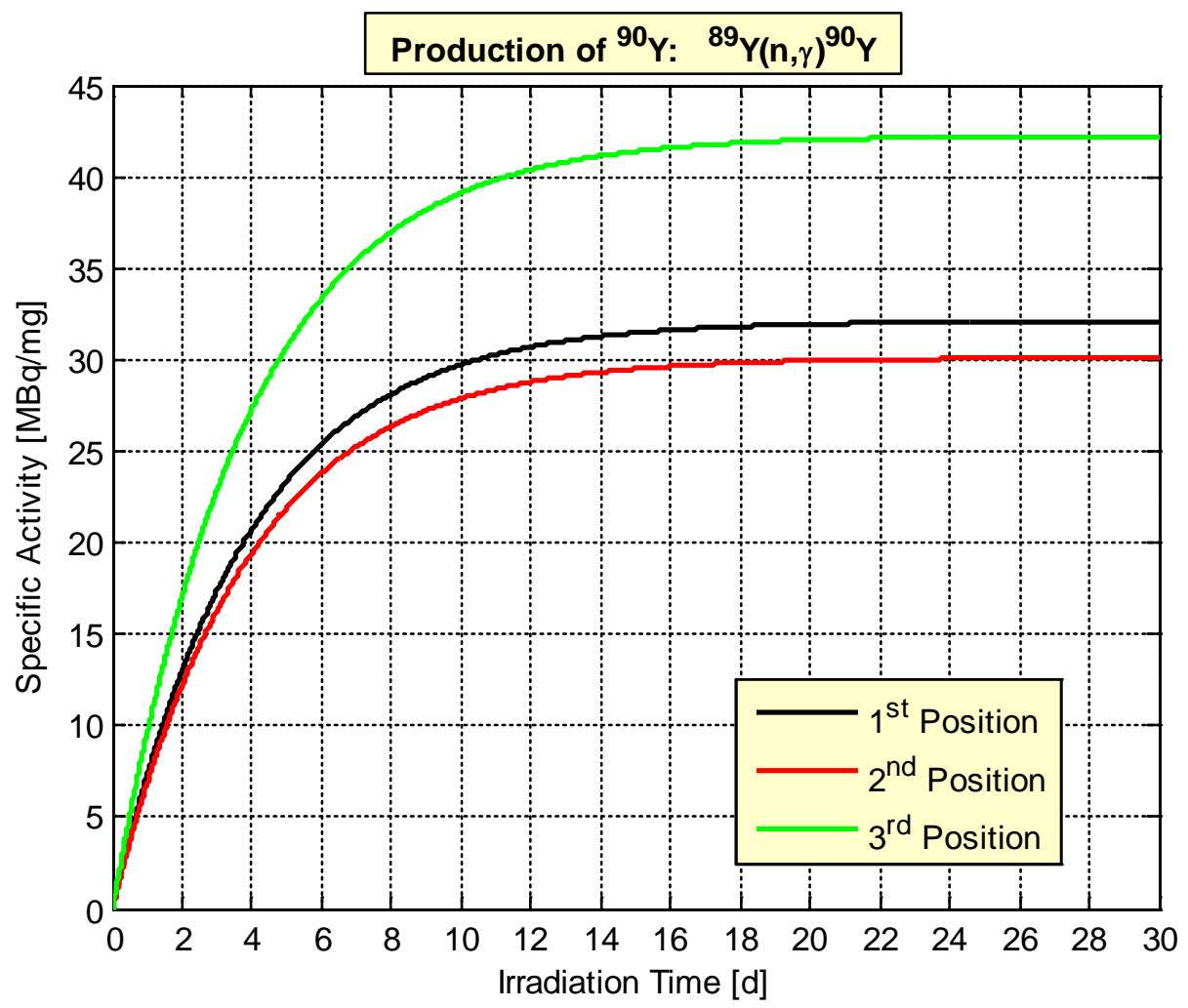

Figure $39 .{ }^{90} \mathrm{Y}$ specific activity as a function of the irradiation time 


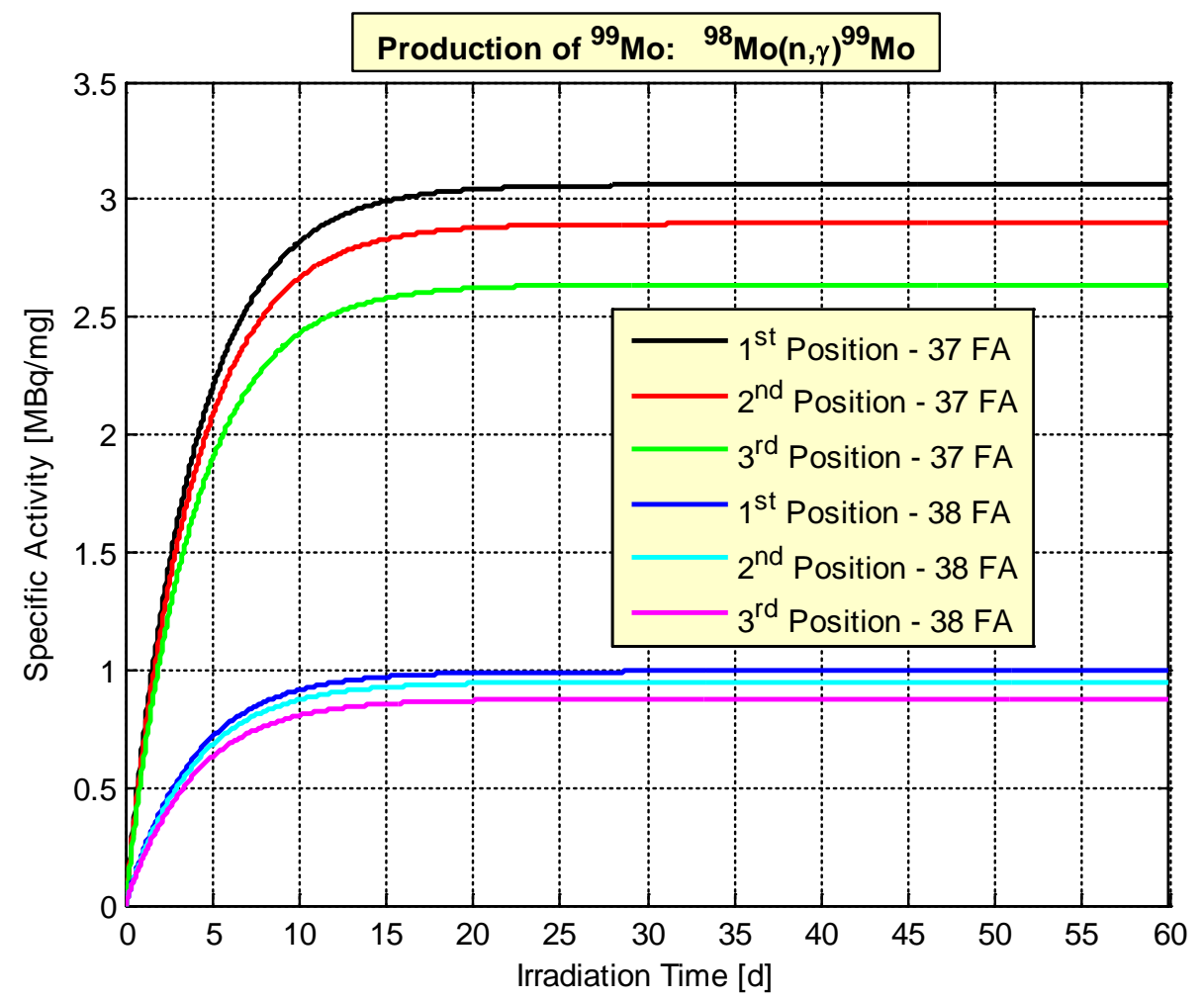

Figure 40. ${ }^{99}$ Mo specific activity from $\mathrm{MoO}_{3}$ irradiation, with self-shielding effect, as a function of the irradiation time for $(\mathrm{n}, \gamma)$ reaction

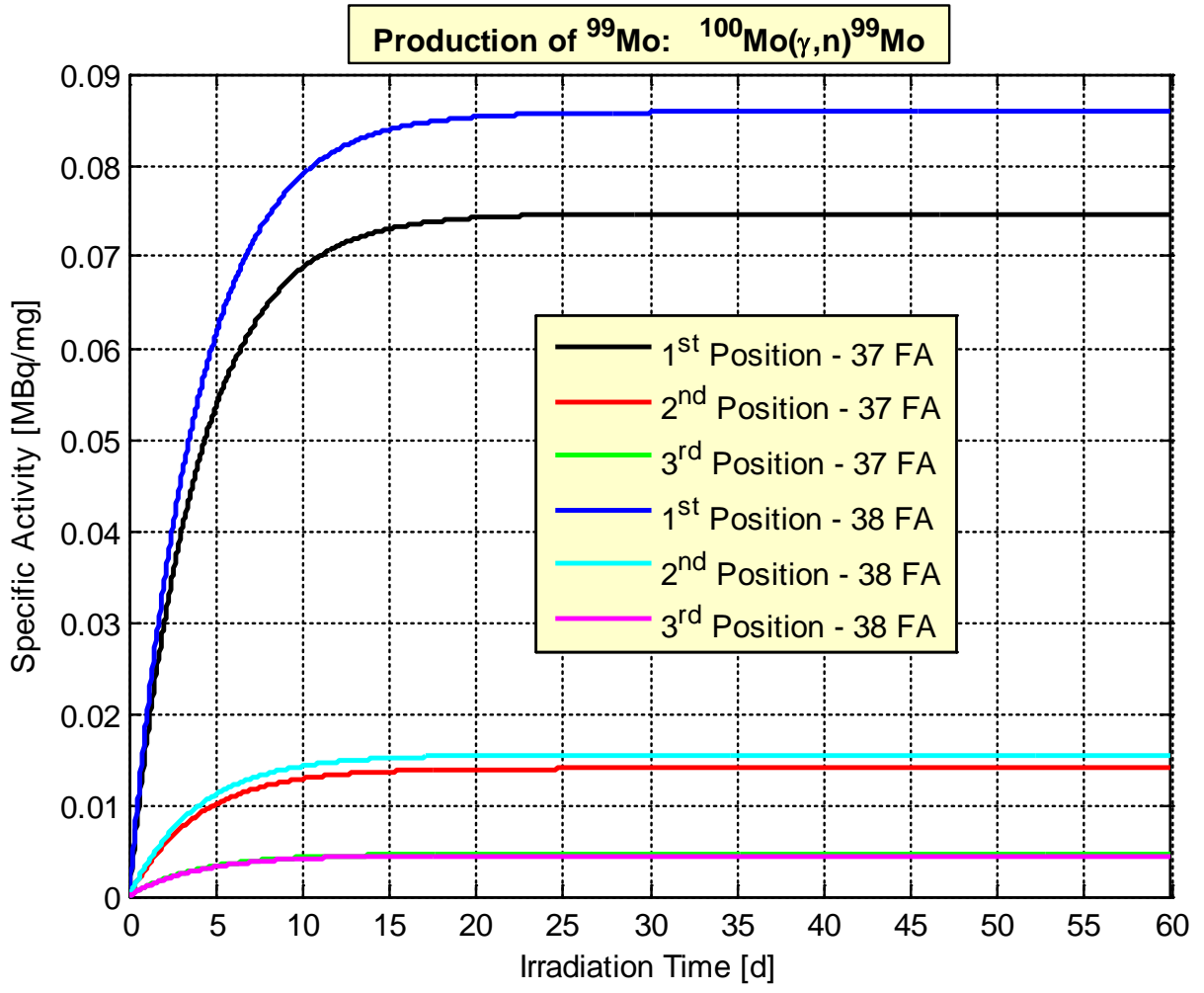

Figure $41 .{ }^{99} \mathrm{Mo}$ specific activity from $\mathrm{MoO}_{3}$ irradiation, with self-shielding effect, as a function of the irradiation time for $(\gamma, n)$ reaction 


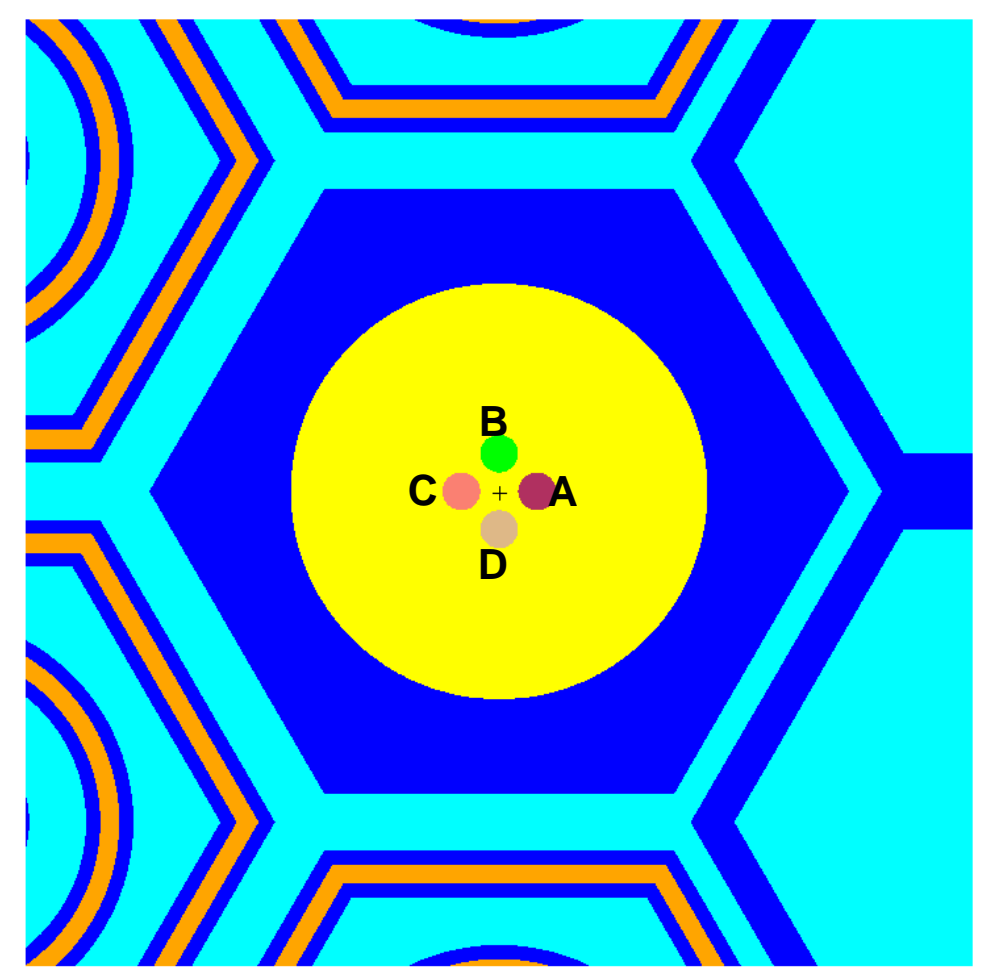

Figure 42. Zoom of the horizontal cross section for the configuration with 38 fuel assemblies and irradiation sample at position 1

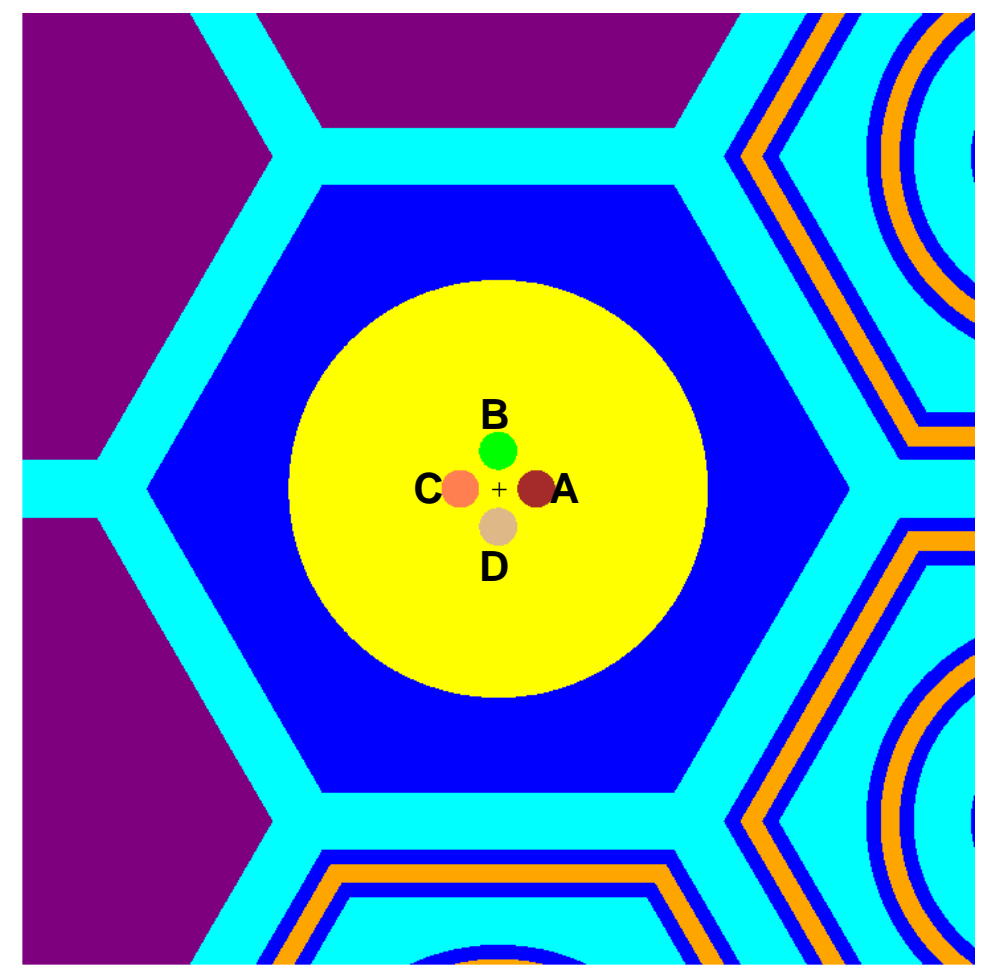

Figure 43. Zoom of the horizontal cross section for the configuration with 38 fuel assemblies and irradiation sample at position 3 


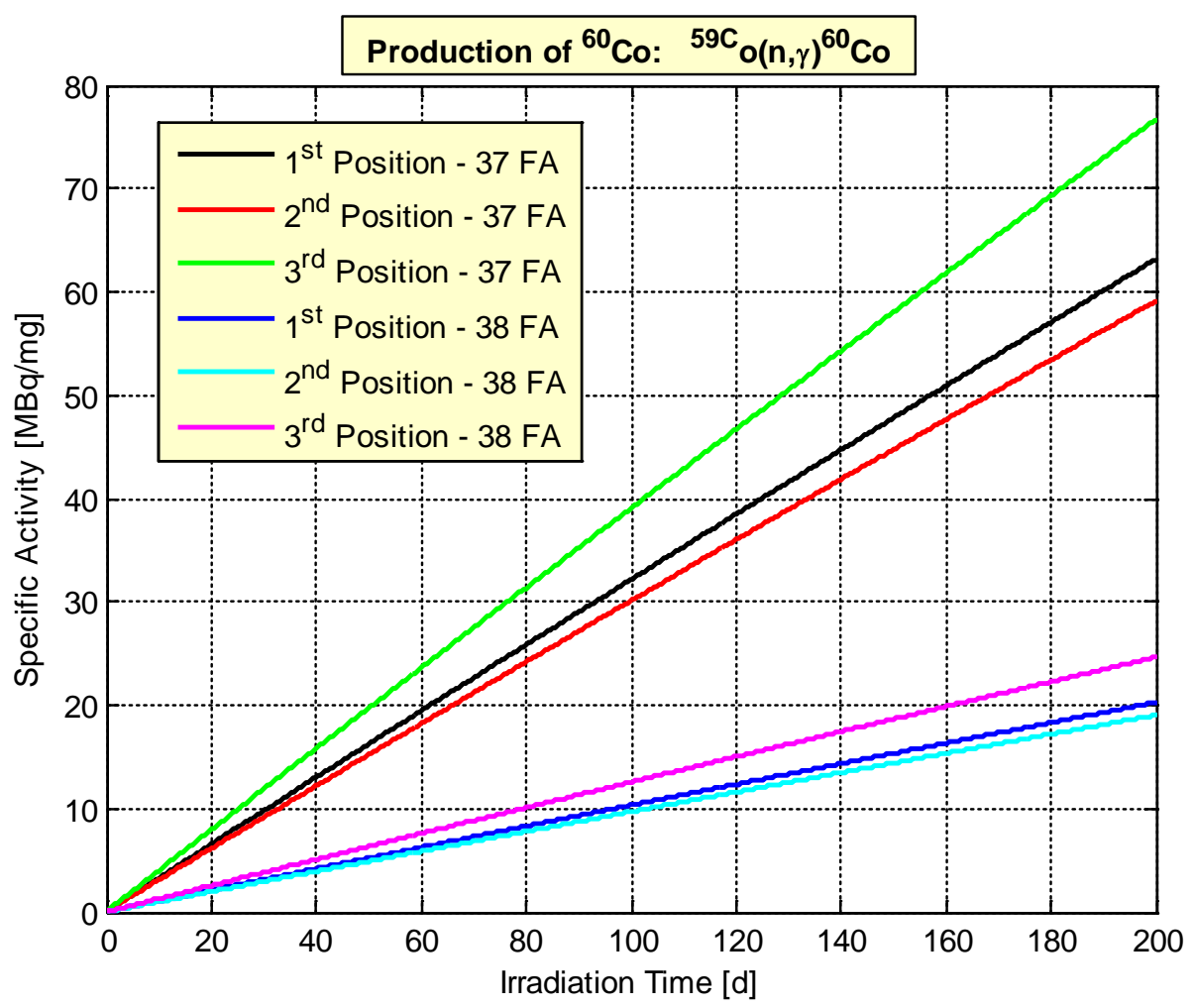

Figure $44 .{ }^{60} \mathrm{Co}$ specific activity, with self-shielding effect, as a function of the irradiation time

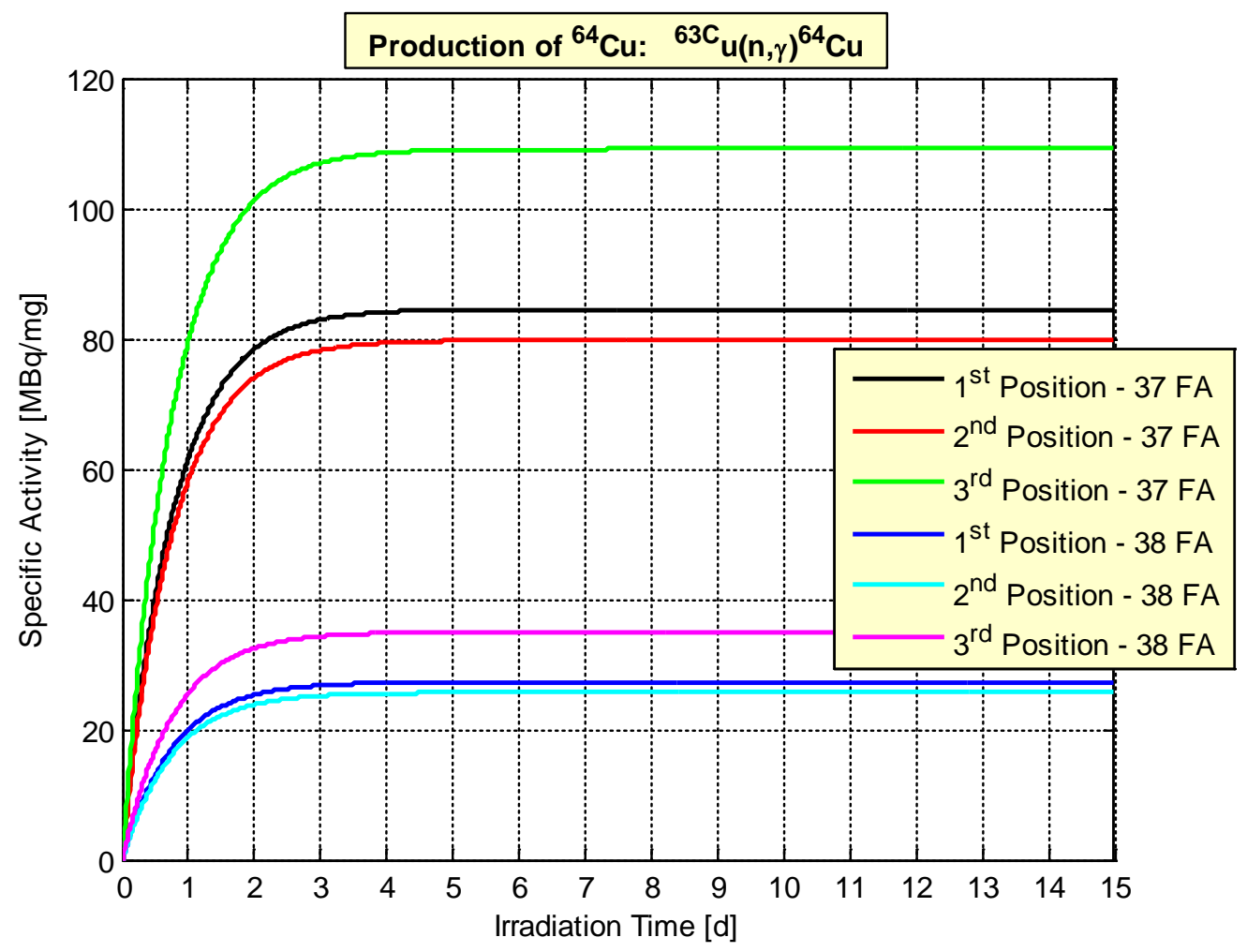

Figure $45 .{ }^{64} \mathrm{Cu}$ specific activity, with self-shielding effect, as a function of the irradiation time 


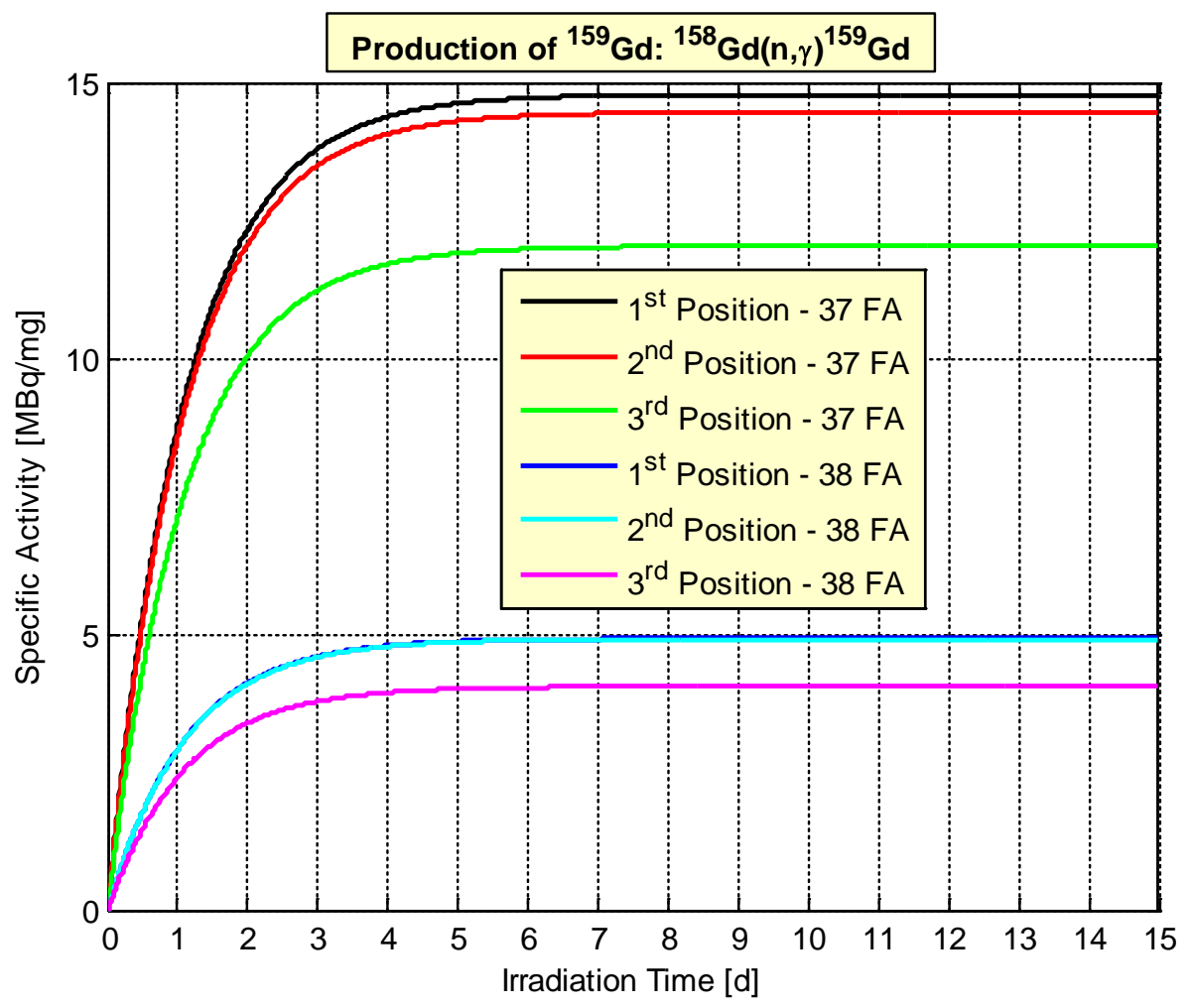

Figure $46 .{ }^{159} \mathrm{Gd}$ specific activity, with self-shielding effect, as a function of the irradiation

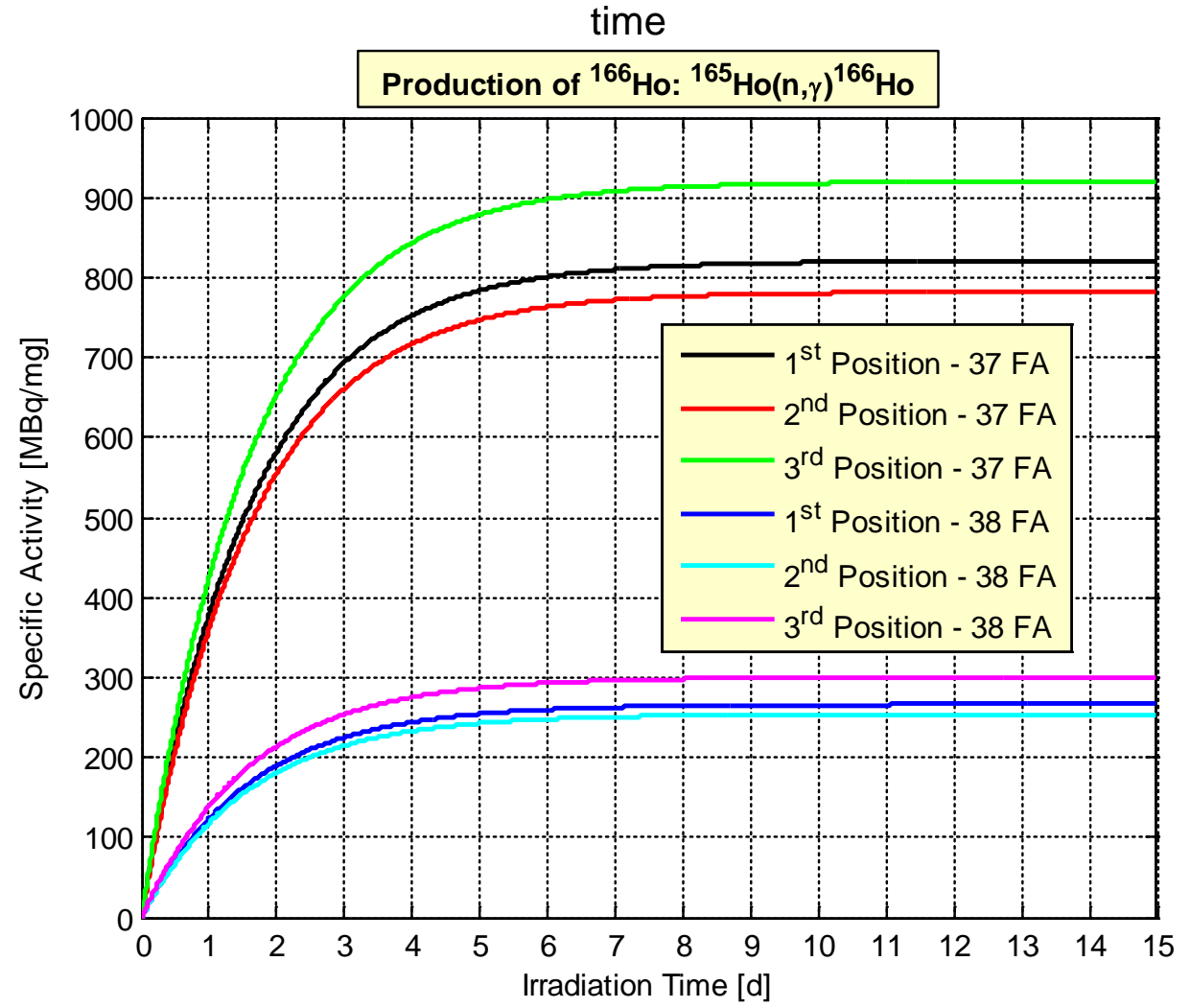

Figure $47 .{ }^{166} \mathrm{Ho}$ specific activity, with self-shielding effect, as a function of the irradiation time 


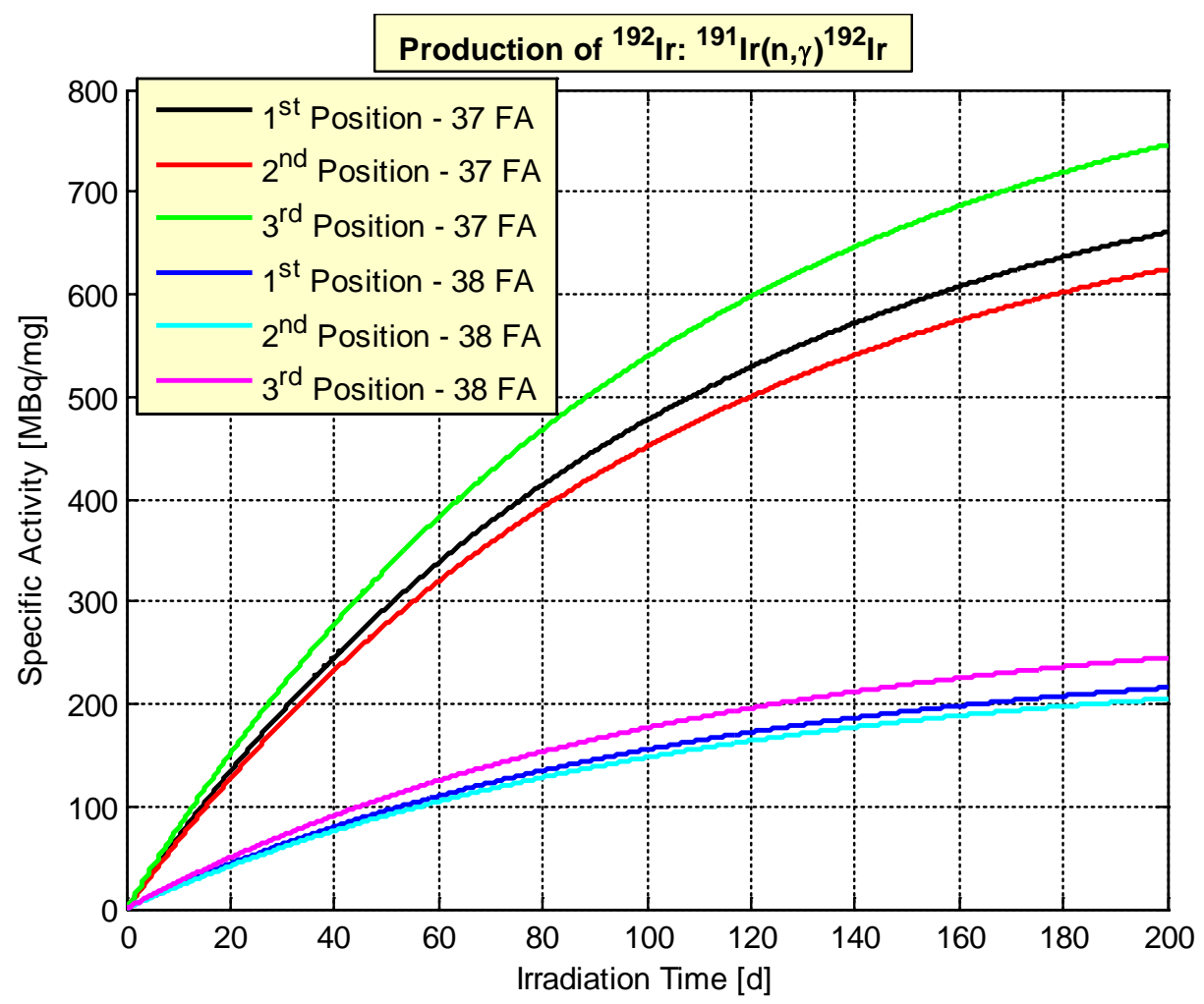

Figure 48. ${ }^{192}$ Ir specific activity, with self-shielding effect, as a function of the irradiation

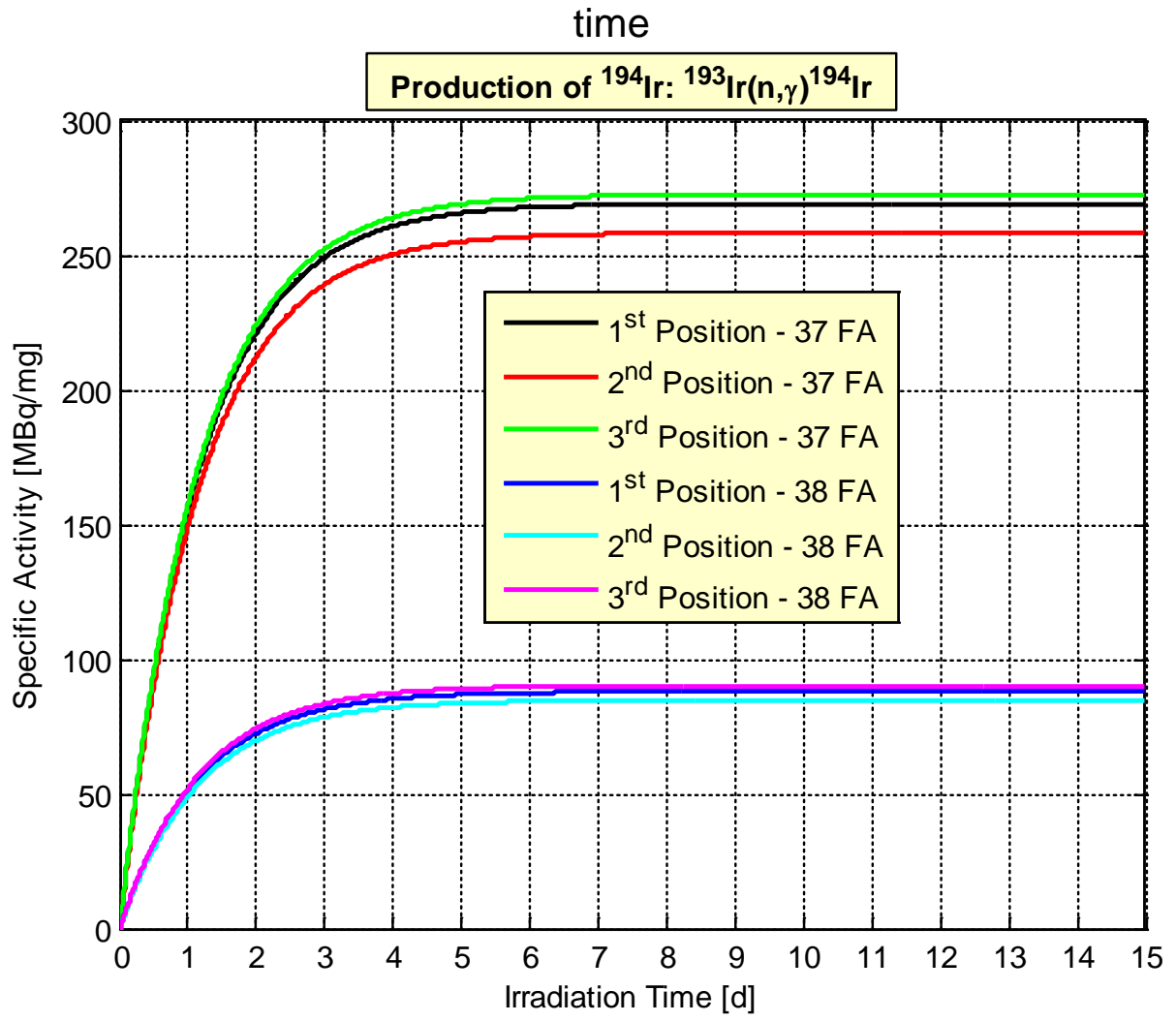

Figure $49 .{ }^{194}$ Ir specific activity, with self-shielding effect, as a function of the irradiation time 


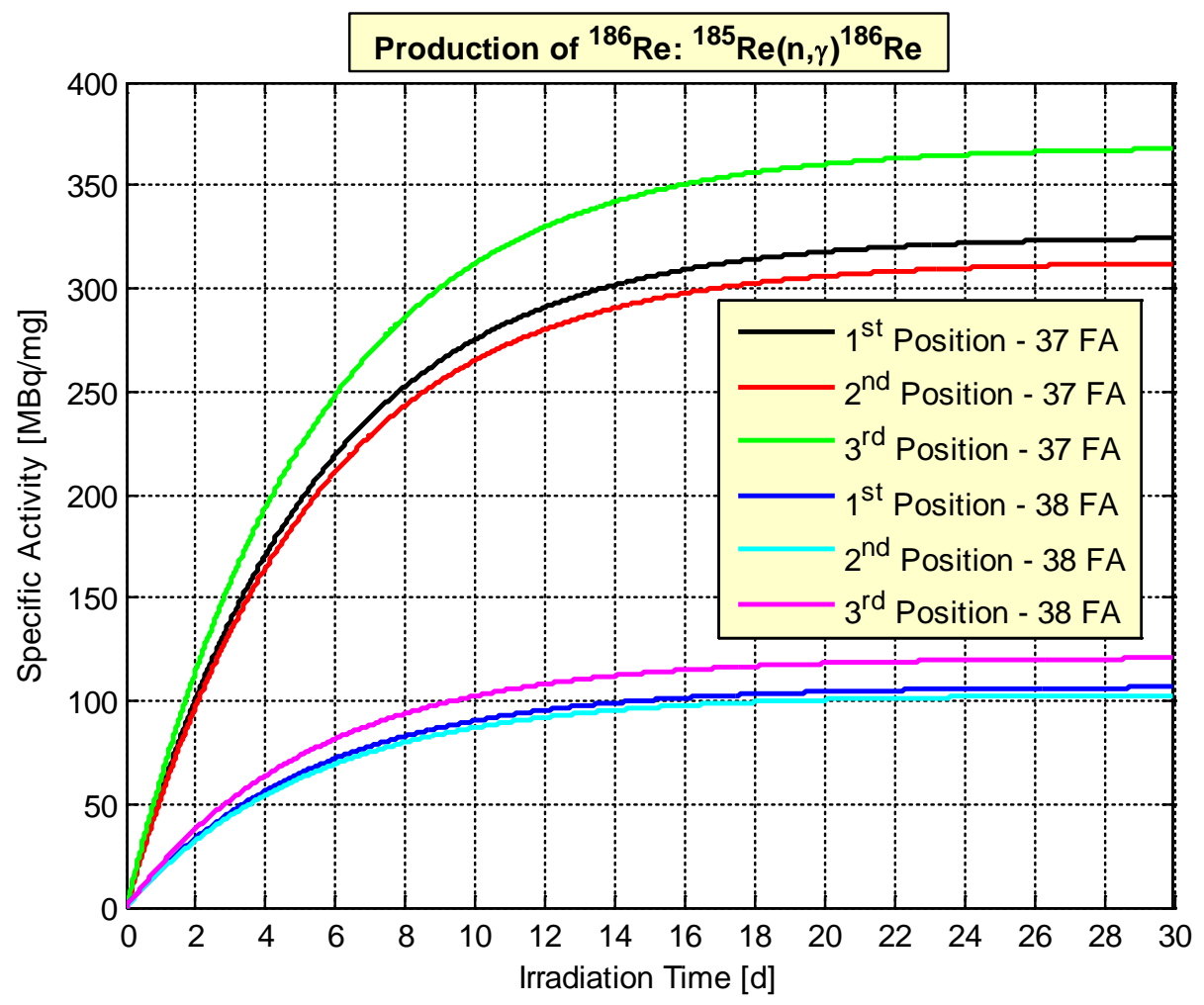

Figure $50 .{ }^{186}$ Re specific activity, with self-shielding effect, as a function of the irradiation

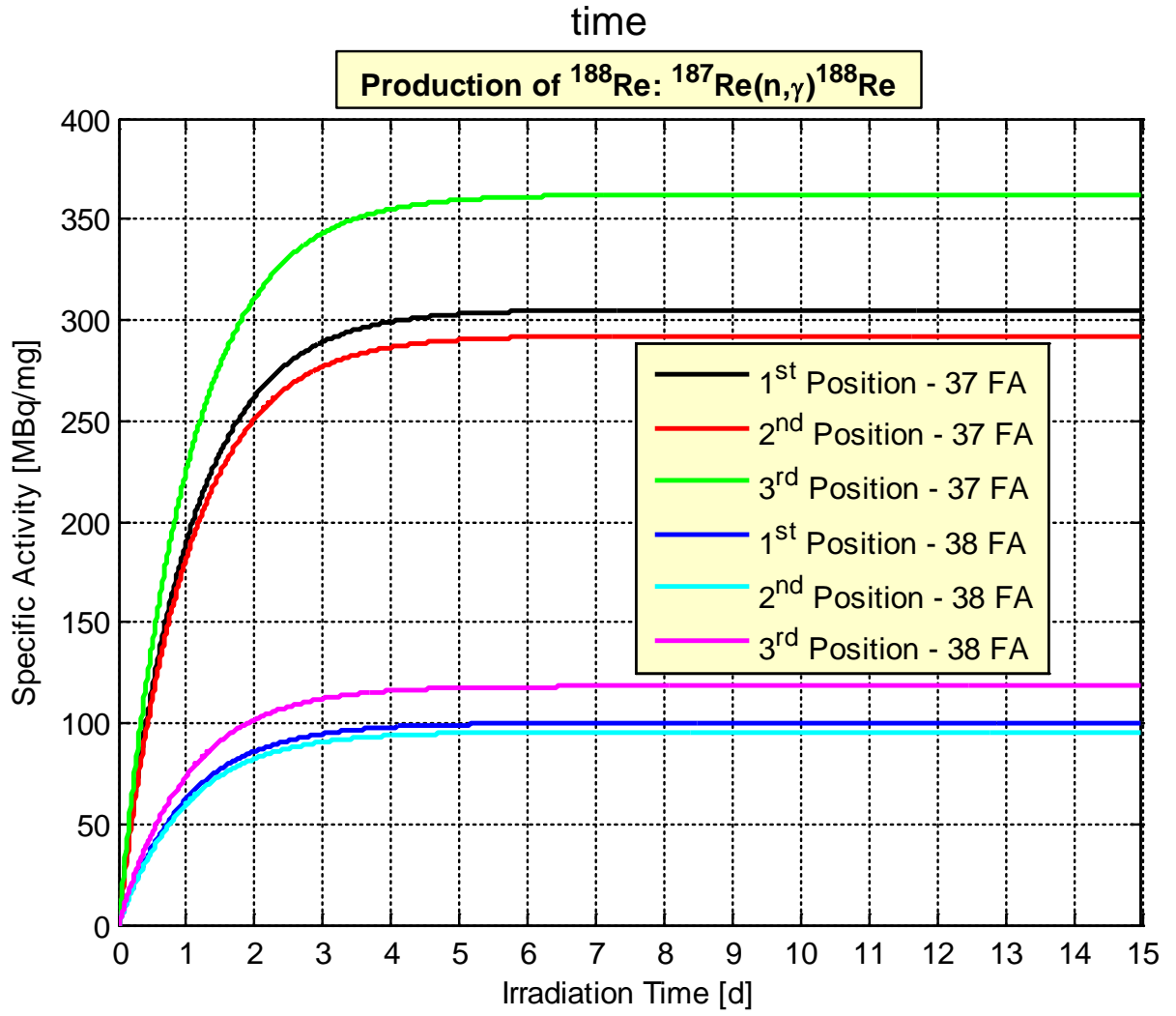

Figure $51 .{ }^{188} \mathrm{Re}$ specific activity, with self-shielding effect, as a function of the irradiation time 


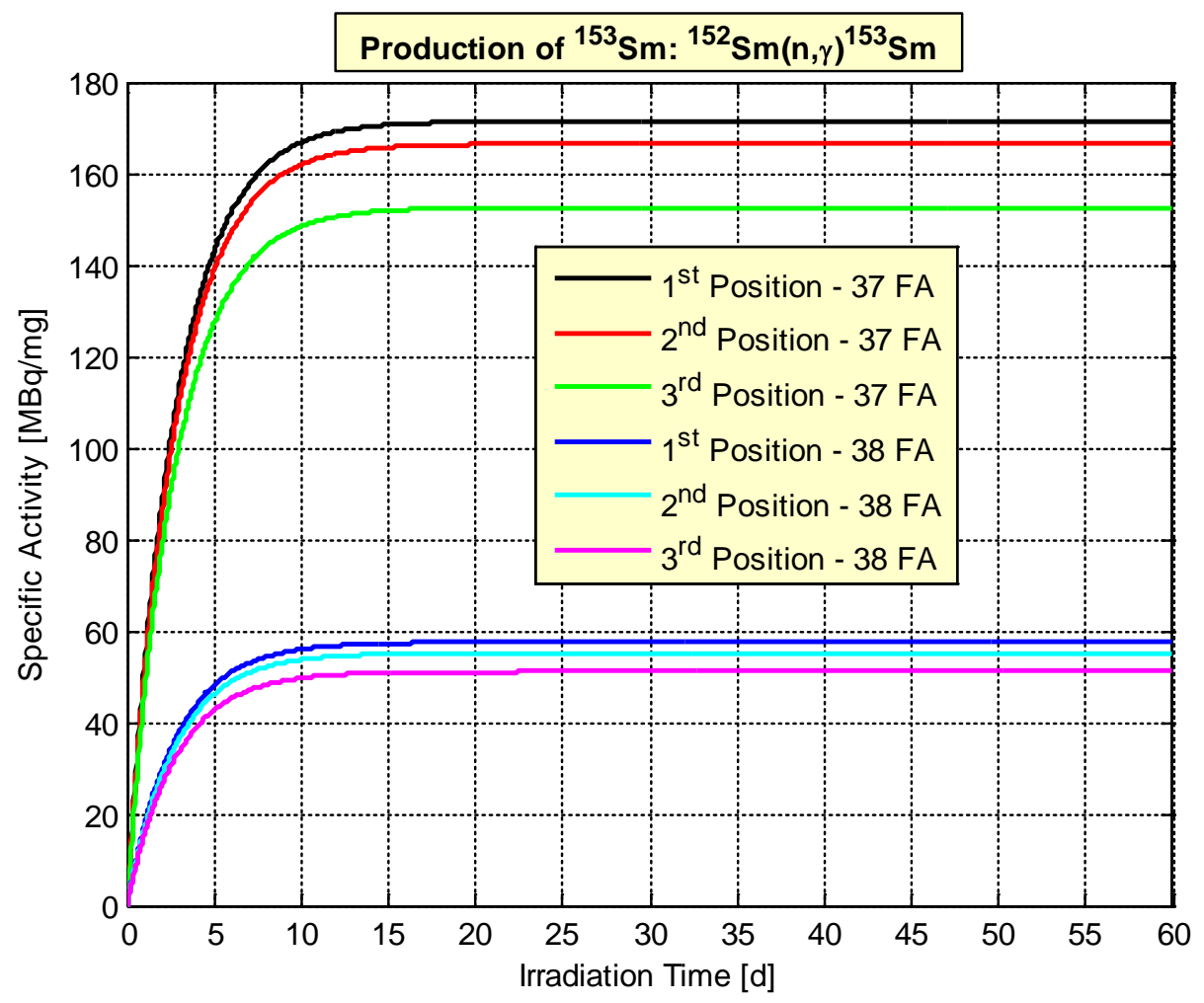

Figure $52 .{ }^{153} \mathrm{Sm}$ specific activity, with self-shielding effect, as a function of the irradiation time

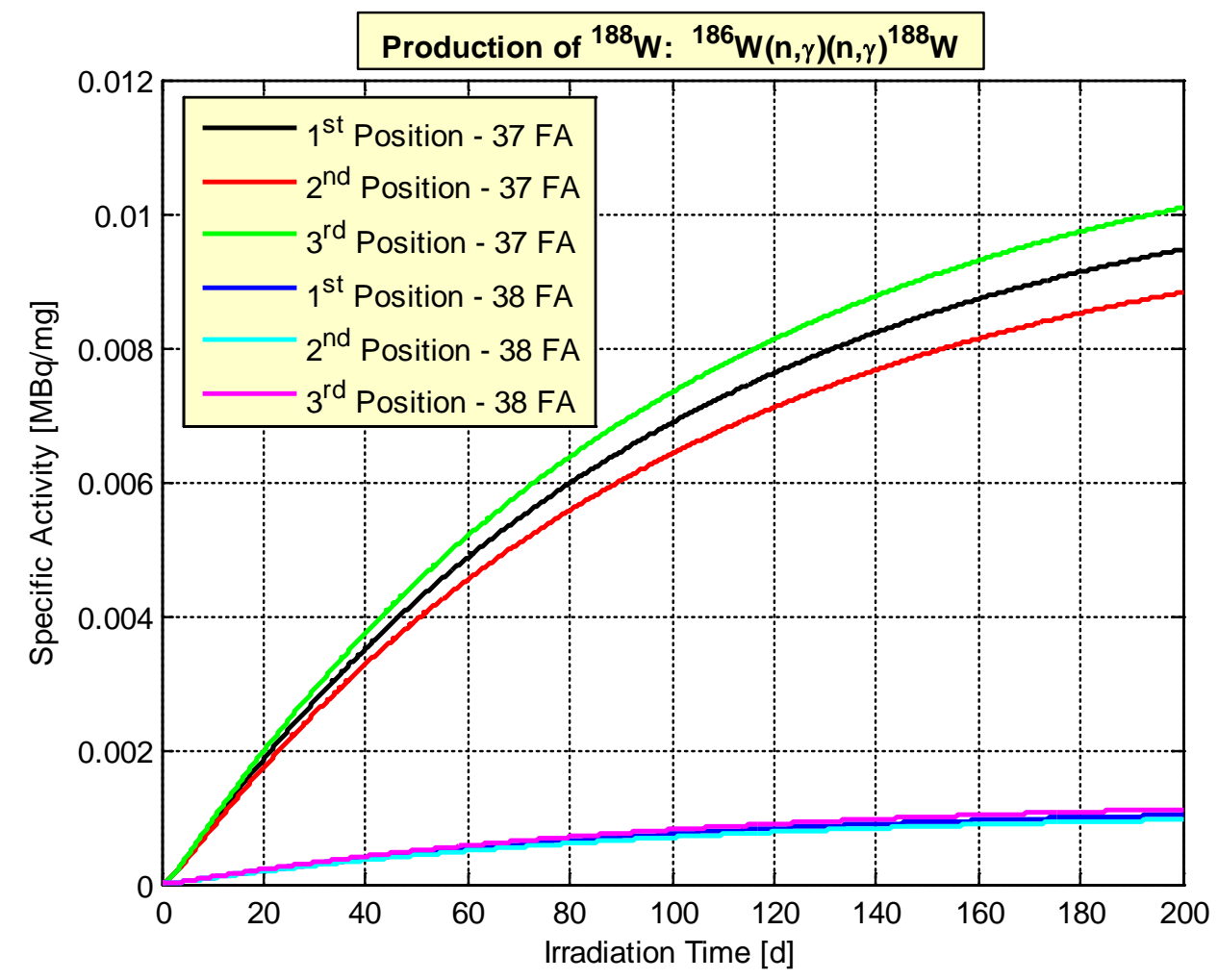

Figure $53 .{ }^{188} \mathrm{~W}$ specific activity, with self-shielding effect, as a function of the irradiation time 


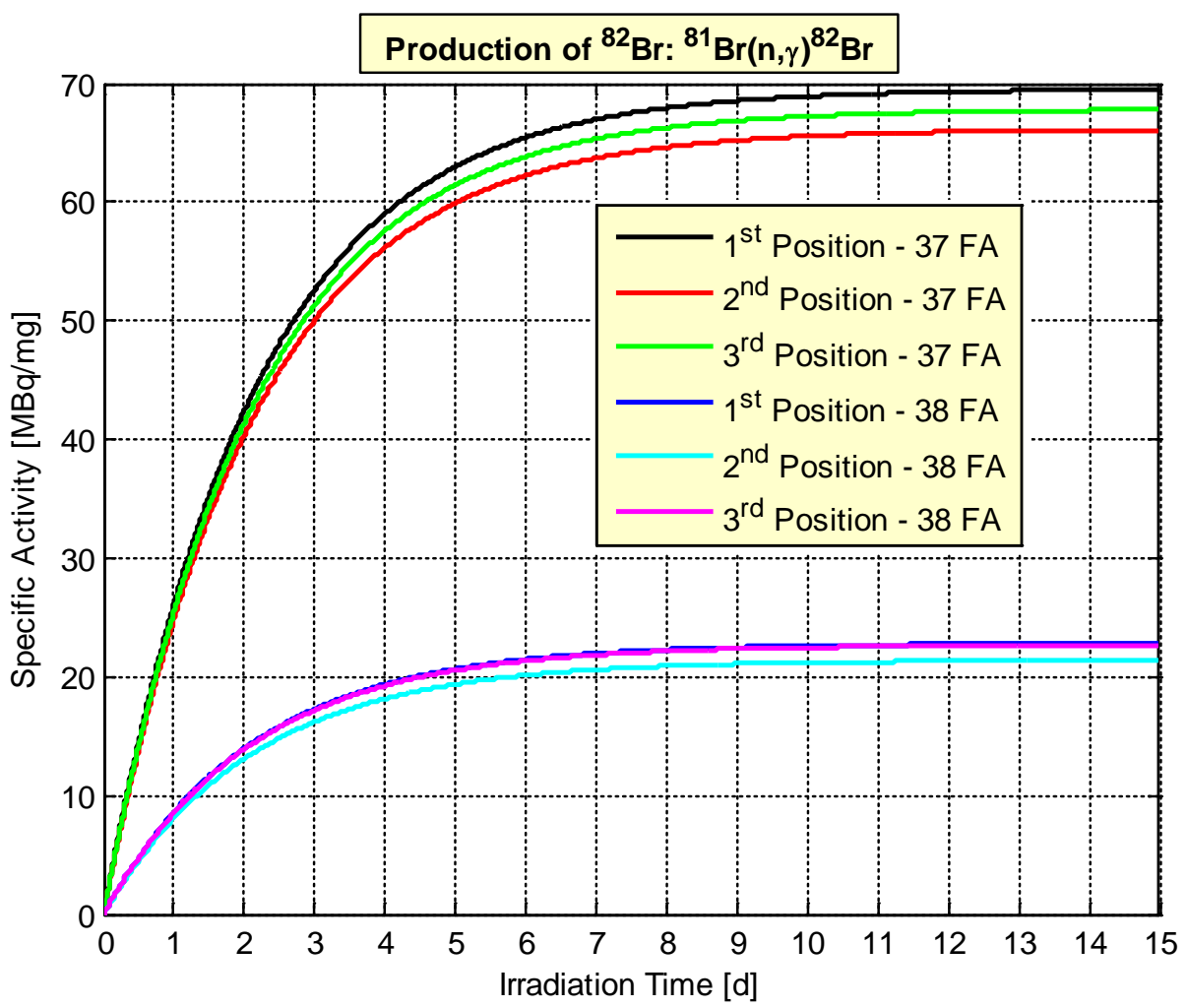

Figure $54 .{ }^{82} \mathrm{Br}$ specific activity, with self-shielding effect, as a function of the irradiation

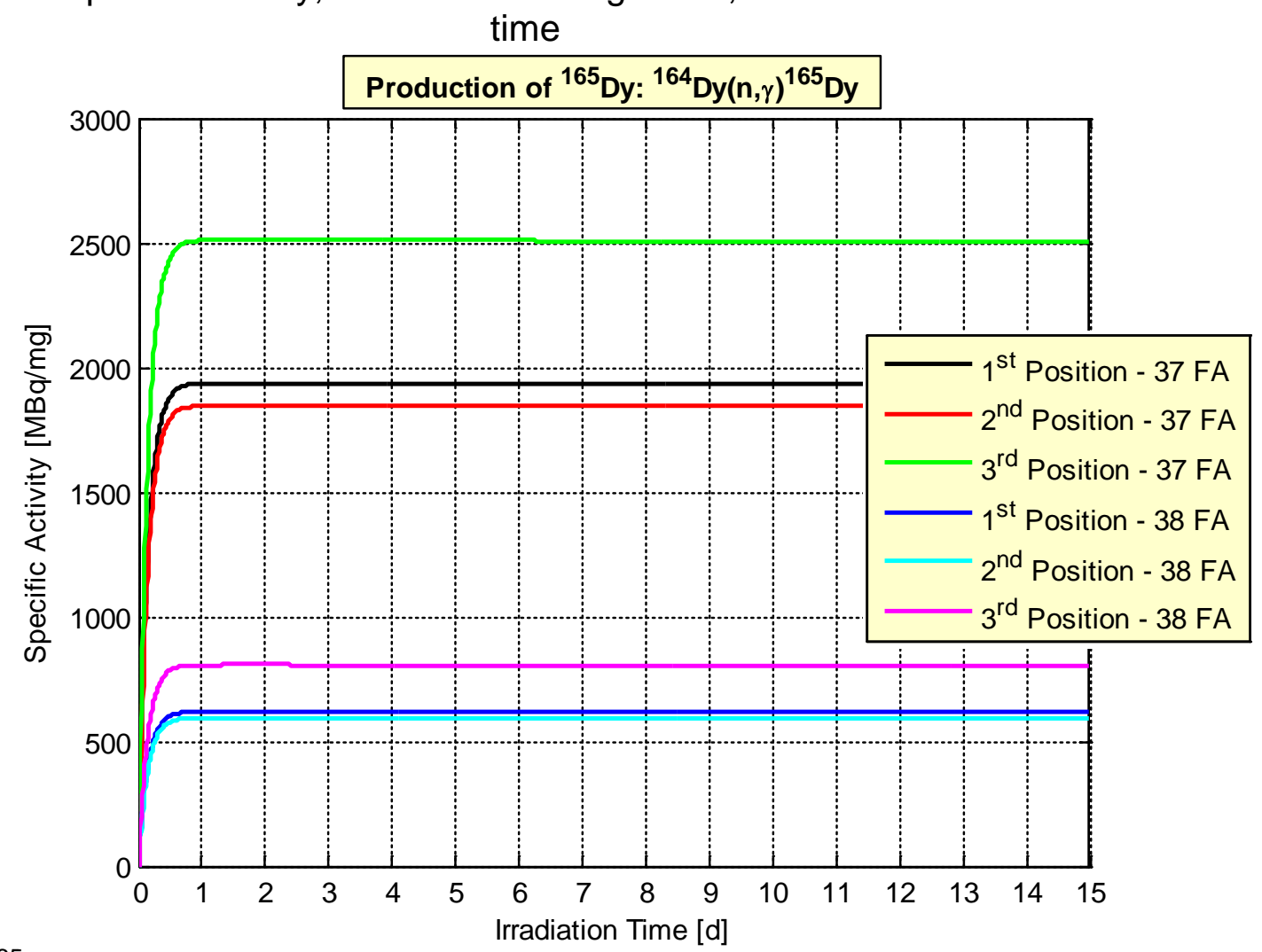

Figure $55 .{ }^{165}$ Dy specific activity, with self-shielding effect, as a function of the irradiation time 


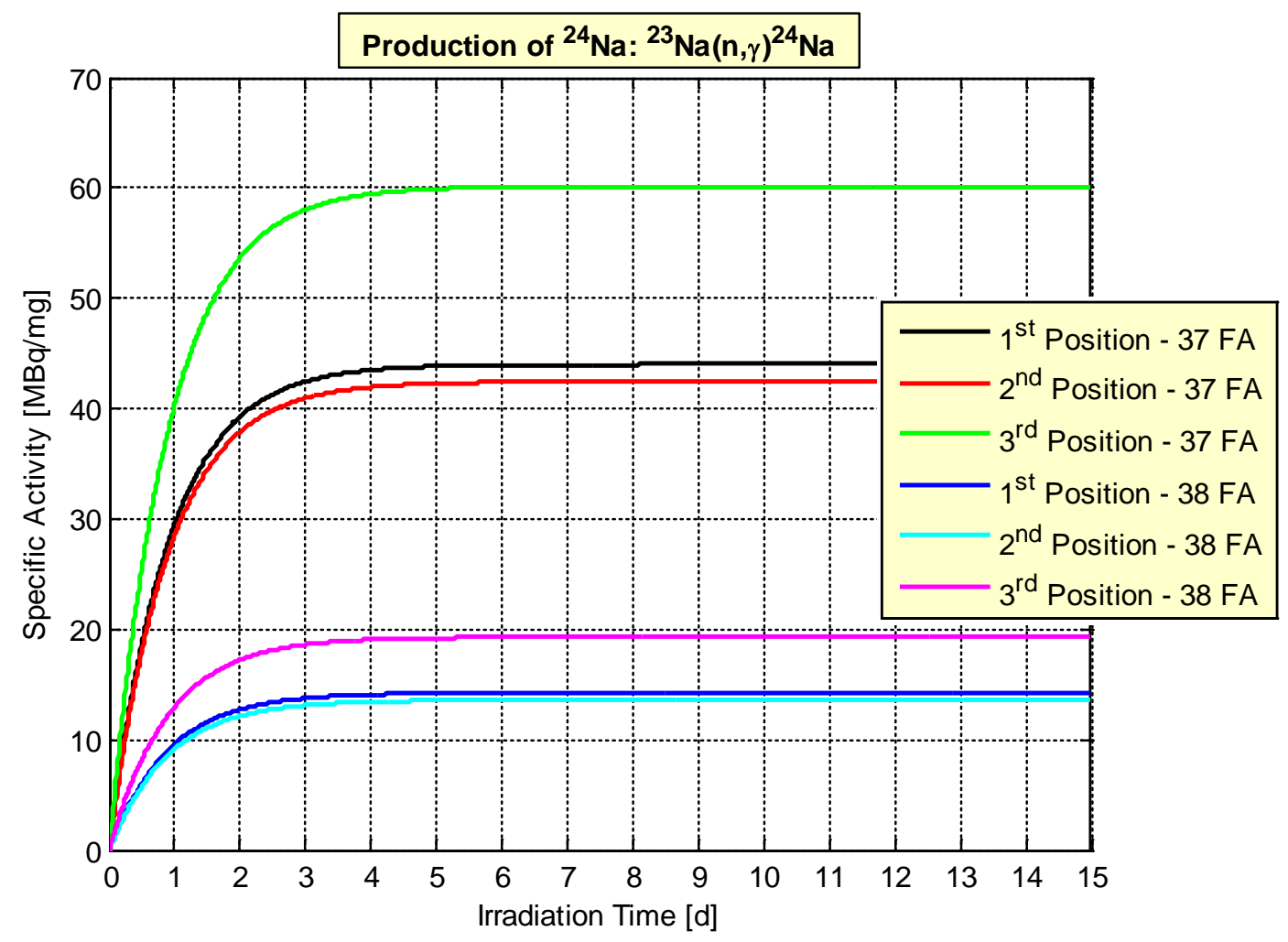

Figure 56. ${ }^{24} \mathrm{Na}$ specific activity, with self-shielding effect, as a function of the irradiation time

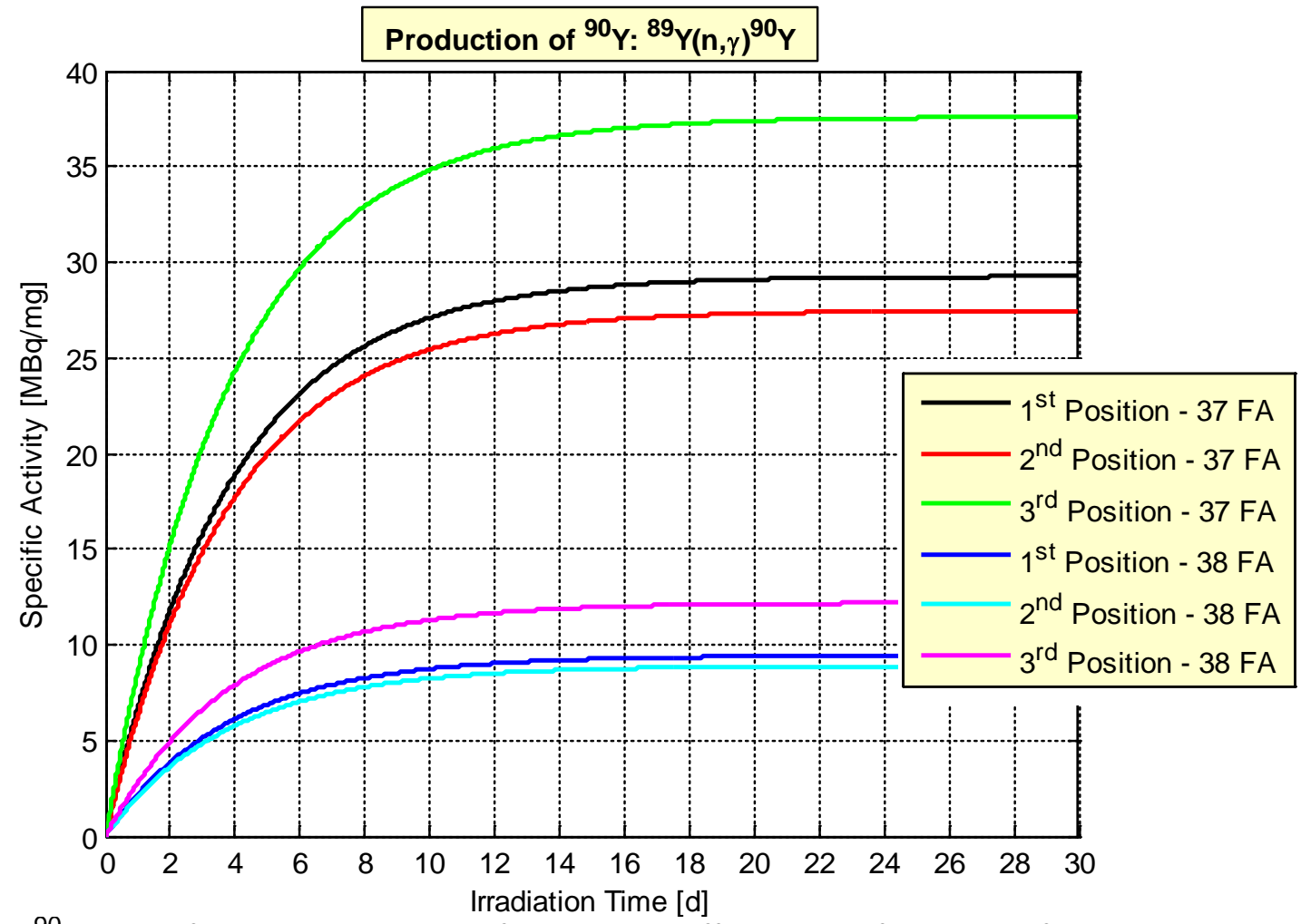

Figure $57 .{ }^{90} \mathrm{Y}$ specific activity, with self-shielding effect, as a function of the irradiation time 


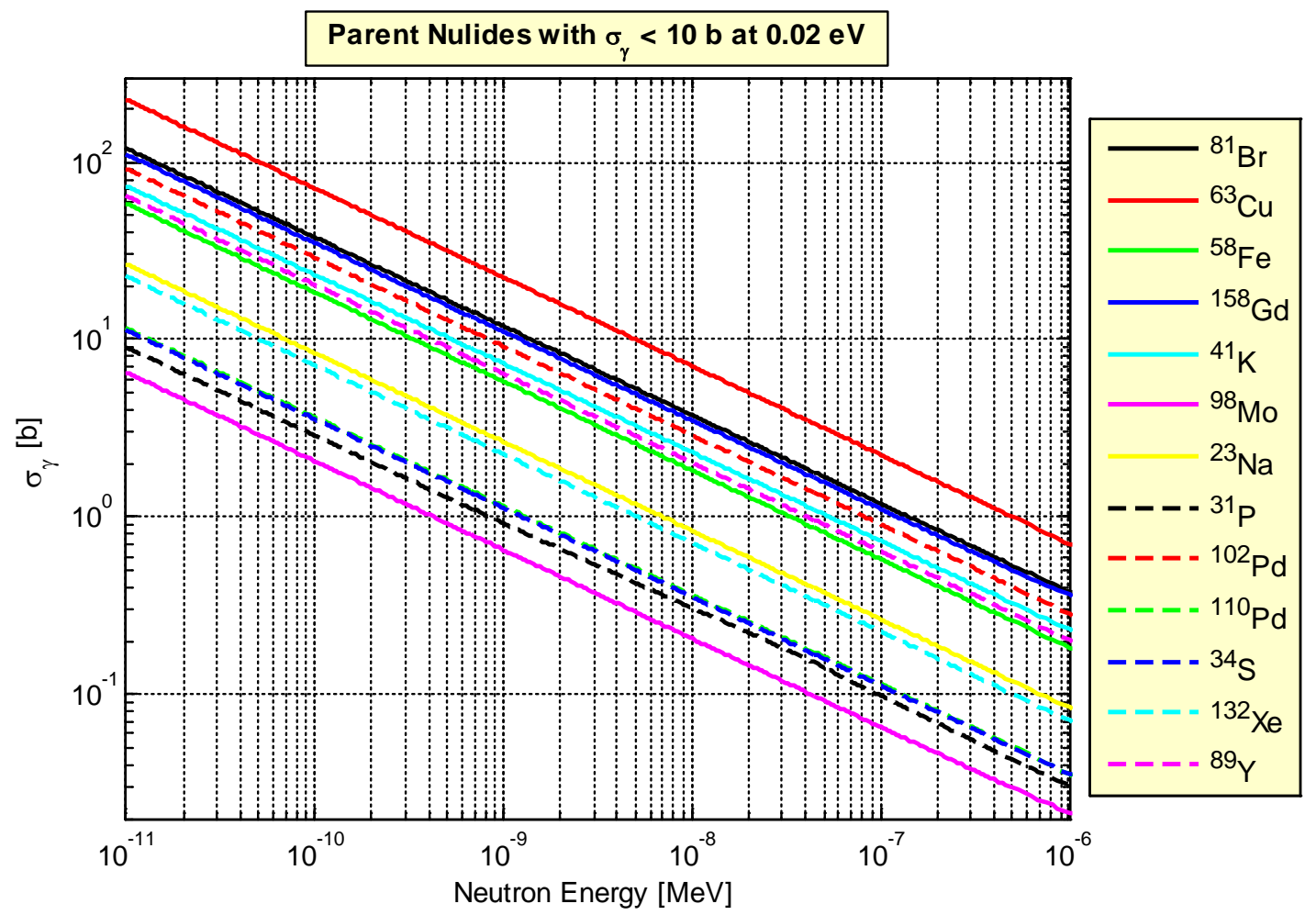

Figure 58. Capture cross section of the parent nuclides with $\sigma_{\gamma}$ lower than $10 \mathrm{~b}$ at 0.02

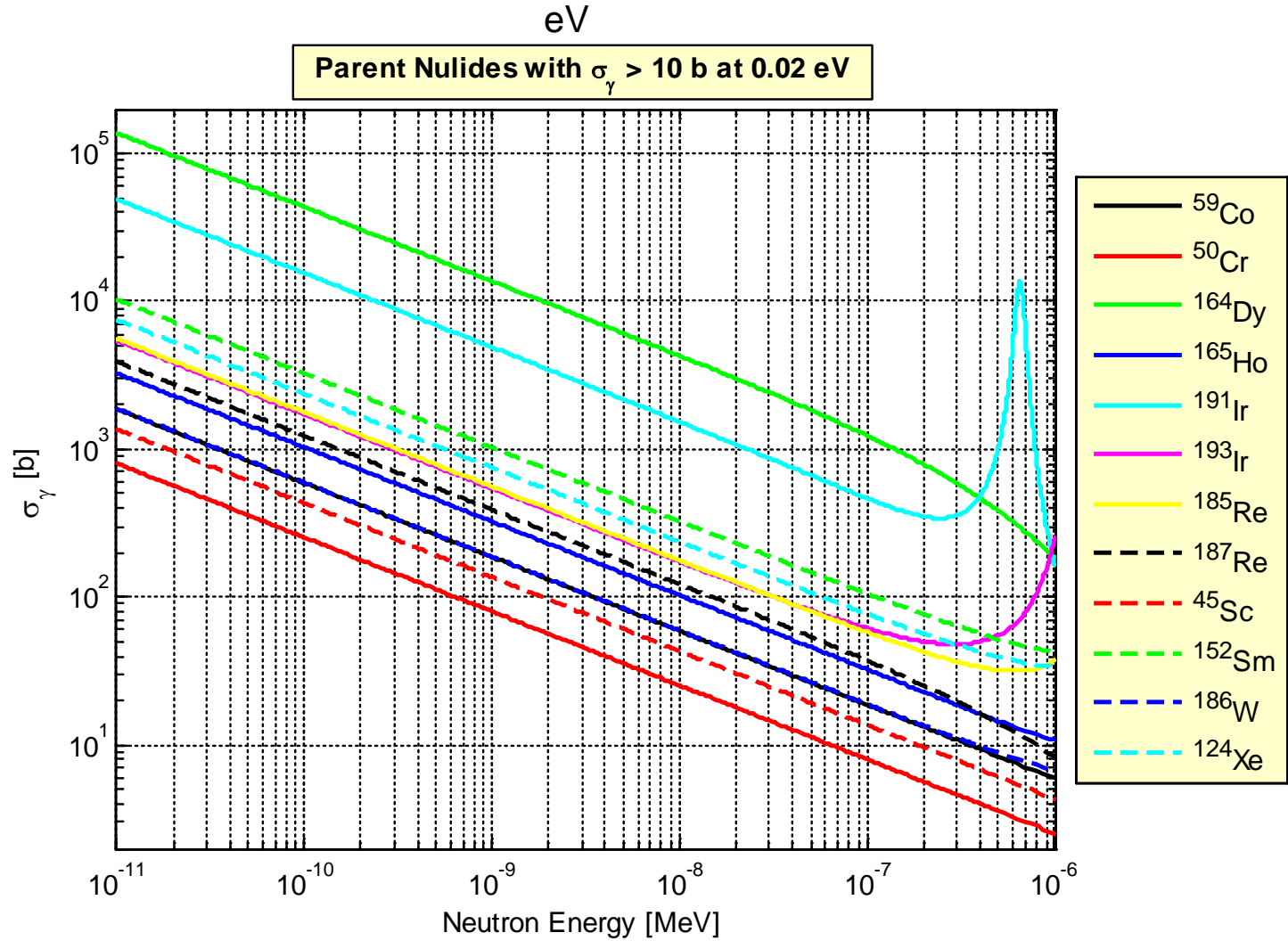

Figure 59. Capture cross section of the parent nuclides with $\sigma_{\gamma}$ higher than $10 \mathrm{~b}$ at 0.02 $\mathrm{eV}$ 


\section{Argonne}

Nuclear Engineering Division

Argonne National Laboratory

9700 South Cass Avenue, Bldg. 208

Argonne, IL 60439

www.anl.gov 